Portland State University

PDXScholar

Winter 2-28-2013

\title{
Women's Actions and Reactions to Male Migration: A Case Study of Women in San Juan Guelavía, Oaxaca, Mexico
}

Julie Boyles

Portland State University

Follow this and additional works at: https://pdxscholar.library.pdx.edu/open_access_etds

Part of the Public Administration Commons, Public Policy Commons, Social Policy Commons, and the Social Welfare Commons

Let us know how access to this document benefits you.

\section{Recommended Citation}

Boyles, Julie, "Women's Actions and Reactions to Male Migration: A Case Study of Women in San Juan Guelavía, Oaxaca, Mexico" (2013). Dissertations and Theses. Paper 659.

https://doi.org/10.15760/etd.659

This Dissertation is brought to you for free and open access. It has been accepted for inclusion in Dissertations and Theses by an authorized administrator of PDXScholar. Please contact us if we can make this document more accessible: pdxscholar@pdx.edu. 
Women's Actions and Reactions to Male Migration:

A Case Study of Women in San Juan Guelavía, Oaxaca, Mexico

\author{
by \\ Julie Boyles
}

A dissertation submitted in partial fulfillment of the requirements for the degree of

\author{
Doctor of Philosophy \\ in \\ Public Affairs and Policy \\ Dissertation Committee: \\ Mary King, Chair \\ Jack Corbett \\ Charles Heying \\ Craig Shinn \\ Margaret Everett \\ Portland State University \\ 2013
}




\begin{abstract}
Using a mixed methods, interdisciplinary case study approach, this research project explores the benefits, risks, and challenges of male migration for women who reside in San Juan Guelavía, Oaxaca, Mexico. In a unique approach in the field of migration studies, this project considers not only women whose husbands have migrated-absent husbands - but also the impact of male migration on women whose husbands have returned as well as women whose husbands have never leftanchored husbands. Women with returned husbands and even women with anchored husbands feel the threat, worry, and fear that male migration could, at an unknown point in the future, fragment their family.

This case study approach looks at how women's work responses are differentiated by husbands' migration status, by age, and by husband's control over women's activities. Women with absent husbands tend be income-producing women as well as women ages 35 to 50 far more than women 35 and under and 50 and over. With motherhood as a cultured priority of rural Mexican women, women's income-producing opportunities are primarily limited to options within the home or in venues that can accommodate their children until the children enter school.

Although this case study showed little or no connection between male migration and educational attainment, substantial policy-worthy findings suggest that the lack of value that residents of San Juan Guelavía place on the local public high school curriculum negatively impacts educational attainment of children
\end{abstract}


beyond middle school. Women's traditional and cultural emphasis of marriage for their daughters as well as their reluctance to expose daughters to the negative influences of the city sway the decisions that women make for their daughters. 


\section{Agradecimientos}

\section{(Acknowledgements)}

It is with great appreciation that I thank the following individuals that have had a positive impact on my dissertation and doctoral work.

First, my greatest appreciation to two stellar Portland State University faculty members without whom this dissertation likely never would have taken place. Dr. Jack Corbett introduced me to Oaxaca and played a major role in my insatiable curiosity for understanding the Oaxaca context. Dr. Corbett's vast knowledge and embeddedness in day-to-day Oaxacan life and long and extensive history living and thriving in the culture offered insight and understanding that could not have been gained in any other way. Thank you, Dr. Jack.

Dr. Mary King is owed as large of thanks as I can offer. I benefited greatly from her support, her high expectations, and the sound guidance that she consistently provided. Her positive spirit impacted me throughout this trying process. Her professionalism peppered with friendship, kindness, and understanding has meant a great deal to me.

The rest of my dissertation committee provided assistance, feedback, and support for which I am grateful. Dr. Charles Heying always offered me a "you-cando-it" attitude with enlightening conversations and an open ear. Dr. Craig Shinn provided the grounding in Public Affairs and Policy and offered more-than-favorable comments late in the process that helped keep me motivated. Dr. Margaret Everett 
brought a perspective not offered by others and a connection to Oaxaca that was appreciated.

Certainly, the women and a few young women in San Juan Guelavía deserve my thanks. Women invited me into their homes, introduced me to their family, and nourished me with fresh juices and responses to my myriad of curiosities and questions. My valued primary research assistant, Nohemí, deserves special recognition for her devotion to my process, her ready smile and delightful laugh, and continued connection beyond the project.

To the few friends and family that saw me through this entire process, thank you. To the friends and close relationships that evolved in Oaxaca, thank you. To those that have made this journey through a doctorate degree and a dissertation more manageable, more pleasurable, and more gratifying, thank you. 


\section{Table of Contents}

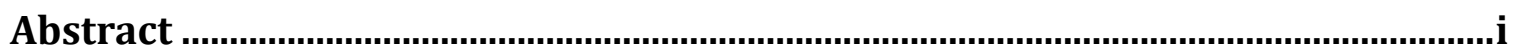

Acknowledgements ….....................................................................................ii

List of Tables ......................................................................................................... vii

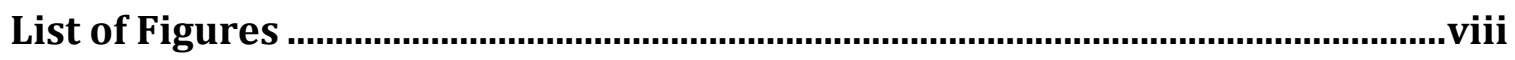

Chapter 1: Introduction, the Research Question, and the Value of the Study.... 1

Rural Mexican Women and Male Migration...................................................................... 1

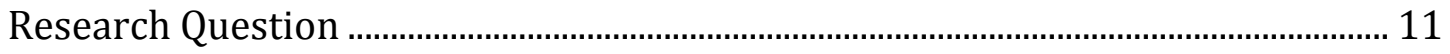

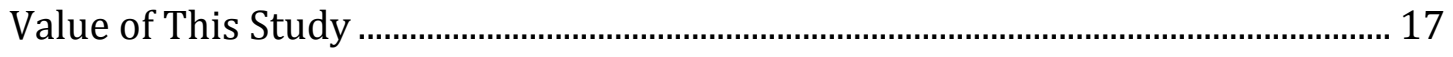

Dissertation Overview...................................................................................................... 19

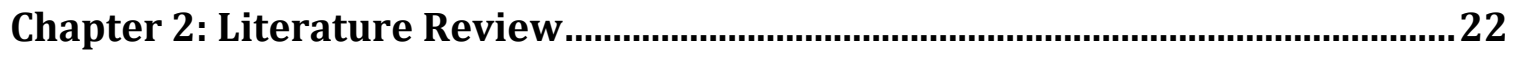

Literature: Fragmented, Contentious, and Ambivalent ................................................ 22

Chapter 3: Conceptual Framework, Methodology, and the Essential Setting ...67

Conceptual Orientation and Framework.......................................................................... 67

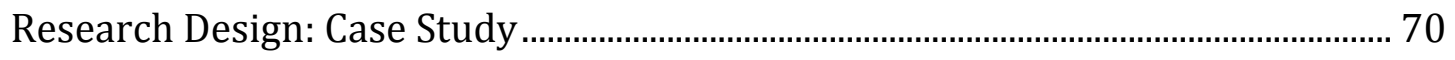

Research Methods ……………………...........................................................................

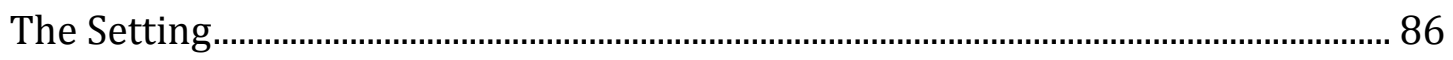

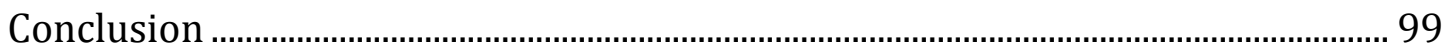

Chapter 4: Guelavían Women and Male Migration.................................................. 100

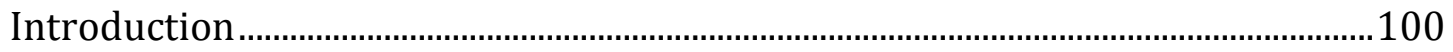

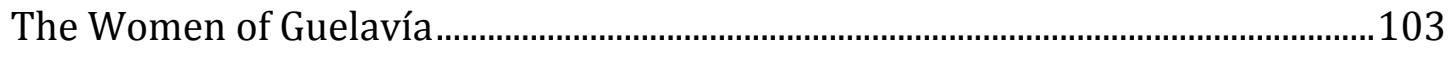

Households, Male Migration, and the Women of Guelavía .........................................110

Threats, Risks, and Fears of Male Migration..................................................................138

Keeping Men at Home........................................................................................................151 
Chapter 5: Women, Work, and Male Migration

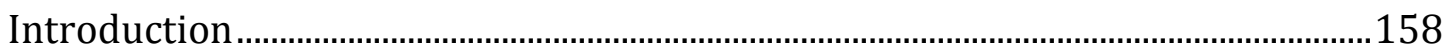

Oaxaca Women’s Work and Guelavía ………………………………………………......159

A Que Se Dedican Los Guelavíans? (What Do Guelavíans Do for Work?) .............164

Which Women Work? …………………………………………………………………....166

Programs and Policies: A Help or Hurt? …………………..............................................181

Chapter 6: Women, Education, and Male Migration ............................................. 186

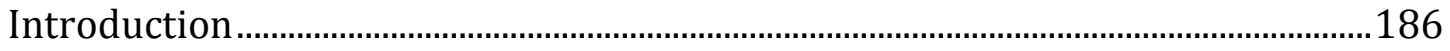

Education in San Juan Guelavía .......................................................................................188

Middle School Heightened Risks and Education Value Revealed.............................189

Teens and the San Juan Guelavía Bachillerato .............................................................193

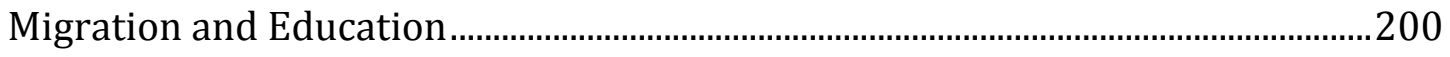

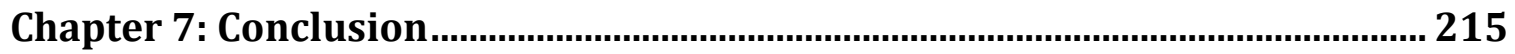

Fragmegration, Male Migration, and Women's Fears and Worries.........................216

Fragmegration, Male Migration, and Women's Work...…………………………....219

Fragmegration, Male Migration, and Education..........................................................222

Contributions to Policy and Beyond............................................................................225

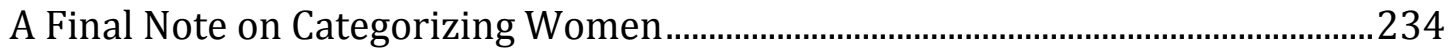

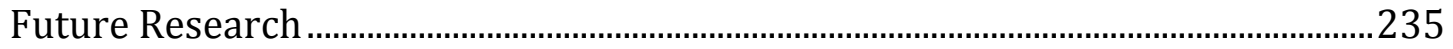

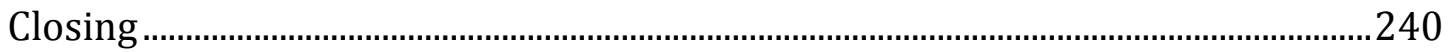

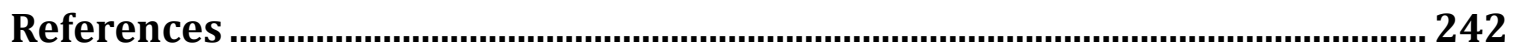

Appendix: Survey Packet for Participants ……............................................... 250 


\section{List of Tables}

Table 1: Health Center Occupation Data................................................................................. 96

Table 2: Education Completion Rates in Guelavía............................................................... 98

Table 3: Civil Status of Women in Guelavía ............................................................................104

Table 4: Husbands' Migration Status in Guelavía ...............................................................110

Table 5: Generational Difference in Male Migration Decision Making ...........................115

Table 6: Remittance Decision Making...................................................................................127

Table 7: Women’s Reasons for Men Remaining in Guelavía ............................................133

Table 8: Educational Attainment by Age of Teen Boys and Girls, May 2010 …...........195

Table 9: Educational Deficiency for Guelavíans Age 15-30, May 2010 …………….....204 


\section{List of Figures}

Figure 1: Framework derived from the work of Beneria and Roldan (1987) and Hondagneu-Sotelo (1994) ............................................................................................. 69

Figure 2: Migration Status of Husbands of Women Surveyed by Generation ............112

Figure 3: Length of Time Women Waited for Remittances ...........................................124

Figure 4: Average \$US Monthly Remittances of Women with Absent Husbands.....125

Figure 5: Wives of Absent and Returned Husbands and Why They Believe that Husbands Do Not Remit ..............................................................................................128

Figure 6: Women's Responses to "Economically Better Off" if Husband Emigrated

Figure 7: Women Who Work for Income, by Age, May 2010 …………………………...161

Figure 8: Women's Work by Husband's Migration Status, May 2010 ..........................167

Figure 9: School Attendance of Boys/Girls Ages 13-18, May 2010................................195

Figure 10: School Attendance of Children Ages 13-18, May 2010, by Father's Migration Status..........................................................................................................201

Figure 11: Average Educational Attainment of Men and Women by Age Category,

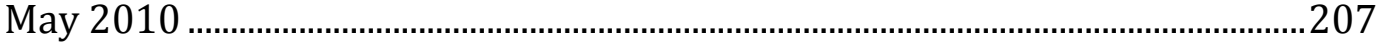

Figure 12: Women's Average Age at Marriage...................................................................208

Figure 13: Women's Education and Average Age of Marriage........................................210 


\section{Chapter 1: Introduction, the Research Question, and the Value of the Study}

\section{Rural Mexican Women and Male Migration}

A stable and consistent feature of Mexican male migration has long been the reliable and steady foundation that Mexican women provide in the local Mexican context. Mexican women are the dependable, capable, local caretakers of the home. They tend to the domestic realm and the children of the migrant. They are ultimately responsible for the family when the husband is absent and away from the home as well as when the husband returns. They are ultimately responsible for the family if the husband chooses to negate his responsibility and not send remittances, cease communication, and ultimately not return. Mexican women are integral to male migration (Kanaiaupuni, July 2000).

Rural women from the southern Mexican state of Oaxaca-often poor, un- or under-educated, strong, and resourceful—have endured international male migration in growing numbers in the previous one to two decades. Typically, rural Oaxaqueñas stay behind and persevere as husbands cross the border building lives in the United States. Other rural Oaxaqueñas grapple with and confront the challenging transition of the family upon a husband's return. Others, often all within the same rural community, worry about the possibility of potential or imminent departure of a husband that has, up to that point, been anchored to the home and has not previously emigrated. 
The power of U.S.-established migrant networks and the economic demand of the United States—along with an abundant Mexican labor supply—have played critical roles in Mexican migration to the United States (Lowell, Perderzini, \& Passel, 2008). However, study of the established migrant networks and the economic magnetism of the United States that attract Mexican migrants offer an incomplete picture of the migration of men from Oaxaca:

Whereas owners of production inputs or commodities, such as bricks or bottles of wine, can ordinarily ship them away ... while themselves staying put, owners of labor must usually move along with their labor. Furthermore, owners of labor have both feelings and independent wills. Indeed, most aspects of human behavior, including migratory behavior, are both a response to feelings and an exercise of independent wills. (Stark \& Bloom, 1985, p. 173)

This 1985 passage is as pertinent today as at its publication more than 25 years ago. The passage warns of perceiving migratory behavior as simply the physicality of location and, instead, notes feelings and independent wills of migrants. Lacking, however, is reference to the feelings, independent wills, and behaviors of family members who remain behind. Women who remained in their rural communities were simply not considered in the vast majority of migration literature.

Rather than transfer their own labor or relocate to accompany their partners studied as "owners of labor," many rural Oaxaqueñas remain in the communities that migrants left behind—frequently with the children of the migrant. The International Organization for Migration defines migration-focused on these "owners of labor"-as "one of the defining issues of the twenty-first century" ("Migration Facts \& Figures," 2008). With three percent of the world's population 
"on the move," 191 million international migrants have left their countries of origin in search of work, with several times that number of family members left behind ("Migration Facts \& Figures," 2008).

According to the United Nations, nearly half of all migrants worldwide are women ("International Migration And Development," n.d.), but Oaxacan emigration is dominated by males (C. Hernandez, Oaxaca State Population Council, personal communication, February 20, 2008; Lowell, 2008; Cohen, 2004). The result is a Oaxaca state population that comprises 91.4 males for every 100 females, ranking Oaxaca as having the lowest ratio of males to females except for Michoacán and Guanajuato with 91.3 and 90.8 males to each 100 females, respectively ("México Hoy," p. 48). As many as four male migrants are estimated to leave the state of Oaxaca for the United States for every one female migrant (C. Hernandez, Oaxaca State Population Council, personal communication, February 20, 2008; Cohen, 2004).

Oaxacan women stay behind to independently tend the home, the children, and often, the extended family that may, also, include the husband's parents. Women remaining behind is cost-effective, abides by the gender norms of Mexican culture-especially rural Mexican culture-and helps to retain the family standing in the community, often enhanced by migration status and a remittance-producing male head-of-household (Kanaiaupuni, 2000; Kanaiaupuni, July 2000). 
Women overseeing and tending to the home and the children is a key factor in "successful" male migration, as described in this account of male migration from interviews gathered in the Mexican states of Morelos, Guanajuato and Jalisco:

... they [women] make men's migration possible and ensure its continuity across space and time. As such they form the invisible backbone of this transnational migration process that has endured for over a century. (Kanaiaupuni, July 2000, p. 2)

Oaxacan women with absent husbands are the "backbone" that hold the family and community together.

"Emigration"1 and "stay behind" are terms most often associated with men who leave and their wives who remain, respectively. Two additional groups of wives, however, are also affected by Oaxacan male migration: 1) women with returned husbands; and 2) women with anchored husbands-husbands who have never emigrated and, therefore, remain in the home.

Women whose husbands have returned-most often from a U.S. destination—recount and share their experiences with other women. They convey their reformulated spousal relationship, they conceal concerns of another potential departure of their spouse, and they withstand anxiety that the local, rural context will not offer as fulfilling of an experience as did their husbands' previous U.S. context.

\footnotetext{
1 "Emigration" and "emigrate" refer specifically to an individual's departure from one country-in this case, Mexico-with movement and intention to work and live in another country-in this case, the United States. "Immigration" and "immigrate," in this study, refer to Mexicans arriving or living in the United States from the U.S. context. "Migration" and "migrate" are used as the general term of movement not necessarily from one side of the border to the other nor from any one specific context.
} 
Women with anchored husbands are indirectly impacted by male emigration, as well. Women whose husbands remain in the home and have never left harbor concerns of potential or imminent departure of their own husbands. Husbands often retain the idea or potential for departure-a prospective strategy, however remote, in reserve.

While the worries and fears for rural Oaxacan women with absent husbands may be palpable, women whose husbands have returned as well as women whose husbands have never left experience similar worries and fears about potential, imminent departures of their own husbands. Is it possible that a simple phone call from el otro lado (the other side) that beckons or invites a brother or cousin to join him in Los Angeles can shift a woman from "wife with an anchored husband" to "stay behind" or "left behind"? Are there strategies that Mexican women use to prevent emigration of their spouse or is emigration desired, secretly or overtly? Do women suspect men's lives in the United States are not filled with the same priorities as prior to their departure? How does male migration affect work, inside and outside of the home for women? Is educational attainment affected by male migration? The questions of those who remain behind and women whose husbands are currently or once again in the home are bountiful; research that contributes to understanding is sparse.

This research project explores Mexican women's actions and reactions to male migration while providing answers to many of these questions within the context of one rural, Oaxacan community. The purpose of this research project is to 
better understand how male migration impacts women in the community of San Juan Guelavía, Oaxaca—women with absent husbands, women with returned husbands, and women with anchored husbands.

Using a case study approach, this research project relies primarily on data gathered from surveys of every eighth home and one- and two-person interviews with the "woman of the home" with level of analysis being the couple, whether living together or geographically apart. Information gathered from casual conversations, observations, participation in community activities, and interviews with various local officials and school personnel are integrated into this case study with data from the municipal San Juan Guelavía Health Center, and data from the Instituto Nacional de Estadísticas Geografía e Informática (INEGI) (National Institute of Geographic and Informative Statistics) ${ }^{2}$.

\section{The Fragmentation/Integration of Male Migration and Gender}

Migration is a simultaneously fragmenting and integrating phenomenon. "Fragmegration," a term coined by Rosenau (2003), is "the pervasive interaction between fragmenting and integrating dynamics unfolding at every level of community" (Rosenau, 2003, p. 11). Migration has all of the pertinent characteristics of fragmegration. Migration integrates the economies of two nation-states while fragmenting members of the same nuclear family. Migration integrates a staybehind woman into the labor force-most often by need rather than by choice-

2 INEGI, the Instituto Nacional de Estadísticas Geografía e Informática (National Institute of Geographic and Informative Statistics), is Mexico's government census agency. See http://www.inegi.org.mx. 
while awaiting remittances from an absent spouse from the distance U.S. context. Migration integrates rural Oaxaca into the U.S. economy-through male migration to the other side of the border-while fragmenting Mexican social norms of the husband as provider and the wife as domestic caretaker with the prioritized role of mother. And, migration integrates women's experiences of male migration from the U.S. side of the border through social osmosis diffused to women who have not experienced it directly while simultaneously fragmenting a community through differences in remittance receiving, educational opportunities for children, and home construction and patrilocal living arrangements. Fragmegration, simultaneous integrating and fracturing, is synonymous with migration, especially synonymous with women's lived experiences with male migration.

In 1985, publication date of Stark and Bloom's earlier passage, omission of women, children, and family members was considered reasonable primarily due to the "migration equals male" perspective that was commonplace in that decade and prior (Pessar, 1999; Kanaiaupuni, July 2000). Little consideration was made of the women and children who remained behind while men crossed international borders thereby creating the integration yet fracturing of a family as well as a community. Until 1985, Mexican migration to the United States was predominantly male. ${ }^{3}$ Men routinely left women behind in their rural communities which allowed for reduced risk and lessened burden when crossing the border, a wider array of housing

${ }^{3}$ Marcelli and Cornelius (2001), using three different migration data sets, estimate that between 59 and 82 percent of those who left Mexico to emigrate to the United States in the late 1970s and early 1980s were male. Their results suggest, "a gradual feminization of the Mexican migrant flow, commencing in the early 1970s and accelerating sharply in the 1990s" (p. 111). 
opportunities upon arrival, and freedom while living away from home (Kanaiaupuni, 2000). "Migration" as an academic theme of study was built on the underlying assumption of a "male" migrant with little to no consideration for anyone other than the migrant himself.

Gender, as an analytical category, entered the migration literature in the early 1990s and gained traction through the first decade of the $21^{\text {st }}$ century. This newer migration literature did consider gender within the context of migration but the focus was on females that were part of the migrant stream, rarely on women who remained in their communities with the burden of mother and father and wife and husband shifted to just one parent.

A small set of studies in the mid-2000s began to present the challenges of women who remained behind. To understand migration at anything more than a superficial level, all participants in the migrant stream-the owners of labor, those who depend on them, those who are abandoned, those who are peripherally affected, and those who may, willingly or unwillingly, change their status-must be considered and incorporated.

Most, if not all, of the 214 million international migrants that work, reside, interact, spend, save, thrive, and survive in another country are part of family units of some type. Many members of those family units remain in the migrants' sending community. It is the Oaxacan wives of the men who are absent, the wives of the men who return, and the wives of men who have never ventured "north" that are the focus of this research. Male migration pervades the lives of women in all of these 
situations. This research project contributes to the gap in the literature of understanding women's actions and reactions to male migration in regard to women's worries and fears, the impact of male migration on work, and the connections between male migration and educational attainment. What follows is a short introduction to the history of Mexican male migration and emigration from the state of Oaxaca, followed by the research question that drives this project, the value of this study, culminating with a dissertation overview.

\section{Mexican Male Migration}

While male migration from Mexico to the United States has more than a century of history, ${ }^{4}$ the impact has been more profound in the last decade (Lopez, Livingston, \& Kochhar, 2009). A PEW Hispanic Center report (Lopez et al., 2009) provides a clear picture of the significance of Mexican migration to the United States as well as the impact on those remaining in Mexico:

- Thirty percent of the total foreign-born population residing in the U.S. is Mexican

- Foreign-born Mexican population living in the United States is nearly 12 million (with the Philippines a distant second at only 4.5 percent with 1.7 million)

- Approximately 11 percent of everyone born in Mexico is currently living in the U.S.

- Foreign-born Mexicans living in the United States increased 28.1 percent from 2000-2007

- Remittance dollars (money transferred from migrants living in the U.S. to their Mexico-based family, primarily to their spouse) transmitted to Mexico from the United States in 2007 amounted to nearly $\$ 24$ billion

\footnotetext{
${ }^{4}$ For a concise history of undocumented migration and settlement in the United States from Mexico, see Chapter 2 of Pierrette Hondagneu-Sotelo's Gendered Transitions: Mexican Experiences of Migration. Also, see Lowell et. al.
} 
Mexican migration to the United States has long been a part of U.S. history as well as Mexico's history. The majority of migration research distinguishes Mexican locales as "old" and "new" sending states. Consejo Nacional de Población’s Carpeta Informativa 2005 offers a portrait of "old" sending states: approximately 35 percent of the population of the Mexican state of Zacatecas resides in the United States; 25 percent of Michoacán; 20 percent of the states of Durango and Jalisco; and 16 percent of residents from Guanajuato, Nayarit, and San Luis Potosí (p. 6). These seven states, combined, represent the "old sending states." An extensive history of migration as well as long-established social networks have created a culture of migration over numerous decades. It has been well documented that males as well as some females use these well-established social networks to traverse the challenges that international migration presents (Kanaiaupuni, 2000; MacEwan, 2006; Massey \& España, 1987; Palloni, Massey, Ceballos, Espinosa, \& Spittel, 2001; Stark \& Bloom, 1985).

Primarily in the 2000s, Mexican migration diversified and expanded to Mexico's southern states. Oaxaca can accurately be described as a "new" sending state. The Pew Hispanic Center identifies Mexican migrants to the United States as "increasingly coming from states further south in the country" (Lopez et al., 2009). The migration stream diversified from the traditional "old" states to the "new" sending states of Guerrero, Oaxaca, Puebla, and Veracruz. Although the old states continue to send migrants to the United States, approximately 30 percent who have 
been in the United States for five years or less have come from the four new sending states (p. 29).

\section{Oaxaca and Migration}

It is typical that new sending states send more male migrants than female. The disproportionate figures of approximately 80 percent of migrants being male leaves thousands of women remaining behind in sending communities (Cohen, Rodriguez, \& Fox, 2008; “Carpeta Informativa 2005”). The state of Oaxaca, predominantly female, primarily rural, significantly indigenous, excessively poor, and socio-economically marginalized offers the backdrop to this research project of women's actions and reactions to male migration for this study. ${ }^{5}$

\section{Research Question}

The majority of migration literature deals with one of four specific, topical themes: the lives of migrants in receiving communities (Hellman, 2008; Hirsch, 2003); debate over whether remittances foster development or dependency (Cohen, 2001, 2004); social networks of migrants and how those social networks serve, abet, dissuade, or challenge migrants (Kanaiaupuni, 2000; Massey, 1987) and, gendered migration studies of women in U. S. environments (Hirsch, 2003; Hondagneu-Sotelo, 1994; Parrado et al, 2005; Pessar, 2005). Lacking is a substantial literature field that contributes to the recognition of the challenges of women's lives in the face of male

\footnotetext{
${ }^{5}$ INEGI data, at http://www.inegi.org.mx, supports these labels for the state of Oaxaca in relation to the other states in Mexico.
} 
migration. As recently as 2005, Pessar noted: "Migration studies often neglect the family members left behind. This leaves us at a loss to appreciate the new activities and responsibilities migrant household members may assume with the departure of husbands, wives, parents, brothers, and sisters." (p. 4). The omission of family members left behind leaves the literature on "migration," and certainly the more specific literature on gender and migration, as incomplete by disregarding the impact on those family members.

The nascent literature on women who stay behind when husbands migrate offers women's perspectives as peripheral to other primary research objectives instead of the central focus. Several researchers have addressed the subject of staybehind or left-behind women (Ahern, Bryan, \& Baca, 1985; Hellman, 2008; Hondagneu-Sotelo, 1994; Stephen, 2007); none, however, have focused on staybehind or left-behind women as central to their research with the possible exception of Ahern et al. in "Migration and La Mujer Fuerte," which dates back to 1985. Instead, most of these researchers use the context of the life of stay-behind women as definition and character or background to a related, but different, migration theme.

In this research project, the differences between "stay-behind" women and "left-behind" women is notable. Many researchers who write about women who remain behind as husbands emigrate, most often to the United States, use "stay behind" and "left behind" interchangeably without definition. This research project is based in the assumption that all women whose husbands emigrate start out as 
"stay-behind" wives - women who remain in the home-usually with children and household responsibilities while husbands cross the border with the supposed motivation of financially providing for the family. Some husbands do not send remittances and cease communication with their "stay-behind" wives, thus becoming, in this research project, "left behind" wives. In this research project, "stay behind" connotes a level of involvement in the migration decision of a husband and, thus, in the decision to remain in the community (although the level and degree of involvement in the male migration decision is debatable). However, no stay-behind wife chooses to be "left behind"-remaining in the community while her spouse emigrates to the U.S. and subsequently terminates contact, avoids sending remittances, and appears to continue a life in the U.S. that leaves his wife in the community to fully fend for herself and often for their children without financial assistance nor communication. In this project, there is clear distinction between "stay behind" and "left behind."

Hondagneu-Sotelo (1994) offers some description of the lives of stay-behind women; however, she uses the description only as pretext for her actual research work of women's impending and eventual decision to migrate north themselves. Hondagneu-Sotelo links women's increased independence and decision making when staying behind to women's resourcefulness at convincing spouses to bring them north (to their husband's U.S. locality) or, more often, in creating their own network and developing their own resources that serve as their own paths to the United States with little assistance and occasional opposition from spouses. This 
research is invaluable in the area of gendered migration, but Hondagneu-Sotelo's (1994) discussion of the lives of stay-behind women is peripheral to the main purpose of understanding what staying behind infers and women's actions and reactions to that status.

A greater dearth in the literature is the lack of understanding of women's lives when absent husbands return from years of living in the United States. And, it appears, there is no literature written to help understand women's actions and reactions to male migration by women whose spouses have never emigrated and still reside in the home-thus, are anchored. While the initial and primary objective of this research project was to help fill the gap in the literature on stay-behind women with absent husbands, the expansion to the inclusion of women whose husbands had returned and women whose husbands have never ventured across the border offers a broader, more inclusive and comprehensive picture of the impact of male migration on women and contributes to the gap in the migration literature.

Derived from the related literature that is available (which follows in Chapter 2), personal experience, and time spent living in Mexico prior to beginning this project and visiting Oaxaca numerous times prior to proposing this research, the research question that drives this study is:

As Mexican men migrate and women stay behind in Mexican "sending" communities, women's personal and family burdens and responsibilities may be altered. In relation to male migration, women's worries, fears, and uncertain futures may create and influence decision making, income-generating work, and education of children. Yet, women whose husbands have returned as well as women whose husbands have never left are also impacted by male 
migration. How do women act and react to male migration in regard to their concerns, their economic labor, and their children's education?

The questions that guide the inquiry of this study include:

- How does male migration impact women and are those impacts differentiated by husbands' absence, return, or presence in the home?

- Are women's actions and reactions to male migration differentiated by generation?

- How is women's income-generating work influenced by male migration?

- Are work strategies adopted in the face of male migration differentiated by educational attainment, generation, or age?

- How does male migration impact and influence education for children who stay behind?

My initial suppositions were that women's increased burden and widening breadth of responsibilities when remaining in sending communities lead to added stress (Salgado de Snyder, 1993), fear of abandonment (Hondagneu-Sotelo, 1992; Salgado de Snyder, 1993), and an increased need, at least initially, to participate in the local labor force for family sustenance (Howell, 1999; Kanaiaupuni, 2000;

Parrado et al., 2005; Ramírez et al., 2006). What I had not fully anticipated was the impact that male migration has on women whose husbands have returned as well as on women whose husbands have never ventured north. Rural Mexican women are impacted by male migration-not solely Mexican women whose husbands have emigrated—but instead, rural Mexican women, in general.

\section{A Note about Categorizing Women}

Categorizing women in relation to the migration status of their husbands is functional, purposeful, and effectual, yet problematic. Categorizing women in this 
simplistic manner merits explanation. First, the categorization of women based on their husband's emigration status appears to place the emphasis on women as secondary, husbands as primary, but is clearly not the intent of this study. Categorization in this manner is used solely as the critical variable for analysis. Second, categorizing women by their husband's migration status-wives of absent husbands, wives of returned husbands, and wives of anchored husbands-may convey an inaccurate impression that women's experiences within each category are homogenous. This assumption would be in error. It is incorrect to assume, for example, that all wives with absent husbands receive remittances or that all wives with anchored husbands prefer that their husbands remain in the home rather than emigrate. Women's experiences, opinions, preferences, and sentiments are individual and should not be understood as homogenous within any one category. Third, women reported their status as wives or as women in relation to their husband's migration status at the time. Depending on their self-reported status, women were asked a different set of questions in relation to their experience within that category. It is important to recognize that this study is a snapshot in time. The category into which each woman falls at the moment of survey gathering or interview collecting is static; the boundaries or borders of those categories are, however, porous. The category in which a woman finds herself one day may not be the same category in which she finds herself the next. 


\section{Value of This Study}

"Abundant as migration literature is across disciplines, little attention has been paid to the social suffering of families fragmented by this phenomenon" (McGuire \& Martin, 2007, p. 178). This research project aims to contribute literature to the void in understanding the potential social suffering of women and families in relation to male migration. This case study of San Juan Guelavía, Oaxaca, Mexico, contributes information and understanding in an effort to begin to fill that void. While exploratory and primarily qualitative, this research does not claim, intend, nor aim to be generalizable to a larger context. Yet, at the same time, the San Juan Guelavía context and landscape offer little that could be deemed unique, outstanding, or distinct in comparison to the thousands of other rural towns throughout Mexico that are experiencing shifts in personal, family, and community life due to migration. While extrapolation to the larger migration experience is not the supposed or proposed intent, this case study does provide insights that contribute to the understanding of the lives of rural women elsewhere when male migration pervades their daily existence.

Building on the well-respected work of researchers who have studied Mexican women on both sides of the border, this research was conducted and written within a conceptual framework influenced by and adapted from the influential, impactful work of Benería and Roldán (1987) and Hondagneu-Sotelo (1994). This research is framed within an economic and social patriarchal 
framework with women's subordination as an overall background and backdrop, explored more fully in Chapter $3 .^{6}$

\section{Policy Contribution}

An important contribution of this research is the opportunity to illuminate change opportunities to policy, implementation of policy, and the activities of government and possibly in non-government organization (NGO) programs. Programs that incorporate goals related to women's wellbeing and gender equity must be informed by research that addresses women's reality-women's work, educational attainment challenges, and concerns, fears, worries, and reactions to male migration. Policies calling for changes in program implementation or expansion could support women in their challenging role as wives of migrants, return migrants, or even future migrants, with a focus on expanded work opportunities, educational opportunities for children, and alleviation of the stresses and strains that male migration—or potential migration-inflicts.

This project contributes to three primary policy arenas: cultural gender awareness policy within anti-poverty programs, education policy in Mexico, and U.S. border policy. First, understandings developed from this research project can contribute to enhanced cultural gender awareness policy incorporated into Mexico's federal conditional cash transfer program, Oportunidades (Opportunities). Second, knowledge gained can help inform policy in relation to girls' challenges in achieving

\footnotetext{
${ }^{6}$ See Figure 1 for the full theoretical framework on which this research project is based.
} 
higher levels of education as well as the benefits of incorporating local priorities in education policy. Third, understandings gained can help inform future U.S. border policy. Each of these arenas are more extensively described and addressed in Chapter 7.

\section{Dissertation Overview}

This dissertation is organized into seven distinct but integrated chapters. Following this introductory chapter, the subsequent chapter offers a literature review of the primary work to date that addresses Mexicanas' gender norms roles, the significance of women staying behind in the face of male migration, how male migration and women's work appear to be linked, and the role that male migration plays in educational attainment of children. Chapter 3 begins with a conceptual framework constructed from the work of Benería and Roldán (1987) and Hondagneu-Sotelo (1994). The framework sets the structure, outline, and backdrop to this research project. The framework is followed by the research design, research methods and data used and gathered, and a detailed description of initial visits to the San Juan Guelavía, Oaxaca, with an in-depth portrayal of the community and profile of its residents. The depth of detail and description of the community sets the context for conceptualization of women's actions and reactions to male migration in the pueblo of Guelavía. ${ }^{7}$

7 "Pueblo," "community," and "town" are used interchangeably in this study. 
The findings are structured into three related and linked but discrete sections-Chapters 4, 5, and 6. The first of the findings chapters, Chapter 4, describes migration decision making, women's skepticism of men's altruistic migration motivation, and women's perceptions of threats, risks, and fears of male migration. While threats, risk, and fear are readily expounded on by women whose husbands are absent, women whose husbands have returned and, potentially, could leave again as well as women with anchored husbands are also profoundly impacted. Keeping men at home is also explored with many of the findings quite different by generation.

Chapter 5 addresses the impact of male migration on women's incomegenerating activities: which women work for income, hours devoted to work, and in which occupations do women labor. Are working women primarily women with absent husbands, women whose husbands have returned, or women whose husbands are present? Do men control women's work and is there a generational difference in the acceptance or rejection of this control? The chapter concludes with programs and policies that may help or may hurt women's income generation.

The third and final findings chapter, Chapter 6, offers the linkages between male migration and educational attainment. The chapter is introduced with educational opportunities in San Juan Guelavía followed by analysis of middle school and high school youth in Guelavía and local school attendance. The connections between male migration and educating children are explored followed by a discussion of gender norms and social norms that impact girls in Guelavía. 
The concluding chapter, Chapter 7, offers an analysis of the integration of a larger context and the fragmentation in relation to that integration"fragmegration." The impact of the findings of this case study on the lives of women in Guelavía is synthesized within a fragmegration framework with contributions of this research and future research possibilities offered and will support policy suggestions based on research findings. 


\section{Chapter 2: Literature Review}

\section{Literature: Fragmented, Contentious, and Ambivalent}

The literature on migration research is fragmented, contentious, and

ambivalent. There is, however, a set of factors within the conventional explanations of migration on which researchers do concur. Kanaiaupuni (2000) summarizes the work of various migration researchers with the following set of generally-agreed upon factors:

a) Human capital investment-education, labor experience, and prior migration experience-as well as self-selection characteristics of motivation, energy, and ambition affect who migrates

b) Socioeconomic status-not the wealthiest, yet not the poorest families - tend to be the emigrants

c) Familial considerations - the household life cycle such as birth of children and children entering school-impact and influence of migration

d) Social networks-migration as a social process that takes advantage of networks and often creates a culture and tradition of migration-influences migration

e) Local, sending community economic opportunities in comparison to receiving community opportunities influence migration tendencies

Yet, as many researchers contend, gender is neglected in much of the migration research. Gender does, however, play a significant role in each of the aforementioned dynamics (Kanaiaupuni, 2000; Pessar \& Mahler, 2003).

A United Nations International Research and Training Institute for the Advancement of Women conference presentation (Ramírez, Domínguez, \& Morais, 2006) acknowledges that gender inequalities differentiate the migratory experience for men and women: "The decision to migrate, the networks utilized or the 
individual migrant's insertion into the labour markets of the destination country, to mention only a few factors, are all affected by gender differences" (p. 7).

Migration determinants-educational attainment, socioeconomic status, familial considerations, social networks, comparison of sending and receiving communities, as well as gender-affect and influence more than just the migrant. All of these determinants impact women and children who remain behind as well.

Literature is scarce in regard to focused attention to women who stay behind (Kanaiaupuni, July 2000). It is nearly nonexistent with regard to the impact of male migration on women whose husbands have returned or never left. The advancement of gendered migration research in the last decade, however, offers sufficient insight to create a solid basis for this research. ${ }^{8} \mathrm{~A}$ weaving of four literature streams follows in this chapter. The first is literature that throws light upon the gendered roles and norms of Mexican women and how the importance of the roles of wife and mother in the Mexican household impact family interactions, decision making, labor, education, and the notion of a "unified household." Second, I review literature that explains women's lesser tendency than men to emigrate from Oaxaca as well as the process of migration decision making. Included are discussions of actions and reactions that impact women's burdens, responsibilities, and living arrangements. The third literature stream offers male migration and women's paid work, with a discussion of the role of remittances. Finally, I review the

\footnotetext{
${ }^{8}$ For an overview of literature on gender in migration scholarship, see Patricia R. Pessar and Sarah J. Mahler, "Transnational Migration: Bringing Gender In," International Migration Review, Vol. 37, No. 3, 2003.
} 
extremely thin body of literature that attempts to link male migration and educational attainment.

\section{Gender Norms and Mexicanas' Roles}

The use of "gender" in this research project is congruent with the usage by most sociologists and feminists: "to differentiate it from sex and indicate its social rather than biological origin" (Benería \& Roldán, 1987, p. 11). In their groundbreaking book on the integration of class and gender in home-based labor work in Mexico City, Benería and Roldán expand the definition of gender as:

... a network of beliefs, personality traits, attitudes, feelings, values, behaviors, and activities differentiating men and women through a process of social construction that has a number of distinctive features. It is historical; it takes place within different macro and micro spheres such as the state, the labor market, schools, the media, the law, the family-household, and interpersonal relations. ${ }^{9}$ (p. 11)

The simplistic designation of gender as solely a binary variable, "M" or "F," contributes to a lack of "theoretical significance and does little to clarify what being a man or a woman means to migration behavior" (Kanaiaupuni, 2000, p. 1314). A United Nations Women's report declares that gender must be "understood as a subordinating variable qualified by other power relationships: class, ethnicity, nationality, migratory/citizenship status, sexual orientation, etc." (Lopez Castañeda, 2008). The socially-constructed, gendered Mexican society impacts all aspects of Mexicanas' lives and certainly the lives of Oaxaqueñas. Family, work, education,

\footnotetext{
${ }^{9}$ For additional clarification and description of the importance of gender within the realm of migration studies, see Pierrette Hondagneu-Sotelo, Gendered Transitions: Mexican Experiences of Immigration, Berkeley: University of California, 1994, p. 3.
} 
migration decisions involving leaving and/or returning, household responsibilities, discipline of children are all impacted by gender roles. The gendered role of wife and mother as an often-subordinated member of a household plays a significant part in the identity of Mexicanas. Mexicanas' gendered role impacts how norms are defined, developed, and implemented in terms of their staying behind in a community while spouses emigrate as well as their status in homes with spouses present in the home.

It is imperative, however, to acknowledge that women are not a homogeneous category. Women cannot be statically categorized by the absence or presence of a husband in the home; one day a woman is in one category, the next day, shifted to another (Stephen, 2007). Women also are not homogenous in their subcategories. Not all stay-behind wives have similar experiences or history nor could or would they recite parallel stories (Stephen, 2007). The stories that staybehind women communicate and share differ in experiences both as a wife and mother but also in differences in personality characteristics, resourcefulness, family and friend networks, amongst a wide array of others. Additionally, there is vast inhomogeneity of women whose husbands have returned and women whose husbands have never emigrated.

Gender within the context of cultural roles, traditions, history, and contemporary relations and relationships plays an important part in Mexican women's lives. The foremost role of most Mexican women is one of "mother"considered a natural state and an ultimate goal by nearly all Mexican women- 
followed closely by the vital role of wife (Benería \& Roldán, 1987; Howell, 1999). Benería and Roldán's research with Mexico City women showed that women "conceived their role in society as essentially that of wife and mother," even though the majority of women described their marriages as unhappy (p. 142). These women, however, "rescued the personally rewarding elements of their enactment of motherhood, and justified the continuation of the overall unhappy married life" (p. 142). Their role as mother and wife and the norms embedded in those roles formed the basis of all other aspects of their lives.

Education is a predictor of gender power as well as reduced adherence to the cultural and traditional role of subordinated Mexicana (Howell, 1999; Parrado, Flippen, \& McQuiston, 2005). Women with higher levels of education tended to marry at a later age, gave birth to their first child at a later age, were more likely to work, were more likely to enjoy their work, and tended to play a stronger role in each of these decisions (Howell, 1999).

Education, as an endowment factor, impacts Mexicanos' and Mexicanas' inclusion in the labor force. Pagán and Sanchez (2000), using 1994 survey data from rural communities in three Mexican states, found that approximately 20 percent of married women ages 15 and older reported being employed (other than selfemployed); for married men, it was approximately 93 percent. Men's higher levels of education-along with other gender-related factors that disadvantage womentranslated into higher employment propensity with substantially lower levels of self-employment. Higher levels of education correlated to salaried positions while 
un- or under-educated women were much more likely to be self-employed (Pagán \& Sanchez, 2000, p. 631).

Whether salaried or self-employed, women's need to defend their labor market activities outside of their domestic realm portrays the personal and social expectation for women of prioritizing the home while minimizing labor market activities. The women in Benería and Roldán’s (1987) study of women working at home in piecework labor in Mexico City justified their work as "necessary and legitimate." Women must justify their participation in the labor force since their first and foremost role is one of wife and mother. In-home piecework employment offered women the opportunity to fulfill their primary wife and mother role while merged with the role of laborer. Women's priorities of wife and mother overshadowed the negative consequences of in-home labor: low and unjust wages, poor treatment by employers, lack of acknowledgement of the need for household assistance by husbands, as well as reduced opportunities in the labor market (Benería \& Roldán, 1987). Employers justified paying less than the standard labor rate while concurrently expecting more of women since they had the "luxury" of working within the home. Husbands justified their own continued lack of domestic chores since women remained in the home and thus, were able to simultaneously fulfill their domestic role, while working. Women justified settling for a narrow range of economic options by understating the importance of their work to household survival, considering their work as secondary or temporary (Benería \& Roldán, 1987; Gledhill, 1995). In Benería \& Roldán's study, all parties-including the 
women themselves-justified the degradation, deprivation, and neglect that women experienced in the in-home labor market due to women's prioritization of their roles as mothers and wives.

Similarly, Gledhill (1995) found that women in rural Michoacan sought ways to add income to the household without having to work outside of the home. Adding income to the household most often means self-employment for women due to structural factors such as household demographics, gender differences in employment preferences, the need to combine work with childcare, maledominated trade unions, and employer practices that favor men (Gledhill, 1995; Pagán \& Sanchez, 2000).

In general, Mexican women participate in the labor force due to necessity. In addition to education, a primary difference between the women in Benería and Roldán's (1987) study who viewed their work as exclusively necessary and something more than pure economic need was women's head-of-household status. Although married at the time of the survey, a portion of the women who had once been heads-of-households viewed their paid work as a "positive sign that differentiated them from weak women afraid of the external world" (p. 142). While some women needed the vindication of external work in order to reconcile their absence from children and spouses, other women saw their external work as offering value that differentiated them from other Mexicanas. Mexican women continue internal and external struggles in reconciling the roles of mother, spouse, and labor force participant. As Fernández-Kelly (1990) states of Mexicanas': 
... marriage and a stable family life are perceived as desirable goals which are, nonetheless, fraught with ambivalent feelings and burdensome responsibilities. (p. 326)

From a young age it is evident to Mexican girls, especially in rural areas, that females are the home caretakers-first in sync with the domestic work of their mothers, followed by the domestic role of wife and mother themselves. Mexicanas are first and foremost mothers; education and career follow, typically only as lower priorities. To express the highest priority to which Mexican women aspiremotherhood-a respondent in Kanaiaupuni's (2000) study stated, "I always felt that my life was for my children" (p. 1318). This is not to imply that rural Mexicanas differ from women throughout the globe but, instead, to illustrate the indispensable, imminent role of la madre (mother) with unequaled value placed on that role. Heading a household slightly disrupts this ultimate calling and prioritization of motherhood, but only minimally (Benería \& Roldán, 1987).

Along with work, whether inside or outside of the home, educational attainment also has a mediating effect on Mexican women's prioritization of motherhood and spouse. While advanced education shifts and slightly delays the reproductive plans of women, the acquisition of formal education, "did not in any way diminish women's respect for motherhood or their desire to be mothers, although it did often result in later first pregnancies and smaller family sizes than is the case for women lacking schooling" (Howell, 1999, p. 120). Girls attend primary school at a higher rate than boys but begin to lose ground toward the end of secondary school (middle school). High school and college is dominantly male. Girls 
are clear: my gendered place is in the home, with education and economic fulfillment as goals only to be considered within the context of motherhood and a spousal relationship (Howell, 1999).

Howell (1999) correlates gender roles and norms with education with two findings, in particular: 1) Women expressed a desire to "defenderse (literally, to defend themselves)"- explaining that, for them, the term referred to "the ability to financially support oneself or to protect oneself and one's family from outsiders" ( $p$. 108); and 2) Gender bias affected educational attainment and types of studies—girls were often relegated to fields more typical of females: nursing, teaching, and secretarial work (p. 109. Generational differences were evident in both educational attainment and chosen career paths with younger women more apt to pursue "nontraditional" fields (Howell, 1999). Understanding the significant differences between typical rural life and typical urban life, it is important to acknowledge that the women in Howell's study were all urban dwellers. Some women came from rural environments but as adults and study participants, all women were living in urban settings.

\section{Gender Norms and Migration}

Migration presents challenges to Mexicanas' calling of wife and mother. Migration can result in a "radical gender-transformative odyssey" when women migrate and leave their children in the care of others in their home community; thus, the norm of what is deemed as "proper" mothering in Latino culture is strained 
(Hondagneu-Sotelo \& Avila, 1997). Migration decisions are intricately linked to gender roles and relations within Mexican families \{Hondagneu-Sotelo, 1994, Gendered Transitions: Mexican Experiences of Immigration;Hondagneu-Sotelo, 1997, "I'm Here`, but I'm There"\}. Men's gendered position in Mexican society advantages and prioritizes them in the initial decision to consider migration as well as after they have migrated north (Hondagneu-Sotelo, 1994; Kanaiaupuni, 2000). Social networks facilitate migration (Kanaiaupuni, 2000; MacEwan, 2006; Massey et al., 1993; Massey \& España, 1987). The majority of social networks are dominated by men, disadvantaging women for domestic as well as international migration. Mexican migration is dominated by men and thus networks tend to be composed of men and arranged around the issues, needs, and concerns of men (Kanaiaupuni, 2000).

Women-based networks were created and developed separately from maledominated networks due to the need for female connection, assistance, and guidance in the migration process; women-based networks have transformed the female migration experience (Hondagneu-Sotelo, 1994; Kanaiaupuni, 2000). When men's networks did not suffice for women's migration, women often found or formed their own networks, predominantly female (Hondagneu-Sotelo, 1994; Kanaiaupuni, 2000).

When women stay behind in their communities as husbands migrate, the role of wife and mother and the responsibilities within are altered. Women often take on additional work, perhaps working for income for the first time, thus changing 
established cultural gender roles within the family. Additionally, the role of "wife" is drastically shifted. Distance from spouses creates gender norm transformation in sending households, in families, and in communities, as does migration when both spouses relocate to a U.S. locale (Hondagneu-Sotelo, 1994).

Gendered Norms and the Mexican "Household"

Inevitably, household and family dynamics are impacted, disrupted, and shifted by migration as well as the potential for migration. The communal household, as well as individual members, experience shifts in status and respect in the community (Stephen, 2007). Migration alters the traditional domestic role of a wife in relation to women's work and impacts children's education. The discussion of women's actions and reactions to male migration would not be complete without considering these alterations within the context of the household.

Household respect from within the community is a crucial component of rural living. Many residents in rural communities believe that migration has deeply affected this important communal concept of respect (Stephen, 2005, pp. 46-49). Stephen's (2005) research on Zapotec women in Oaxaca describes how the concept of respect is integrally linked to a community member's ability and aptitude to hold community positions of authority, to hold influential opinion within the community, and to access resources. Gender roles play an important role in community household respect since the woman of the home is often the household member 
who engages in "extensive damage control to repair harm caused by deviant household members" (p. 49).

When migration is a "success" and remittances arrive in a timely and consistent manner, not only is respect gained by household members but additionally, social status, as well (Cohen, 2001; Levitt, 2001). “Target earners with the financial ability and social networks to risk border crossings were able to use their successes [italics added] to increase their status vis-á-vis the community at large" (Cohen, 2001, p. 963). Cohen's nebulous description of "success" appears to be focused on migration to the north—with men in the United States and women at home-with remittances returning and securing social status for the household within the community. Cohen's work in Santa Ana del Valle, Oaxaca, a community with a high rate of male migration, circumscribes women as somewhat peripheral and superficial in the attainment of a higher rung on the socioeconomic ladder or a higher level of respect.

The norm in Mexican culture has been that women are usually the beneficiaries—rightly or wrongly, positively or negatively—of their spouses' social networks and that women benefit or suffer from the resources and expertise situated within their husband's networks (Hondagneu-Sotelo, 1994; Stephen, 2007). This places women in a subordinate, submissive, and superfluous role. HondagneuSotelo's (1994) ground-breaking book, Gendered Migration, challenged the notion that women benefit or suffer solely from their spouses' migration networks and that instead, women access or form their own networks. Women's networks, not the 
networks of previously-migrated husbands contributed to women's migration. It is important to note, as discussed by Hondagneu-Sotelo, that "gender relations in families circumscribe migration options and decisions. Together with age, class, and marital status, gender places various constraints on individuals" (p. 7). Mexican women's options in a patriarchal household remain constrained by gender norms whether in migration, decision making, the domestic sphere, the workplace, or the realm of education.

Women living in a Mexican patriarchal household and society endure constrained roles and expectations and the inhibited potential for self-achieved respect. ${ }^{10}$

There is indeed ample evidence that Mexican gender relations are patriarchal. Yet urbanization, women's increased participation as income earners, and immigration have begun to erode men's dominance over women in Mexican families. (Hondagneu-Sotelo, 1994, p. 14)

While urbanization, labor participation, and immigration to the United States by women may erode Mexican patriarchy, so may "stay-behind" status of women. Gender norms must shift and transform when women are burdened with a larger and deeper household load.

The domestic sphere has traditionally been the domain of women, certainly in the case of Mexican women. The notion of "household," and the importance placed on the household as a unit is central to rural Mexican life. Mexican women are habituated to the household with the domestic sphere being central to their lives

\footnotetext{
${ }^{10}$ For a discussion of machismo and marianismo, see Pierrette Hondagneu-Sotelo, Gendered Transitions, pp. 9-10.
} 
(Fernández Kelly, 1990; Kanaiaupuni, 2000). The household sphere is so dominant and powerful that it impedes women from exploring outside of that physical realm and requires negotiation of the gendered boundaries that rule the domestic and economic spheres (Fernández Kelly, 1990). Rural women, especially, often do not venture into the streets without accompaniment, most often by a family member (Kanaiaupuni, 2000). Limitations on women's mobility impede their ability to continue education since few rural communities include high schools. Girls must commute daily or move to the city to continue their studies-neither of which are easy or popular choices for parents since girls are needed for the domestic chores of the home and to care for siblings (Dr. Jack Corbett, Portland State University professor, personal communication, September 20, 2008). Girls from rural locales are also expected to be accompanied by another female rather than being alone with other men when being transported from their community to any other location (Corbett 2008). These rural cultural norms limit girls' and women's education, career choice, and labor force opportunities. Women are much more "tied to the home" than men; their limited education and their labor-force participation are intimately linked to what they can achieve while still being tied to the domestic household (Benería \& Roldán, 1987; Gledhill, 1995; Pagán \& Sanchez, 2000).

Given the Mexican priority on motherhood, advanced levels of education do not equate to declining desire of the coveted role of "mother." However, Howell's (1999) research reveals that higher levels of formal education afforded women the opportunity to make economic and social choices that differed from lesser-educated 
women. The 70 women in Howell's study unanimously confirmed that education had positive impacts on Mexican women's lives (p. 123). Although highly educated women expressed a similar desire to be wives and mothers as did Mexicanas with less education, her research group "rejected many of the stereotypical trappings of the institution [of marriage]" (p. 123) by taking husbands that were accepting of their career and working role, often planning their children's births, and viewing their economic work as integral to the well-being of their families.

One of Howell's conclusions - that educated women viewed their work as integral to the well-being of their families-contrasts with researchers' work with more typical Mexican women with low or even average levels of education. Cohen's (2004) work in twelve central valley communities near the city of Oaxaca found that "women often discounted their work as unimportant in the maintenance of their households over time" (p. 42). Cohen, rather than the women themselves, recognized that women's work was "critical to the success of their households" (p. 42). Similarly, Stephen's (2005) research in Teotitlán del Valle, also near the city of Oaxaca, confirms women's tendency to discount their own economic input. Severe undercounting of women's economic inclusion in INEGI data often stemmed from under-reporting by the women themselves (p. 204-5).

\section{Who Stays Behind?}

Women who stay behind as husbands go north assume that their spouses will, quite promptly, send remittances and will eventually return as productive 
members of the household and community. This expectation holds for some women as some husbands do, in fact return. For other women, the expectation is dashed since some husbands never return. Other households include women whose husbands have never ventured across the border. Which women fall into which category is a static snapshot of one moment in time but is a dynamic status long term. One day a woman has a spouse who has never ventured north; the next, she is shifted to and labeled as a "stay-behind" or even "left-behind" wife. Mexican men tend to migrate; Mexican women tend to remain. History, gender roles, gender norms, and a patriarchal society contribute to men's tendency to migrate and women's tendency to stay home (Gledhill, 1995; Hirsch, 2003; Hondagneu-Sotelo, 1994).

A historical basis as to why women often stay behind, at least initially as their spouses emigrate, is offered by Hondagneu-Sotelo (1992):

Direct labor recruitment of Mexican men by U.S. employers, dating back to the nineteenth century, and the Bracero program, a temporary contract labor program established by the United States and Mexico between 1942 and 1964, institutionalized family stage migration. (p. 400)

"Family stage migration" is a strategy where men go first with the potential that wives and children may follow at a later "stage." The structure and omission of women in programs such as the Bracero program, instituted in 1946 by the U.S. government, helped established the pattern that men travel north while women maintain the home in the sending community. This "family stage migration" fit well with women's domestic gendered norms and men's economic provider role. 
The omission of women in programs such as the Bracero program with a dearth of Mexican women emigrating alongside their husbands suited men well. During the Bracero program women remained behind to care for children and the home allowing men the opportunity to leave to fulfill their economic provider role with women in the traditional family obligation role (Gledhill, 1995; HondagneuSotelo \& Avila, 1997). Without women at home, men had little possibility of emigrating. Gendered norms, cultural roles, the economic environment, the program structure, and the social construct all contributed to Mexican men going north Mexican women staying behind.

Salgado de Snyder's (1993) research sample of 202 rural Mexicanas who had never left Mexico-all with their husbands in the United States—found that when their sons reached adolescence their sons were prepared to emigrate with their fathers whereas daughters "tend to remain at home and help their mother until such time they get married, usually to an [im]migrant" (p. 399). A woman's place is in the home with responsibilities less conducive to migration as men's gender expectations (Gledhill, 1995; Hondagneu-Sotelo, 1992).

Kanaiaupuni (2000) defined three reasons that helped explain the pattern of male-dominated migration in her research of 43 Mexican pueblos. First, women's social norms of motherhood prioritization limit the social acceptability of migration. Second, women's domestic responsibilities and mothering demands limit women's physical, geographical mobility. And third, the expense of family life in Mexico is considerably less than in the United States. This lower cost of living encourages 
"split household migration strategies" (Kanaiaupuni, 2000, p. 1318). While some women surveyed had accompanied their husbands north, 74 percent had never migrated themselves. Some women remained in their community despite their partners' long migrant career (p. 1325). Kanaiaupuni notes that with each birth women are more tightly tied to the household and the community while men, in fact, become less tied. ${ }^{11}$ Kanaiaupuni's statistics show an increasing potential of migration to the United States among educated women and a decreasing likelihood of migration among educated men. "These findings strongly implicate education and family as primary mechanisms through which we observe the interplay between gender and migration" (p. 1335).

Kanaiaupuni's low female migration statistics coincide with Cohen's (2004) and Cohen et al's (2008) study in rural Oaxaca which found that 78 percent of migrants to the United States were male. Most wives of migrants remain in their rural communities, so much so that Cohen's 12 randomly-chosen Central Valley communities were populated with 46 percent men and 54 percent women even as recently as $2005 . .^{12}$ But do women remain in their community by choice? Do they have a voice in the household decision making process pertaining to international

\footnotetext{
11 "Less tied" is derived from the assumption that a growing family requires more resources, often thought to be more accessible in the United States and thus, financially maintaining and providing for a family becomes a growing need with the birth of more children.

${ }^{12}$ The calculation is my own generated from 2005 INEGI census data using Cohen's 12 communities. Of the 12 communities, one community, San Lorenzo Albarradas, had 50 percent male/50 percent female; the other 11 communities had more females than males with Santa Ines Yatzeche being the most extreme with 42 percent men and 58 percent women.
} 
migration? Do women in rural Oaxaca play a role in keeping men from migrating?

Are women's voices heard in relation to the migration decision?

\section{The "Household," Decision Making, and Migration}

Cohen (2004) describes some of the challenges of examining decision making at the household level:

... it is important to remember that the decision to migrate and to use remittances are made by households, but outcomes are still determined by the actions of individuals. To ignore the motivations that push an individual to migrate, even as we focus on the household decision making, risks overlooking just how delicate the balance is that exists between the individual and his or her domestic group. (p. 34)

An individual springs forth from the household from which he or she comes. "The household establishes a foundation upon which the individual can build success" (Cohen, 2004, p. 35)—or, potentially, the opposite. Cohen's 2004 The Culture of Migration in Southern Mexico conveys to the reader the fundamental role of the household in Mexican culture but fails to adequately acknowledge the differentiated individual parts of those households. Those differentiated individual parts, predominantly male, are usually the decision makers in those "households" even in decisions as important as migration.

Given Mexican gender roles, households cannot be viewed monolithically or as a "homogenous economic unit" (Bever, 1999, p. 16). Bever offers a succinct summary and accompanying examples of the generalized view of several researchers on the topic of migration, decision making, and the household: "Recent 
research now approaches the problem of migration by addressing the significance of household and gender relations within the household" (p. 16). Households, and the congruent members within, are not motivated by one equal preference or priority but are, instead, motivated by individual motivations and priorities with power and gender dynamics at play within (Bever, 1999).

In regard to households and migration decision making, Salgado de Snyder's (1993) 202 surveys of wives of migrants who themselves had not left Mexico offers an example of migration decision making and the non-monolithic nature of the household. Nearly half of women surveyed, 47 percent, expressed feeling that they had not participated in the migration decision of their husbands (p. 395). Sixty percent of women also commented that if given the opportunity, they would remain in Mexico; 40 percent would go to the United States and live with their husbands. The decision making of household members was not equally held nor made and the power dynamics of decision making resides primarily with the husband.

Hondagneu-Sotelo (1992) disputes any potential notion of a unified family decision making process:

In all of the families in which men preceded their wives [to the United States], patriarchal forms of authority prevailed, so that migration decisions did not arise as part of a unified family or household strategy. Generally, husbands unilaterally decided to migrate with only token, superficial regard for their wives' concerns and opinions. Women were not active decision-making participants. (p. 408) Ahern et al's (1985) research closely aligns with Hondagneu-Sotelo's assessment: "Typically a husband will tell his wife that he is going and then he will 
be gone within a week" (p. 15). Rarely does a clear plan develop from discussion between the wife and husband, but instead, the husband tends to justify trips to $e l$ Norte with generalized statements of family obligation and his responsibility for betterment of his family (Ahern et al., 1985).

While there is generalized agreement in the literature that women are not significantly involved in the migration decision of males, there does not tend to be agreement as to the level of acceptance or disagreement in regard to husbands' emigration. Hondagneu-Sotelo (1992) found that many women reported "having been vehemently opposed to their husband's migration" (p. 400). Yet, Salgado de Snyder (1993) reported that 59 percent of the women she interviewed felt that the husband's decision to migrate was "a very good one," while significantly fewer, 31 percent, had negative feelings about the decision (with 10 percent ambivalent) (p. 395).

However, no matter the level of agreement or disagreement in the decision to emigrate and the level of satisfaction or dissatisfaction with the decision, the aspect most worrisome to women is the fear of abandonment (Ahern et al., 1985; Gledhill, 1995; Hondagneu-Sotelo, 1992; Salgado de Snyder, 1993; Stephen, 2007), the "fear of their husbands' desertion, of becoming a mujer abandonada (an abandoned women)" (Hondagneu-Sotelo, 1992, p. 400). Fear of abandonment as a "real foundation in community experience" appears anchored in women's anxiety of men finding and securing a new relationship in the United States (Gledhill, 1995, p. 137) 
and leaving them and their relationship behind. Gledhill cites undocumented men in the United States as often looking for a path to legalization. Expanding on the topic:

The formation of new relationships (and often another or several other families) in the United States is, however, a much broader phenomenon, and does not necessarily lead to any formal separation or divorce, particularly where the migrant continues to support his original family. Survey methods often fail to record such behavior because questions are restricted to formal legal categories. (Gledhill, 1995, p. 137)

Infidelity within the context of emigration and/or abandonment of wives who stay behind is minimally addressed in the literature. However, the fear, the worry, and the stress that women experience is addressed. Approximately half of the women suffered psychologically from fear of abandonment in Salgado de Snyder's (1993) research. While challenging to document, men's infidelity while away from their homes and communities clearly affects women who stay behind. Likely, as well, these fears and worries impact women with anchored husbands but, as previously mentioned, are aware that their status could potentially change. Women stay behind in Oaxaca in vast numbers with many more wondering if they, too, potentially could become a left-behind wife.

The Significance of Staying Behind: Transnational Lives of Mexican Women

Hirsch's (2003) transnational research on Mexican migrant women in Atlanta and their female relatives and friends living in the sending communities of Degollado and El Fuerte in the state of Jalisco, Mexico refers to women staying behind as an older pattern of migration - possibly accurate for Jalisco but still a 
normative household migration strategy in the newer-sending state of Oaxaca. Hirsch also affirms that this older pattern creates situations in which women had a great deal of autonomy and decision making power (p. 208). Women who remain in their rural communities while spouses emigrate carry a wider and heavier household burden but with potential for transition to increased decision making power as women are transferred to head-of-household with expanded independence and accountability (Cruz, 2008; Hirsch, 2003).

Women often remain in the home and within their familiar community but must simultaneously endure transnational lives. Mahler (1999) most accurately describes the impact and reality of transnational lives: "To my mind, the term transnational should communicate the fact that people's lives span borders, while acknowledging that borders, nation-states, and national identities still exist and are of consequence" (p. 692). The realities of daily life for women who have stayed behind has transnational implications through the worry of the relationship, of receipt of remittances, and of the influences in the north that impact and affect the husband while the wife remains in her rural Mexican context. Women remain dependent upon husbands in the north with her anchored position in the sending community, much to the content of many migrating husbands (Hondagneu-Sotelo, 1992).

Stephen's (2007) research in Teotitlán del Valle, a weaving community located 45 minutes outside of the city of Oaxaca, describes life in the pueblo as having extensive connections to the United States. In describing the life of one 
Mexican family with a long history of migration, Stephen writes, "Most important, the ability to construct space, time, and social relations in more than one place simultaneously is a part of the daily framing of life in this extended family as well as in others" (p. 5). While many Oaxacan women stay behind in their sending communities, their lives are influenced from the transborder relationships and voids that continue to transcend space and time. Their "daily framing of life" involves obligations, responsibilities, burdens, decision making, and obstacles that are the result of the transnational context that they and their family have entered into when a spouse emigrates to the United States. Stephen urges reconsideration of how we conceptualize rural communities in Mexico as does Levitt (2001) in The Transnational Villagers: "A transnational perspective drives home the point that sometimes migration is as much about the people who stay behind as it is about those who move" (p. 62).

The importance of viewing rural communities in Mexico within a transnational context begs two questions: 1) How does transnationalism impact women who stay behind in their sending communities, and 2) What are these women's actions and reactions to their new reality? Dissecting these questions begins with the migration decision itself, followed by the finalized decision often made by individual actors in the household rather than the household as a "whole." What household arrangements, family considerations, and networks are involved in the decision to leave as well as the decision to stay? 


\section{The Significance of Staying Behind: Wife-Helper Networks}

When women stay behind, Ahern et al. (1985) describe one of the husband's responsibilities as to "assure that there will be a support network to assist and protect his wife during his absence" and to set up a "network of wife-helpers"people who provide and assist with short-term loans, animal care, repairs, selling of animals, accompanying wives to the town doctor, and emergency care of children (p. 15). The labor division of wife-helper tasks is divided by traditional gender lines-

... the mother-in-law helps with illnesses, especially if the wife gets sick; the father-in-law and brother-in-law usually help with animals, arrange business affairs, and money loans; and compadres [godfather] are consulted in affairs involving their godchildren. (p. 15)

Salgado de Snyder (1993) questions the extent to which a network for a staybehind spouse exists as well as its functionality. Fifty-six percent of the 202 rural Mexican wives with husbands in the United States responded that they had someone who could provide important information when needed; 59 percent felt they had someone from whom they could borrow money, if needed. However, the majority of women did not perceive their network as people on whom they could rely (Salgado de Snyder, 1993, p. 396). Only 41 percent of Salgado de Snyder's respondents indicated that they had a trusted person on whom they could count (p. 396).

Similar views were shared by Hondagneu-Sotelo's (1992) research group of women:

While some of the male respondents reported securing help in this manner [by requesting assistance for their wives while away], their 
wives did not always agree with them on the degree of help this strategy provided. Some of the women acknowledged receiving assistance from their own parents or siblings, but most of them saw themselves as struggling alone with their children. (p. 66)

Salgado de Snyder's (1993) and Hondagneu-Sotelo's (1992) findings contrast with Cohen's (2001) reporting that "social networks mitigate the stress involved with migration and are important supports for those household members who remain at home as well as for the migrants living in the receiving community" (p. 962). The assistance, absence, burden, or support of a network in the sending community in regard to women who remain is unclear, ambivalent, and disputable.

The wife-helper idea may be a mirage of male's patrimonial ego in assuming women's need for such a network. A wife-helper network may impede women's independence in making women beholden and responsible to this set, established network. The network, however, may also be a fulfillment of a husband's role in providing women with assistance while absent. Cohen (2004) describes a "typical Oaxacan migrant" as a married man in his mid-twenties, a wife about two years younger with two or three minor children in the household that usually reside adjacent to the male head's siblings, parents, or both (p. 73). This physical/geographical closeness creates, through necessity, proximity, and traditional pooling of resources, a built-in network—a so-called "wife-helper network."

Ahern et al (1985) describe an extended and advanced network of individuals that require, expect, and receive gifts or money upon a migrant's return 
(p. 16). The extent of formalized and expanded networks of assistance beyond the already-established family network remains ambiguous. Dealing with that network-whether a formalized "wife-helper" network or the built-in family network (including in-laws and other relatives of the husband)—require action and reactions by women who stay behind as their spouses depart.

\section{The Significance of Staying Behind: Patrilocal Living Arrangements}

The potential of a "wife-helper network" and the decision of a husband's migration are often beyond the locus of control for many women. The decision of where to reside while enduring the absence of a husband does, occasionally, fall under the locus of control of stay-behind wives (Hondagneu-Sotelo, 1992). When women were given a choice, the majority opted to stay with their own parents. Of those without that choice, some lived with their in-laws while women with longer histories of staying behind often opted to live on their own with their children (Hondagneu-Sotelo, 1992). Many of Hondagneu-Sotelo's participants complained of the wife-helper network as a drain on resources rather than as a "helping" network (p. 67). Hondagneu-Sotelo describes women's frustration and indignation with this type of living arrangement and drain of resources by members of the family intended to be of assistance as one important factor in shaping women's eventual decision to also emigrate to the United States. The living arrangements and wifehelper networks could have a strong impact on women's autonomy, decision making, and self-esteem when remaining in their local communities. 
Published shortly after Hondagneu-Sotelo's 1992 article, “Overcoming Patriarchal Constraints," and her 1994 book, Gendered Transitions: Mexican Experiences of Immigration, Gledhill (1995) offers a very similar scenario from the state of Michoacán: “In Quiringüicharo, 'containing women' seems a major male preoccupation" (p. 157). The mother-in-law's house offers the advantage, to the absent spouse, of a watchful eye over the wife. The stay-behind woman tends to lack authority in the home since she resides in the home of her mother-in-law, a challenge for an adult Mexican woman, often with children, to accept a subservient domestic role within the home.

Published at approximately the same time, Salgado de Snyder's 1993 research offers:

... the majority of women interviewed lived in the same household with members of the extended family, such as in-laws, parents, and siblings. Although they had to interact daily with each other, our respondents did not identify these interactions as stress-producing situations. (p.397)

However, the women in Salgado de Snyder's research identified their preferred coping mechanism as "avoid[ing] confrontation by doing as they [primarily mothers-in-laws] say" (p. 397). Hirsch (2003) described patrilocal living arrangements as: "In the past a woman whose husband was away might live with her own parents, or her in-laws, so as to continue under the moral and physical protection of an adult man, and married women without children continue to do so" (p 45). 
Pessar (2005) offers a broader, more general statement of patrilocal living arrangements for the majority of Mexican women:

Not surprisingly, the outcomes for women are conditioned by existing gender ideologies, the flexibility or rigidity of proscribed gender roles, family organization and post-marital residential norms. In those [rural Mexican] communities and family structures in which women are highly dependent on males and patrilocal residence prevails, women may find themselves residing with their husband's kin, carefully monitored by them, and afforded little or no control over their movements, their income-generating activities, and the use of remittances. (p. 4 )

As recently as 2008, an article by Julia Pauli, “A House of One's Own: Gender, Migration, and Residence in Rural Mexico," describes the plight of women in patrilocal ${ }^{13}$ living arrangements. Pauli's ethnographic narrative describes women's suffering while living within the strict confines of the grounds, the watchful eye, and the tutelage of mothers-in-laws. Pauli balances the suffering of the daughter-in-law within the context of the mother-in-law's compound with the construction of their own homes from "migradollars" (remittances from their spouses living and working the United States). For Pauli, a home's construction represents a constitution and expression transformation in gender relations, shifts in self-worth and self-esteem, as well as a transformation from under the tutelage of the mother-in-law to the woman's own worth through the construction of her own family's home. While neolocal residences are preferred by nearly all women in conjugal relationships, only a very few could begin their married lives in such a manner. Generational

\footnotetext{
${ }^{13}$ While this research uses Hirsch's terminology, "patrilocal" living, Pauli uses "verilocally" in describing what appears to be the same living arrangement-a woman living within the confines of a mother-in-law's residence.
} 
differences were slight in the "existing but slow increase in neolocal residence" (Pauli, 2008, p. 182). Pauli's accounts of rural women's experiences with patrilocal living arrangements were similar to the stories offered by Hellman (2008). Patrilocal arrangements can often be suppressive, domineering, and even abusive. As recounted by several wives living in patrilocal situations while husbands lived abroad, suppression and abuse "should be understood as typical, not exceptional" (Hellman, 2008, p. 49).

However, without a husband within the household, many young women are confronted with their first challenges at independence (Ahern et al., 1985). Amid accounts of negative repercussions can be found stories of a more positive perspective. A patrilocal arrangement can, potentially, offer a stepping stone or bridge from the young woman's own home to the domestic environment she will eventually set-up with her husband. A young woman may see it as a step toward independence without having to venture too far from the familiarity of a family environment.

A young woman from San Martin Tilcajete (personal conversation, March 2009) conveyed to me her own living situation as one of adjustment, learning, new experiences, and optimism. She repeatedly referred to her own "maturing" in reference to her husband's absence and her feeling of comfort by living with her inlaws' during her husband's absence. She had lived with her in-law's home during her husband's three-year absence and emphasized to me that her in-laws had always allowed, even pushed and encouraged, her to make her own decisions for 
herself and for her and her husband's daughter. The young woman expressed her own patrilocal living situation as favorable and beneficial to her own maturity. However, she emphasized that her story and her experience was not the norm. She was aware of her good fortune in relation to other young women, even friends and family, that had not had the positive experience that she had had. For this young woman to be allowed, even expected, to make her own decisions, including monetary decisions that led to her entering a bank for the first time, was somewhat unique and unexpected, even to the young woman herself.

Patrilocal living arrangements can serve multiple purposes and roles: 1) It can offer a safe, comfortable haven that can enhance maturity of a young; 2) It can be a type of apprenticeship for a married woman (Hellman, 2008); 3) It can put the wife in the role of submissive assistant and forced laborer to the mother-in-law (Hellman, 2008); 4) It can provide economic assistance to the mother-in-law (Hondagneu-Sotelo, 1992); and 5) It can offer monitoring by the in-laws of the young wife's activities, most often unwanted by the young wife (Gledhill, 1995; Hirsch, 2003). Women in patrilocal situations also must contend with changes, once again, when a husband returns. Which factors lead to which actions and reactions continues to be an empirical, unanswered, and explorable research question.

It is important, additionally, to consider that patrilocal living situations of wives who stay behind do not exclusively impact women in the patrilocal situation. Instead, patrilocal living can touch and impact other women's lives through networks of family and friends. Women not in patrilocal living arrangements since 
their husband is living in the home may be concerned for their own potential changes and how others' living situations may potentially become their own with possible gained independence and increased burdens. The significance of staying behind is not felt only by those who stay behind but also by a wider array of women with a rural setting.

\section{Actions and Reactions of Staying Behind}

The challenge remains to understand more comprehensively and empirically the changes that stay-behind women experience. The current literature falls primarily on the side of women's advanced competence through new and expanded tasks, increased levels of autonomy, role expansion, and new or additional inclusion in the local labor force in order to generate income (Ahern et al., 1985; Stephen, 2007). Researchers like Bever (1999) emphasize the shifts in gender and cultural roles and norms while husbands are absent but with those roles and norms returning to their prior state once husbands return.

In a sense, Hondagneu-Sotelo's (1992) subheading, “The Women Who Stay Behind: New Rewards and New Burdens," in her "Overcoming Patriarchal Constraints" article accurately describes women's lives as they remain in their local communities as husbands leave for the United States. While domestic burdens were greater-a logical, obvious assumption when daily tasks of two are reassigned to one-women discovered "unanticipated rewards during these spousal separations" (Hondagneu-Sotelo, 1992, p. 401). Skills gained include budgeting, handling of 
business issues, and public negotiations (Ahern et al., 1985). Many of these tasks are taken on by the wife even though she often lacks relevant experience or skills to do so (Salgado de Snyder, 1993).

Ahern et al's (1985) description of the process and progression of first being a stay-behind novia (girlfriend) to esposa (wife) to madre (mother) to abuela (grandmother) coincides with young girls' initial, favorable view of their partner's departure, shifting to slight disfavor, and settling into acceptance of the separation and frequent departures of the partner as a way of life. Throughout these life stages women become more equipped and capable of handling the role of both mother and father as well as being the businessperson and the community representative. While the process of embracing the role of a migrant's wife is long and arduous, women eventually gain in esteem and social prestige through advanced skills and responsibilities (Ahern et al., 1985; Cruz 2008.

Conversely, Salgado de Snyder (1993) disputes a connection between added responsibility and gains in esteem. The emphasis on mental health and stressrelated factors leads Salgado de Snyder to comment that, "The female empowerment phenomenon as a consequence of migration, discussed by Gonzalez de la Rocha (2001), was clearly observed. However, contrary to the way many may think, most women were not happy with their empowerment" (p. 398). This prompts us to recall that the concept of empowerment is connoted differently in different cultures and contexts. It would be remiss to draw correlation between 
female empowerment and newly-acquired responsibilities and positive characteristics, attitudes, changes in habits or views, and happiness.

McGuire and Martin (2007) also dispute a positive view of gains that staybehind women might develop. "The distress felt by women left behind appeared related to their roles in providing security, safety, and nourishment for family members, spouses, and children" (p. 183). McGuire and Martin describe women as maintaining a feeling of helplessness as well as sorrow that underpins and undermines the hope they have for an improved standard of living.

As inconclusive, peripheral, and diverse as is the literature of stay-behind women, the literature of the impact of male migration on women whose husbands have returned and women whose husbands remain is nearly non-existent. As previously mentioned, literature is available on the social, cultural, and economic context in which Mexican women exist, co-exist, thrive, survive, and confront obstacles when husbands leave to migrate internationally, but considerably less is understood about women's actions and reactions to male migration by those not directly affected through spousal absence.

\section{Male Migration, Remittances, and Women's Work}

While the challenges of carrying a wider and heavier burden in the family tests stay-behind women, the economically-compromised position that women experience in trying to sustain their families likely produces an even greater and more significant burden (Cruz, 2008; Stephen, 2007). 
The most frequent outcome for women left behind whose husbands, fathers, brothers, or sons have migrated elsewhere to work is the challenge of finding a steady source of household income until men can begin to send remittances (if and when they do), and to maintain this through difficult periods. (Stephen, 2007, p. 6)

Women may often be obligated to initiate or increase earned income for the family to replace income lost by the missing spouse (Pessar, 2005).

Yet, Mexico's rural economy offers little work with very few opportunities. ${ }^{14}$ Men go in search of economic resources due to a dearth of employment in their local communities. González de la Rocha (2001) offers two important elements of the lack of economic opportunities in Mexico: 1) the larger socioeconomic context of the Mexican culture and environment; and 2) at a micro level, the socioeconomic context of the economic insecurity in which stay-behind women often-perhaps, always—find themselves. Although males often leave their communities for the United States in order to gain access to the economic resources that González de la Rocha discusses as lacking in rural Mexico, women are often the ones perilously left behind for an undetermined length of time until one of two things occurs-men begin sending remittances or women attain their own sources of sustenance to provide for themselves and their children.

\footnotetext{
${ }^{14}$ I heard the short but descriptive phrase of, "no hay nada aquí, nada" [there is nothing here, nothing] spoken by rural Oaxacans so commonly in various rural towns throughout Oaxaca that I began to pay closer attention to the regularity of "no hay nada aquí." Anecdotally, there were few days spent in a Oaxacan pueblo that the common "phrase" was not heard repeatedly.
} 
Women's Economic Insecurity and Gendered Work

Rural Oaxacan communities offer few, if any, economic opportunities, especially for women. Mexican women often feel there is no choice other than to look to and rely upon remittances to sustain their families. Remittances play an important role in the economic lives of families in rural Mexico but with widely varying levels of success (Hondagneu-Sotelo, 1994; Stephen, 2007). For the women in Hondagneu-Sotelo's (1994) research for Gendered Transitions, remittances received from migrant spouses arrived "sporadically and in smaller amounts than expected" (p. 62). With this often being the case, women must devise ways to feed, clothe, and shelter their families whether it is just until remittances start arriving or to replace the income lost when the husband in the household is lost (Pessar, 2005). Hondagneu-Sotelo's stories of Mexican women's economic strategies to replace male income range from taking on agricultural wage labor to craft work to cooking to selling whatever item they can create, prepare, or purchase and attempt to resell. Preparing and selling homemade food and drink from women's homes-with assistance of family members, often children--was common.

As mentioned by King, labor force participation by Mexican women has long been "controversial, as different Mexican survey instruments have yielded quite disparate estimates" (2008, p. 5). In large part, this is due to challenges in counting and integrating Mexican women's work in the informal sector, women's remunerated or unremunerated work for family members, and women's own undercounting (as previously mentioned in INEGI data). What is less controversial 
and remains a traditional and cultural path for Mexican women is work that coincides with their prioritized role as mother and their child-rearing responsibilities (Benería \& Roldán, 1987; Fernández Kelly, 1990; Gledhill, 1995; Hondagneu-Sotelo, 1994).

The Mexican women in Hondagneu-Sotelo's (1994) study tended to rely heavily on the economic resources that women earned themselves, often diminishing the importance of the role of wife. This shift advanced the importance of their maternal role in financially providing for their children while simultaneously providing for children's needs within the home. Women's selfemployed, often home-based income generation often left women vulnerable: without domestic support or spousal understanding of the need for support, at the mercy of patrónes (boss or owner of a company that subcontracts), with a lack of any type of benefits that may be offered in a wage or salaried position, susceptible to market supply and demand, and with only a small array of viable income-generating opportunities (Benería \& Roldán, 1987). Conversely, home-based income generation offers women easy entry into the labor force even if they lack education or an employment network, a flexible work schedule to manage an array of roles, and work from location that keeps them with and/or close to their children (Pagán \& Sanchez, 2000).

The lack of labor market opportunities and the prioritization of motherhood and wife over economic provider challenge Mexican women in providing for or helping to provide for a family. An additional challenge is the subordination and 
classification of women's work as temporary or extra regardless of its importance to family subsistence (Bever, 1999; Gledhill, 1995). Gledhill describes women in two Mexican communities as understating and devaluing their rural work as "temporary" due, in part, to the gender division of agricultural work as being of the domain of men (p. 141).

The Mexican women in Hondagneu-Sotelo's study (1994), all living in the United States, had emigrated from Mexico. What women recounted as previous staybehind wives was the importance of stay-behind activities, autonomy in their situations, shifts in self-esteem, and stability of their remaining behind that sustains male migration. These factors thus, simultaneously, contributed to creating a basis from which some women sprang forth and migrated themselves. Earning and managing income while not having to attend to demanding husbands and their daily needs played a role in women's transformation, often leading to wives' migration. Women who remained behind were responsible for discipline, household tasks, and outside-the-home responsibilities as well as securing some level of income for family sustenance (Bever, 1999; Cruz, 2008; Hondagneu-Sotelo, 1994, p. 66; Stephen, 2007). Husbands had emigrated to raise the wellbeing of their families and send remittances, but for many women the reality and outcome was often quite different. With remittances arriving after multiple delays or not at all, many women had to accept the role of economic provider in addition to the multitude of home and community roles that they previously endured. Women viewed men residing in the 
United States as having diminished accountability while their own accountability grew (Hondagneu-Sotelo, 1994).

Women's augmented accountability often comes in the form of work that generates income, in addition to home-based, income-generating work, women often must take on agricultural tasks. Few Mexican women, if any, resort to agricultural work unless they are severely impoverished as it is rarely-or never-a desired method of income generation (Gledhill, 1995; Pagán \& Sanchez, 2000). As is most work in Mexico, work in the fields of rural communities is divided by gender. Women often take on the care of plots of land for growing corn and other crops but more so for family consumption rather than for family income (McGuire \& Martin, 2007). Field work is the domain of husbands, domestic work is the domain of wives; children tend to follow the gendered path created for them by their parents and the larger Mexican society as a whole. Male migration shifts these traditional and predictable domains of rural families. Women whose husbands are absent may take on some or all of her absent husband's field work, but it is not expected that she simply step into his shoes. Women often take on male tasks within a genderedacceptable manner rather than exactly as had the absent husband (Gledhill, 1995).

The role of staying behind and having to accept previously-unexplored responsibilities such as farm labor while maintaining the role of traditional Mexicana is chronicled by Ahern et al. (1985). A mujer fuerte, (strong woman)— defined as the wife of a veteran migrant-is a woman who has had to take on the 
work of husband and wife while doing so in a culturally-appropriate gender manner:

She is esteemed for the way she carries out his work rather than doing man's work. In the words of a respondent, she does her husband's work "como una mujer" [like a woman].... The woman who takes responsibility for her husband's work role must cultivate new talents to deal with men. (Ahern et al., 1985, p. 18)

Some scholars, such as Ahern et al. (1985), describe a transformation from disempowered, stay-behind women to empowered labor force participant. But, as noted by Parrado, Flippen, and McQuiston (2005) the literature is divided on the correlation between labor force participation and power and autonomy. Pessar (1999) offers a brief overview of research that has pointed to a link between migrant women who are part of the labor force and gains in personal autonomy and independence even though the marketplace is fraught with gender inequities (p. 27). Kanaiaupuni (2000), from a different perspective, warns: "The relationship is not direct ... between increasing female labor-force participation and growing autonomy or awareness among women-especially poor women who work because they are impoverished rather than empowered" (p. 67). Paid employment and/or labor force participation cannot be assumed to engender empowerment or autonomy, shift gender dynamics, nor necessarily assure more egalitarian gender relations (Parrado \& Flippen, 2005; Parrado et al., 2005). In their study of Mexican women migrants in Durham, North Carolina, Parrado et al (2005) go so far as to conclude that: 
Contrary to expectations that are prevalent in the literature on gender and migration and in resource theories of interpersonal power, women's employment had no effect on any of the three dimensions of relationship power that we considered [relationship control, sexual negotiation, and emotional dissonance]. Thus, the more plentiful employment opportunities in the United States do not automatically translate into greater power for migrant women, and hence, the previous emphasis on employment may have been overstated. ( $p$. 366)

Stephen (2005) offers a detailed description of the daily lives of rug weavers in Teotitlán de Valle. Historically, men weaved. Women and girls were brought into the weaving labor force primarily in the 1970s, in part, due to increased male migration:

Male out-migration appears to have accelerated in the late 1980s and 1990s; some women migrated as well. In this process the social construction of women's work grew to include weaving as well as food processing, child care, animal production, and reciprocal exchanges. Systematic incorporation of women in the weaving labor force appears to have had mixed results for them (p. 207).

Most women weavers participate in the labor force from the confines of their own home while concurrently tending to daily chores of raising children, tending to a husband if present, and maintaining a home, thus conforming to the priority of motherhood.

While a direct link or connection between women's increased autonomy, esteem, and empowerment while participating in the labor force is disputed, the following list by Kanaiaupuni (2000) summarizes various researchers with the following in general agreement: 1) Male migration leads to women's increased burden, both within the home and in the economic realm, with varied outcomes and 
levels of success; 2) Remittances play an important but unreliable role in the lives of women who remain; 3) Gender roles and norms severely limit women's opportunities as well as self-perceived economic contribution; and 4) Women's subordinated role within society-at-large and the economic realm, in particular, is not necessarily overcome by women's labor force participation. While women's work is often crucial for family sustenance, women's work remains marginalized by Mexican society, by men, and even by women themselves (Kanaiaupuni, 2000).

\section{Male Migration and Education}

Establishing correlation between remittances received and children's educational attainment is fraught with challenges. There is little research on the impact of migration, especially male migration, on the educational attainment of children who remain in their Mexican communities (Kandel \& Kao, 2001). Remittances received from a husband and father living in the United States may be used for children's educational expenses or as a substitute for children's labor while keeping them in school; the tradeoffs endured by parental absence, however, has been understudied (Kandel \& Kao, 2001). Family and educational research, as a broad theme, shows that "parental absence yields disadvantages for children, including poor school performance" (Kandel \& Kao, 2001, p. 1208).

A study of student surveys in the Mexican state of Zacatecas-a state with very high rates of emigration—concluded that U.S. migration by Mexican family members is negatively associated with university aspirations for children who 
remain in Mexico (Kandel \& Kao, 2001). Children that are exposed to the phenomenon of migration through familial connections perceive migration for themselves as a viable alternative to higher education (p. 1224). Since it is widely agreed that Mexican education is not rewarded with higher wages or advanced responsibility in the U.S. labor market, children that view migration as their path are not motivated to continue their education past high school and often not even that far.

In contrast to university aspirations, Kandel and Kao found that migration by family members positively impacted children's school performance in standardized test grades. Kandel and Kao argued that remittances received from the migrant residing in the United States lowered children's likelihood of labor participation as an alternative to attending school. The benefit of remittances that helped alleviate financial strain and possibly helped keep children in school up to a point was, however, overshadowed by the negative message of migration as a viable path rather than higher levels of educational attainment. The effects that Kandel and Kao observed occurred irrespective of gender as well as in both urban and rural settings (p. 1225).

Studies that attempt to tie educational attainment to migration must be considered within a broader picture. Data are challenging to measure due to weak correlation between school performance or educational attainment, for example, and the difficulty to control for factors that may affect migration tendencies, the priority or lack thereof that families place on education, and the access or lack 
thereof to quality education. Families with migrants may or may not be the poorer families of the community, may or may not place higher value on education, may or may not be the economically-motivated families, may or may not have accessibility to quality schools, and may or may not have high achieving children prior to migration.

\section{Conclusion}

The set of factors generally agreed upon by researchers in the migration literature does little to capture the challenges that gender within a Mexican context creates for Mexicanas, especially when confronted with male migration. The gender norms and cultural expectations that require Mexican women to prioritize the roles of wife and mother impact all aspects of their daily lives-migration, decision making, labor force options, and education, to name just a few.

The literature also lacks focus on detail to women who stay behind and less so on women who may have been left behind. Often peripheral and supplemental to the task at hand, the literature on stay-behind women offers a fragmented and ambivalent picture of women's lives and the burdens, responsibilities, requirements, and challenges they confront when husbands emigrate. What appears less ambivalent, however, is the priority of the role of mother and, to a lesser extent, of wife. Rural Mexican women's labor market opportunities are premised on the primacy of motherhood, thus reducing women's options to home-based work which offers numerous disadvantages. In the face of male migration, women must often 
turn to income-generating activities to sustain their families either while awaiting remittances or to maintain the household when husbands lose contact and turn away from the connection with their Mexican family. 


\section{Chapter 3: Conceptual Framework, Methodology, and the Essential Setting}

\section{Conceptual Orientation and Framework}

This research project springs from and is embedded within a conceptual framework grounded in the work of two texts that have shaped gender-based literature in the areas of social class, development, Mexican paternal-based culture, and immigration: The Crossroads of Class and Gender: Industrial Homework (Benería \& Roldán, 1987) and Gendered Transitions: Mexican Experiences of Emmigration (Hondagneu-Sotelo, 1994).

Benería and Roldán (1987) built their research on the assumption that class and social patriarchy play fundamental and extensive roles in women's economic and social subordination. Within the context of women's subordination are three significant factors:

- Both male and females' perception of husbands' "vital" household economic contribution

- Women's "perceived" need for husbands' social protection

- The existence and reproduction of prevailing patterns of conjugal exchange

These three factors played a significant role in women's continued economic and social subordination and prejudiced and influenced every aspect of women's lives.

Hondagneu-Sotelo's (1994) research for Gendered Transitions is premised on patriarchal gender relations and how those relations organize migration and, conversely, how migration reorganizes gender relations. Her work, as does this research, supposes three constructs: 
- Migration is an adaptive response to family consumption needs outstripping local resources

- Households construct strategies and develop calculations to meet household needs

- The household is a unit, yet household members often do not act as a unit. Divergent and conflicting interests over migration and relationship challenges do not necessarily coincide with the generalized decision or position of the household as a unit.

The research for this project is framed by combining and integrating the foundations from the works of Benería and Roldán (1987) with Hondagneu-Sotelo (1994) and wrapped within the broader context of economic need, gender relations and norms (patriarchy), and political and economic policies. From these combined bases comes migration and, more specific to this study, male migration within a gendered context. Male-dominated migration comes from four gendered norms in Mexican society:

- Care of the children falls to the woman of the home

- Men are responsible for the economic sustenance of the family

- Women staying behind and caring for children and the household creates stability that allows men to leave and, in some cases, return

- It is most appropriate for men to migrate to the United States, by themselves, or, secondarily, accompanied by family

From this conceptual, pooled framework come the areas of women's actions and reactions to male migration and from this framework springs the research for this study: women's perceptions of their own worries, fears, and uncertainties within the context of decision making and the household; women's labor as influenced and impacted by male migration; and male migration's impact on education. Figure 1 visually depicts the framework for this research: 
Figure 1: Framework derived from the work of Beneria and Roldan (1987) and Hondagneu-Sotelo (1994)

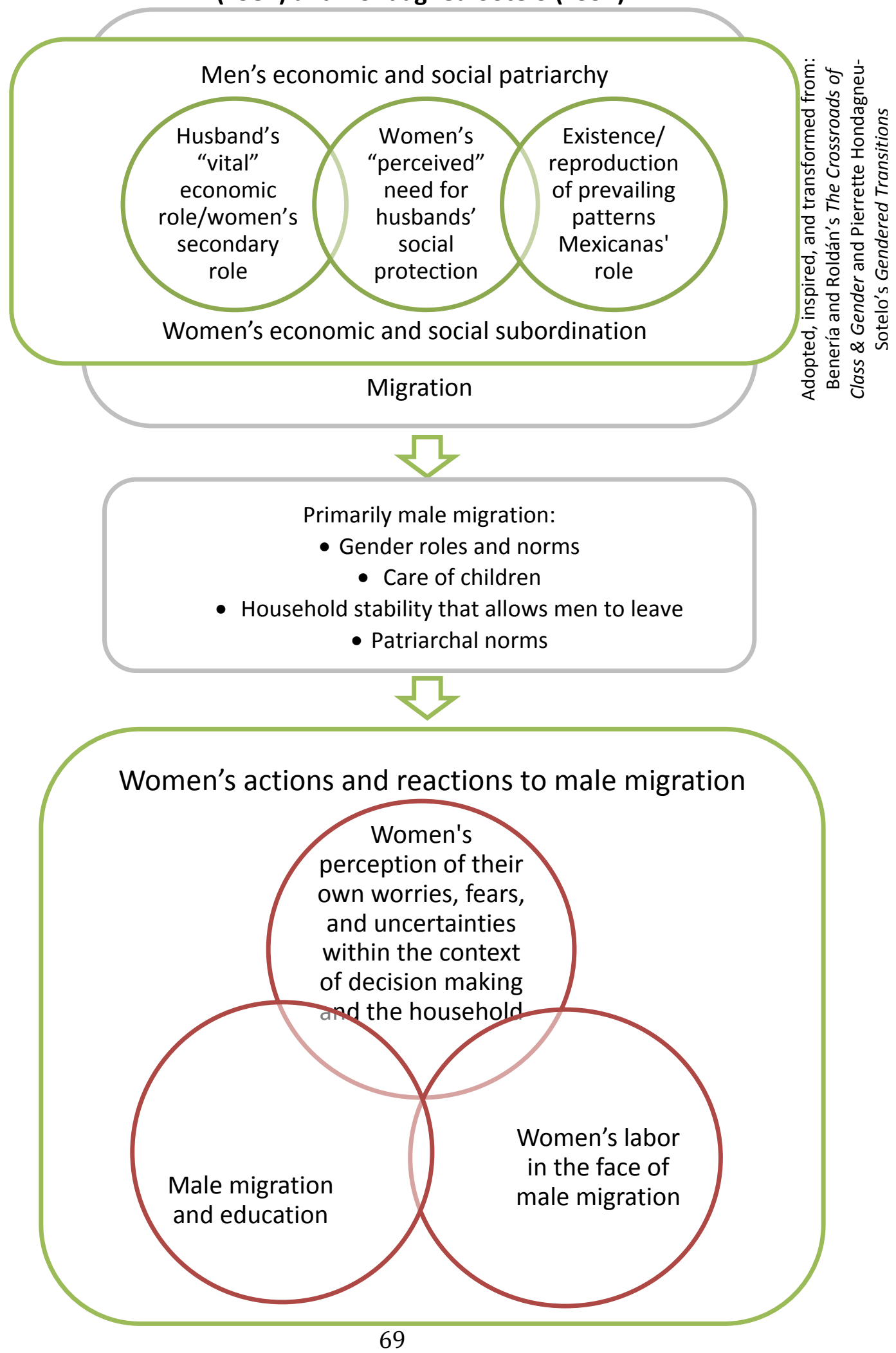




\section{Research Design: Case Study}

Without substantial literature to draw upon as well as a research question that focuses on the "how" and "why" of women's actions and reactions to male migration, a case study approach is the most appropriate as asserted by Yin (1994):

In general, case studies are the preferred strategy when "how" or "why" questions are being posed, when the investigator has little control over events, and when the focus is on a contemporary phenomenon within some real-life context. (p. 1)

As a "comprehensive research strategy" (Yin, 1994, p. 13), the case study inquiry uses multiple sources of evidence, with "many more variables of interest than data points," and "benefits from the prior development of theoretical propositions to guide data collection and analysis" (p. 13).

An inductive, multi-strategy, mixed-method approach permits a type of "bottom up" approach which allows for a research question to be proposed within a constructed framework but with latitude for findings to emerge. With the framework developed from the broader associated literature and the larger research design incorporating personal experiences from visiting as well as living in Mexico, an inductive research approach was undertaken. An inductive approach is appropriate for investigations that lack a solid basis of understanding, agreement, or acceptance.

The context from which the empirical details emerge plays an important role in case study research. Empirical details—comments gleaned through casual conversation or open-ended interviews, observations within a humble home or 
along a dirt path, or words gathered from surveys, Health Center documents, or posted signs in shops along the street-evolve and emerge from within the context of the case study. In a case study approach, the empirical details are considered within the context of the defined case and from such, derive their meaning (Hamel, Dufour, \& Fortin, 1993). The integration of various sources of empirical data are interpreted as a major advantage and a strength of using a case study approach: "The development of converging lines of inquiry, a process of triangulation" offers depth and strength to the case study approach (Yin, 1994, p. 96).

Converging lines of inquiry—a process of triangulation-is appropriate for a case study approach for this research project since neither quantitative nor qualitative data alone can offer a sufficient picture. Gaps in literature corroborate a multi-strategy approach since the investigation topic has little which has previously been explored (Bryman, 2004). With challenges in beginning to fill those gaps, a multi-strategy approach offers a more comprehensive picture than does quantitative or qualitative alone (Bryman, 2004).

Multi-strategy data for this study include two primary sources and one secondary source but also incorporates observations, participation, and countless informal conversations. Triangulation of these converging lines of inquiry from the multi-strategy approach helps corroborate findings as well as offers a richer, deeper, and more comprehensive picture in response to the research question.

The converging lines of inquiry derived from a variety of empirical sources must be considered within the context of participants' point of view-the "meanings 
social actors attribute to their own personal experiences" (Hamel et al., 1993, p. 30). Empirical details must be considered within the larger physicality of locationparticularly relevant for a rural setting geographically located near a metropolitan area. While not isolated but not inclusive, rural locations offer unique characteristics. A location situated near the city of Oaxaca offers participants that are protective and insular yet informed and resourceful. The case study places value on the meanings that "social actors" (participants) place on their own experiences within their own geographical context.

Subjectivity of the researcher is important in a case study approach where observations, informal discussions, and open-ended interviews play an integral part in the project (Hamel et al., 1993). Yet, with acknowledgement of the researcher's position and with the researcher's subjectivity defined, understood, accepted, and recognized, the object of study is more clearly and objectively defined. "The researcher's subjectivity does intervene, but to the extent this intervention is clearly stated, it then becomes objectified into an object that is clearly the sociologist's point of view, or more precisely, the sociological point of view" (Hamel et al., 1993, p. 42).

The intervention of a researcher upon participants and a community led to pursuit of a single case context rather than multiple contexts. Even minimal acceptance and entry into a rural community for the purposes of research is long and arduous, a process likely amplified for a light-skinned, middle-age, middle-class, highly-educated, single, female citizen of the United States with adequate-but-not- 
perfect-Spanish. These characteristics were a contrast to the majority of rural women-most dark-skinned and indigenous, of lower socioeconomic class, un- or under-educated, and married with Spanish, possibly Zapotec, as their language. Living alone and traveling by myself further distanced me from the vast majority of rural Mexican women. However, the valued common ground for connection between Mexican women and myself was that I was a mother. Mexican women in any pueblo can relate to motherhood and from that, many connections were made and communication often flowed more easily.

Being welcomed into one rural community at greater depth rather than several communities peripherally and potentially superficially complements the advantages of the case study approach. The desire to understand the "empirical details" that one community offers in a richer sense than multiple settings could offer at a lesser level also influenced the decision of a single case context. The "single case context" that was most appropriate and fitting of the criteria defined for this study proved to be San Juan Guelavía, Oaxaca, a semi-rural setting just outside of the urban metropolis of Oaxaca de Juarez in the state of Oaxaca.

\section{Research Methods}

\section{Data}

The two primary sources of data that were collected and used in this research project include:

1) Seventy-one random surveys conducted in a structured, organized manner of every eighth home in Guelavía; and 
2) Six extensive follow-up interviews with a total of nine women One secondary source, a Censo de Población (Population Census) survey from the Centro de Salud (Health Center) of San Juan Guelavía, helped clarify who Guelavíans' are, how they live, their professions, and their educational attainment. The Population Census is an annual survey conducted every December of every home in Guelavían boundaries by the members of the Health Committee. The Health Committee consists of six members, all female, that are elected by the community. Traditionally, the education and health committees of rural towns in Oaxaca are populated primarily—often exclusively—by females. Women are rarely elected, however, for positions in the local government or elected to committees that are tasked with the most power in the pueblo nor which administer municipal, state, or federal finances. Of Oaxaca's 570 municipios (counties), 418 municipios use a “usos y costumbres" (uses and customs) form of local government to elect municipal authorities and prohibit the intervention of electoral political parties (Vázquez García, 2011). Of the 418 municipios, each with its own Presidente(a) Municipal (municipal president), 18 were women, an exceedingly low 4 percent (p. 31).

Surveys

Surveys, the initial phase of primary data gathering, generated sociodemographic data, responses to an array of migration-related questions in regard to the spouse or partner, and replies to numerous open-ended questions about work and education. The level of analysis of survey data was the couple-the wife and 
husband or a couple living together or geographically apart. All data was gathered directly through the "woman of the home."

The survey required grammatically-correct Spanish but just as essential was that wording and phrasing be familiar and quickly comprehensible by the general female population of Guelavía. Two months was devoted to enhancing, editing, and perfecting the survey instrument to this end. While piloting the survey instrument I noted how quickly women responded to questions taking very little time to contemplate or reflect on the question or admit that they may not have understood the question. Extensive time was devoted to appropriate wording that would quickly and accurately convey the intent of the question.

Two examples demonstrate the attention required in formulating appropriate questions that would result in intended and useful data. First, it would be inadequate and generate inaccurate results to simply inquire if a woman "worked outside of the home." Many women combine domesticity with income-producing activities within the home. Equally inadequate would be to simply inquire if a woman "worked" due to misconstruing domestic work and income-producing work. Inquiring if a woman "worked" could also be interpreted as salaried or wage labor and miss women who generate their own income through self-employment. In order to elicit accurate responses in a straight-forward manner, the direct: " $¿$ Trabaja por dinero?" (Do you work for money?) was used. This intentionally eliminated domestic, non-paid work within the home, field or crop work for family consumption, as well as work for other family members in lieu of income. The 
question was directly followed with “QQué tipo de trabajo hace para ganar dinero?" (What type of work do you do to earn money?) in order to emphasize that in this context, "work" was synonymous with "income." These questions were not intended to understand women's activities of income substitution performed in or around the home but instead to derive data on women's income-generating activities.

A second example of extensive, but valuable, editing involved a question about husbands who were absent currently or who had lived away in the past. A question about remittances was ultimately phrased as "Usted recibe remesas/dinero de su esposo quien vive en los EEUU?" (Do you receive remittances/money from your spouse who lives in the U.S. [modified for husbands who had lived in the U.S.]). Due to the sensitive nature of questions involving money (with judgment and social issues wrapped within the framework of migration and remittances), the question was verbally prefaced with informal language such as, "We understand that issues of migration are sensitive and private, but it would help us to know ...". At this point, as well, participants were reminded of the confidentiality of all responses. Appropriate and accurate wording was important and in this case, "remesas or dinero" (remittances or money) was used to ensure that women who were not familiar the more formal "remesas" would still clearly understand the question. ${ }^{15}$ The carefully-constructed wording proved valuable as

\footnotetext{
15 "Envios" was also verbally used as a third descriptor if women hesitated or appeared to not fully understand the question. "Envios" is a commonly-used term referring to "something sent" but in this context, "envios" refers to money sent from family members living in the United States.
} 
every woman answered the questions on migration and remittances without hesitancy.

The intent of survey data collection was fourfold:

1) To gather accurate data on individuals and the household in homes with male migrants because conflicting INEGI and anecdotal data on percentage of homes with migrants, an accurate "lay of the land" proved necessary

2) To collect data on women's perceptions and opinions;

3) To gather a group of women from which to choose for semistructured interviews;

4) To be seen, known, recognized, and accepted in the community

One primary research assistant and two secondary assistants, all with at least minimal Zapotec, were used for survey data gathering. Simply putting the word out through the Health Center staff helped me located my very valued primary research assistant. She knew nearly every family in Guelavía, she knew how many small homes were contained behind one large portón (garage-type door), and she knew which homes were abandoned and which had occupants that may simply be away for the day. She offered insight to the traditions and culture of the town that an outsider could not know and would never be privy to. It took only one day to discern the value that Nohemí, my primary research assistant brought to the project. She was a young woman with a studious manner, a good reputation, and a respected member of the community that became obvious as she was warmly welcomed into every home without hesitancy.

The process of data gathering with the survey instrument proceeded by approaching every eighth home and requesting to speak with the "woman of the 
home."16 Empty homes were noted and revisited until occupants were available to participate. The survey process began with a greeting by Nohemí, seemingly readily recognized as a young woman from the community, with a brief introduction of myself and my work. It was important to describe why I had interest in Guelavía as well as a brief description of my background. The introduction included three items: 1) a visual and verbal description of a letter of permission to conduct research in the town from the Presidente Municipal; ${ }^{17}$ 2) a visual and verbal description of the Human Subjects Review Board letter from Portland State University-with a copy left with each woman; and 3) verbal emphasis on the confidentiality of the research with reassurance that responses would not be shared with any member of the municipal government and that research assistants were required to keep all information confidential (the letter of permission by the Presidente Municipal, approved PSU Human Subjects Research Review Committee letter, and the survey are provided in the Appendix). After agreeing to be surveyed, my research assistant smoothly segued into the initial socio-demographic questions. All survey questions

\footnotetext{
${ }^{16}$ Many homes or compounds in rural Oaxaca include more than one residence or living area. Therefore, it was important for the person who answered the door to be the person who they considered the "woman of the home." In compounds where a grandmother, mother, and/or one or more daughters or daughters-in-law resided, the person or persons who answered the door made the determination who they considered the "woman of the home." This occurred naturally and without explanation.

${ }^{17}$ Soliciting the permission of the Presidente Municipal (something similar to a county mayor) to engage in research within his town is not required but advised. While not mandatory in Guelavía, the effort of three trips to communicate with him in his office was worth the effort as it showed respect for his position and for his community. Two additional trips resulted in a signed letter of support and acceptance of my doing research in Guelavía. The permission letter was explained and shared with every woman surveyed as well as emphasizing that all data were confidential and would not be shared with anyone from Guelavía. Possibly in part due to my manner, in part due to the familiarity of my research assistant, but in part due to the signed permission, only one of seventy-two women chose not to participate in the survey.
} 
were verbal due to a high percentage of illiterate or semi-literate women in Guelavía as in most rural Oaxacan communities with women's self-report data offered verbally and hand-written by the research assistant. ${ }^{18}$

Discussions with several Oaxacans who grew up in small towns similar to Guelavía as well as Guelavíans informed many of my decisions with the survey process. It was strongly suggested that I use research assistants from Guelavía due to their familiarity with the town and with participants' familiarity with them. Also, small towns have a competitive factor among them; several Oaxacans thought that women from nearby communities would not be readily accepted. Young women from the city would be viewed as unrelatable and unable or unwilling to connect with the participants.

The informal discussions with various Oaxacans also informed my decision to choose to politely and gracefully exit the interview at the approximate halfway point. The decision was made for the more sensitive question pertaining to husbands' migration, remittances, and possible abandonment to be answered in the presence of other Mexicanas. Confidentiality was emphasized prior to these sensitive questions as it had been prior to the beginning of the survey. This strategy proved successful in that the assistants appeared to encounter no resistance or disapproval during the more sensitive questions.

\footnotetext{
${ }^{18}$ Since all questions and responses were verbal, an important aspect of the survey was the confidentiality of the exchange between the research assistant, the respondent, and me. If the husband or any male was near, one of my roles was to distract him with inquiries about surrounding plants, animals, the home, or whatever was available to pull him away from the side of his wife so as to gather all information in a confidential manner. This approach proved successful in that all surveys were conducted out of earshot of any male of the home.
} 
Determining what physical structure and plot configuration would be deemed a "home" was initially challenging. Many homes in Guelavía house extended families. One central, exterior gate, or portón (large garage-type door), is often the main entry to the compound-like setting with separate living arrangements that share outdoor space. The decision was made that each gate or portón would be counted as a "home."

My primary research assistant's knowledge of every nook, cranny, alley, and path that contained another family home-some of which would have gone unnoticed if not for a knowledgeable research assistant from the pueblo of Guelavía-proved invaluable. The Health Center displays a crude map of the town on the waiting room wall that was initially considered usable; but after speaking to the "cartographer," was deemed too rudimentary to be of value. Fortunately, on the second day of surveys Nohemí arrived with a large 3' x 3' map of every street, path, and alley in Guelavía. The map was comprehensive and precise and was used to plot and track all surveyed homes. Surveys were started in the center of town and extended in a systematic manner to cover every eighth home throughout Guelavía during a four week period starting in May 2010. Small, missing details or clarifications were finalized by the end of June, 2010.

During the initial week of research, the 807 homes mentioned in the Health Center data and the 710 homes from INEGI data were determined to be physical structures rather than physical, occupied structures. Likely, between 560 and 600 homes are occupied in Guelavía offering future research opportunities to 
understand the 10 to 15 percent "ghost" population that has either left Guelavía, moved to newly-constructed or alternative homes, or are in staged migrationfamilies living away without having fully abandoned their Guelavía homes. Likely all three of these occur but with entire families having abandoned their homes due to migration is the most likely. ${ }^{19}$ Although neither INEGI data nor Health Center data clarify if the count of homes includes physical structures, abandoned homes, or homes with occupants, the research for this project included only occupied homes. INEGI statistics show San Juan Guelavía with a population of 3,047; Health Center data show 2,430. The calculated population of Guelavía from this research project is 2,499 based on 71 surveys of every eighth home with 4.4 members as an average members living with each home. ${ }^{20}$ The 71 random surveys were completed in June, 2010, followed by two months of data transcription.

\section{Semi-structured Interviews}

The final question on the survey instrument asked if the participant would be willing and available for a follow-up interview. Ninety-seven percent, 69 of 71 women, replied that they would be willing to participate. In order to test the acceptance or tolerance of potential two- or three-person interviews, women were also asked their interview preference: 1) an individual interview; 2) a two- or three-

\footnotetext{
${ }^{19}$ The majority of emigration from Guelavía is to the United States, primarily Los Angeles (or the surrounding area), although there is also internal migration to Ensenada, Veracruz, and Tijuana, Mexico.

20 The INEGI II Conteo de Población y Vivienda 2005 (Census of Population and Housing) (http://www.inegi.org.mx/sistemas/mexicocifras/default.aspx?ent=20) shows an average of 3.8 members living in each "home." The 71 surveys for this research project revealed an average of 4.4 residents per home, thus calculating a population of 2,499.
} 
person interview with one or two women who they chose or of whom they approved; or 3) a "focus group." ${ }^{21}$ Individual interviews were slightly preferred with two- or three-person interviews slightly more favorable than focus groups. There was only slight variance among the three. Additionally, 13 women responded that any of the three would be acceptable.

The affirmation that two- or three-person interviews were acceptable presented the opportunity to complete both individual interviews and two-person interviews. Three individual interviews and three two-woman interviews were conducted.

A slight snowballing method was used in the open-ended interviews in order to gather a representative sample of women with absent husbands, returned husbands, and anchored husbands. ${ }^{22}$ Limiting interview participants to only surveyed women would have limited the pool and left out women who could potentially offer valuable information.

Interviews were conducted in January 2011, approximately eight months after survey data gathering was completed. Patience and perseverance is required in interviewing in a rural Oaxaca pueblo. Social research that involves "real people" brings with it challenges. One woman that I had chosen to interview from my survey respondents was unavailable due to her husband having fallen in a well the previous weekend at the end of a three-day wedding. Inebriated the last time anyone had

\footnotetext{
${ }^{21}$ As questions were carefully worded so as to convey the appropriate understanding, substitute wording replaced "focus group" for familiarity.

22 Three women were interviewed who had not been survey participants. Survey data were gathered on the three women as background information but was not included in the survey findings.
} 
seen him and missing for two days, her husband's body was discovered in the well which was, unfortunately, located next to the outdoor bathroom of the wedding party's home.

After selecting a group of women who met the criteria-equal numbers of women with absent husbands, returned husbands, and husbands in the home--the first day of interviewing arrived and proved challenging, but typical. Six women were scheduled-two individual and two, two-person interviews. One woman arrived 30 minutes early and was upset that I arrived only 15 minutes early. An early arrival was, in my experiences in Guelavía, very unusual. She had arrived early to convey that she had another commitment and would not be attending at all. The interview was reset for the following day. The participant never showed up the following day nor any day thereafter. Four of the remaining five women never arrived the first day even though a research assistant had visited their homes twice with reminders. Only one woman arrived for an interview on the first scheduled day $-1 \frac{1}{2}$ hours late. The first day of interviewing proved to be a typical interview day.

Three individual and three two-person interviews were conducted. The open-ended interviews began with a clear set of questions but with allowance for related topics as well as expansion on topics of greatest interest, passion, or opinion. All interviews were recorded as agreed upon by participants and transcribed. Recording interviews proved valuable by contributing much more than notes could 
offer-details, additional stories, interactions among participants, clarifications, phrases, and even emotion and inflection.

The mixed methods, multi-strategy approach offered the following: 1) quantitative data gathered through random surveys with qualitative data of the open-ended survey questions; and 2) qualitative interview data rich in women's conveyed opinions, preferences, and beliefs. These two primary data methods were complemented with the Health Center survey data. Participation in activities and events such as in-home children's immunization, concerts of Zapotec language rap, and English classes offered in the Casa de la Cultura (Cultural Center) also contributed to this research project. Delaying breakfast on days of a Guelavía excursion offered the opportunity to buy fruit, tortas, and fresh-squeezed juice while conversing with the women in the mercado (market). Not bringing water offered the opportunity to patronize a local, tiny community store just for the opportunity to chat, inquire, and learn more about Guelavía and women's lives. These experiences, and countless others, along with many hours spent simply watching, wandering, waiting, and walking around Guelavía worked in parallel and in coordination with the surveys and interviews.

\section{Confidentiality and Privacy}

According to the Portland State University (PSU) Human Subjects Research Review Committee's (HSSRC) guidelines and the approved research proposal for this study, privacy of all participants was respected and adhered to. Irrespective of 
literacy, a letter pre-approved by the HSSRC was verbally read to all women as well as additionally paraphrased with invitation for questions or concerns (see Appendix A). Mention was made of a Portland State University contact but with emphasis on a local contact with address and phone information for additional inquiry. All women, literate or not, were given a copy of the letter and encouraged to share it with a trusting person who could reread it to them if necessary.

A letter of approval by the Presidente Municipal for research in the town of San Juan Guelavía was also presented to women with emphasis on the confidentiality of responses not to be shared with any member of the local government (see Appendix A).

The concept of privacy holds different meaning in a rural Mexico context than in a typical town or city in a U.S. context. As an example, the tattered map in the waiting room of the Guelavía Health Center displays streets, paths, waterways, and houses of Guelavía. Brightly-colored pushpins are distributed throughout the map representing illnesses or diseases of each home's occupants. Although some streets, paths, and homes appear to be missing, the data is open and viewable to anyone entering the clinic. The data in this research project was more intently disguised by changing the names of all women and taking care to not divulge detail as to be able to uniquely identify a survey participant or interviewee. However, in a rural context, much is known about one another whether it be the neighbor across the dirt path or the woman on the other side of town whose husband just left for a supposed attempt to cross the U.S./Mexico border. Despite Guelavíans knowing much about 
the lives of their friends, neighbors, and even acquaintances, all expected standards of the PSU HSSRC were adhered to and embraced for this research project.

\section{The Setting}

Case study research requires a carefully chosen case, a "purposive and illustrative, not random or inclusive" case (Mason \& Beard, 2008). With the decision to research the depth of one as opposed to the breadth of several, the selection of which purposive community commenced in mid-2009. After five months, the community that met the criteria was the pueblo of San Juan Guelavía in Oaxaca, a community located 30 kilometers from the metropolitan city of Oaxaca. After a few more months, survey data gathering began.

San Juan Guelavía offered explicit, sought after characteristics: an average level of male migration; a high percentage of women who remain in the community; and, women who were willing to communicate and share their reality, their opinions, and their perceptions with an outsider. Additionally, adequate access to resources-geographically located near education and work opportunities—was important in that residents of the pueblo would, theoretically, have options and opportunities.

Guelavía proved to be an appropriate environment for additional reasons. Guelavía offers no outstanding characteristics or traits that would appear to make it unique. Initially, it seemed not to be an extremely poor community (as are numerous pueblos with high marginality, based on INEGI data); it appeared not to 
have an excessive migration flow; it has a myriad of work-related activities rather than just a few in one industry; and it is a farming community, like numerous rural Oaxacan communities.

\section{Initial San Juan Guelavía Visits}

Colectivo drivers-taxis that "collect" an optimal five passengers along a regulated route that each pay a set fee-offered personal stories and estimates of the extent of migration from their Guelavía community in my initial half-dozen visits. One driver commented, "every family has someone in the U.S. and almost all homes receive envios [remittances]," a common response to my inquires about emigration from Guelavía. Drivers routinely estimated that 70 to 80 percent of homes in Guelavía had migrants living in the United States; similar estimates were offered of homes that receive remittances. The general inquiry was not specific to homes with spouses that had emigrated—the focus of this research project—but, instead, was a generalized conversation around the prevalence of male migration in the community. Additionally, colectivo drivers consistently stated that some families completes (complete families) had emigrated but that the vast majority of emigrants were males who left wives and children behind in Guelavía.

Colectivo drivers' anecdotes, accompanied by similar informal conversations with Guelavíans in the mercado and the streets, offered one perspective of the migration picture in Guelavía. Yet, INEGI statistics offered a dramatically different picture. This dichotomy in anecdotal stories compared to INEGI data was 
instrumental in discerning the need for random sample surveys prior to launching the more exploratory phase of the research project. ${ }^{23}$

Guelavía is a pueblo located near an urban locale—a rural/urban setting. The state of Oaxaca has the highest percentage of persons living in rural populations in Mexico ("México Hoy," 2007). Guelavía is considered one of the thousands of "rural" locations in the state of Oaxaca; yet, the close proximity to the large metropolitan city of Oaxaca de Juarez (population 263,357) and the smaller, regional setting of Tlacolula de Matamoros ${ }^{24}$ (population 19,625) offer Guelavían residents the urban amenities of government services, employment, and education opportunities that are not accessible from more remote pueblos..$^{25}$

The rural/urban dichotomy was also clear in the initial visits to Guelavía in comments by residents of Guelavía. The Presidente Municipal stridently portrayed Guelavía as a progressive, gender-equal, open-minded community; ${ }^{26}$ yet numerous residents-including the director of the cultural center, a high school teacher, and vender in the mercado-spoke of Guelavía as being more conservative than surrounding pueblos. These three also, independently and in separate

\footnotetext{
${ }^{23}$ INEGI data shows that 18 percent of homes in San Juan Guelavía receive remittances; numerous informal conversations with colectivo drivers and Guelavía's consistency estimated between 80 and 90 percent.

${ }^{24}$ The official names, Oaxaca de Juarez and Tlacolula de Matamoros, are most often referred to as simply "Oaxaca" and "Tlacolula."

25 Population figures come from INEGI, http://www3.inegi.org.mx/sistemas/mexicocifras/default.aspx.

${ }^{26}$ These were primarily indications made by the Presidente Municipal (Municipal President--similar to a mayor or the head of a county in the United States) in early 2010. He communicated various examples of how Guelavía was different and more progressive than nearby communities. His pride at expounding on how many women had run for local political office (which I later found to be untrue) seemed to be stories that he wanted me to hear and views he'd like me to espouse of Guelavía rather than the reality of the pueblo of which he was the head.
} 
conversations, spoke of Guelavía as a town that, in general, did not value education. Additionally, all three mentioned that many Guelavían families prefer to "marry their daughters off" at a young age so as to keep them in the community and eliminate the possibility of corruption from the negative influences of the city. These wide-ranging and dichotomous anecdotal portrayals of Guelavía contributed to the need for an initial random survey of Guelavían homes prior to interviews.

Guelavía is a pueblo with a variety of educational and work-related activities. It is often identified as a basket making community (Cohen \& Browning, 2007). ${ }^{27}$ The designation remains but the reality is something different. The wild, native reed used in basket making that grows near waterways around the exterior of Guelavían has become more difficult to acquire with many Guelavíans attributing the diminution to decreased rainfall. But the bigger threat to Guelavían basket making has been mass-produced, Chinese-made plastic woven baskets that sell for less than locally-made baskets. Inexpensive Chinese imports have nearly driven basket making out of existence in Guelavía.

The current reality is that Guelavía is a "farming community." Women's role in farming was unclear in initial visits to Guelavía. Commentaries of women being domestics (women who cleaned, possibly cooked, in homes in the city) as the primary work of women was common. Yet, another routine comment was that

\footnotetext{
${ }^{27}$ Exercises in private Spanish-school workbooks also mention San Juan Guelavía as a basket making or basket weaving community.
} 
Guelavían women did not work outside of the home and, moreover, chose not to work. ${ }^{28}$

In addition to work opportunities, this project required a community with access to and interest in education. Guelavía has a pre-school, a primary school, a middle school, and a high school, all part of the state and federal public school system. A government-funded high school in a small town the size of Guelavía is unusual.

\section{San Juan Guelavía as a Community}

Upon entering the pueblo, San Juan Guelavía does not appear particularly noteworthy. Two miles off a two-lane highway, Guelavía sits among open acreage and semi-arable land, most covered in weeds, sagebrush, and an array of plastic bottles, bags, and other trash. A few comedores (open-air, simple, roadside restaurants), several solid and well-constructed homes, and the elementary school line the narrow, paved road entering Guelavía. Typical large billboards advertising or promoting the most recent government program dot the landscape. The two-mile road that leads to Guelavía from the highway that joins Oaxaca to Tlacolula is paved with ever-present potholes and a few oddly-placed topes (speed bumps). Guelavía has the appearance of a rather tidy, orderly, traditional pueblo.

\footnotetext{
${ }^{28}$ Some of these comments came from a former migrant who had lived in the U.S. and had returned to Guelavía. He opened a Chinese restaurant ("restaurant" in the loosest sense since it was an outdoor area with one wall of hay bales, another a half-wall of cement, with a makeshift, outdoor kitchen) and planted fields of flowers to market in local communities. During several conversations he mentioned that he had sought help with cultivation and the process of marketing but that women chose not to work. Is his summation accurate or is his level of pay too minimal for women to consider his work viable and worthy of their time?
} 
Located 30 kilometers southeast of the city of Oaxaca, public transportation is the method of transport of the majority of Guelavíans. The route takes 45 to 60 minutes dependent upon the redirecting of traffic for the perpetual protests throughout the city of Oaxaca. Public busses arrive and depart from Guelavía approximately every two hours. Colectivos, twice as fast as public busses, pass through Guelavía more frequently but at three times the expense.

The majority of homes in Guelavía are fairly well constructed and well appointed when compared to more remote rural Oaxacan communities. Large differences exist between the grand, affluent homes (by pueblo standards) and the homes in greatest need of improvement and repair-generally constructed and pieced together with various scraps of cardboard, metal laminate, and random pieces of plywood. The vast majority of Guelavían homes fall into the middle range of construction quality, size, and space allotment.

Based on annual Health Center survey data, nearly all Guelavíans, 99 percent, own their own homes. Eighty-eight percent of homes are concrete constructed, ${ }^{29} 93$ percent include a dedicated, somewhat separate kitchen, ${ }^{30}$ with 94 percent are appointed with two or more rooms. Ninety-nine percent of homes are equipped with electricity; 99 percent include drainage. Contemporary devices are standard in nearly every Guelavían home—99 percent have a radio, 98 percent include a

\footnotetext{
${ }^{29}$ As opposed to adobe (clay), embarro (clay), lamina (laminate), abesto (asbestos), carton (cardboard), or mal estado (bad state or poor condition).

${ }^{30}$ As opposed to cooking over fire usually located on the ground within the home or just outside the home's perimeter.
} 
television, 75 percent have a landline telephone, ${ }^{31}$ and 95 percent include a refrigerator. ${ }^{32}$

The town includes a center square bordered by local government buildingssimilar to nearly all Mexican towns. The Palacio Municipal (municipal building) houses the town's administrative offices, a one-room, barred jail viewable by anyone passing by, a small and uninviting community library, restrooms without running water or toilet paper, and a small array of vacant rooms reserved for various municipio (municipal or county), state, or federal programs. Next to the two centrally-located government buildings is the local mercado which offers an array of puestos (stands) owned and/or operated by locals that sell vegetables, fruit, tortillas, plants, meat, prepared food, and a small array of knickknacks and gift items—nearly all imported from the city. The mercado, open seven days a week, is the primary gathering place for women shopping for their families as Guelavían grocery stores are no larger than one room with only basic staples and convenience food.

Modern conveniences are fairly easily accessed in Guelavía—copy machines, telephone cards, mototaxis (small, electric taxis that carry residents only within the Guelavía boundaries), a hardware store, and one small Internet shop that is closed far more than it is open. A few of the streets in the center of town are concrete but the majority are dirt. Both paving surfaces offer an abundance of gaping potholes.

\footnotetext{
31 TelMex, the monopoly landline telephone service corporation, is quick to turn service off for nonpayment. This statistic is likely derived from a question asking if the home physically has a telephone; the percentage of landlines that are active with service is likely considerably lower. 32 Unless otherwise noted, all data in this section are from the December 2009 Health Center's Population Census.
} 
Guelavía offers little that is out of the ordinary and much that is typical of traditional Oaxaca.

\section{A Profile of Guelavíans}

San Juan Guelavía is an indigenous Zapotec community. A key local informant strongly suggested that the questions regarding indigenous identity be removed from the survey. Abruptly and unmistakably the woman explained that Guelavía is an indigenous community and the two questions were unnecessary--"somos Zapotecos" (we are Zapotec). After further inquiry, the two questions were deleted..$^{33}$

According to Health Center data, 66 percent of Guelavíans speak both Spanish and Zapotec, 30 percent speak only Spanish, and just 4 percent of residents speak only Zapotec. The few residents who speak only Zapotec are the oldest residents; many younger residents speak only Spanish. The few residents that have moved into Guelavía from other parts of Mexico also do not speak Zapotec. Although many younger children and teens do not speak this indigenous language, it is just as commonly heard in the streets as is Spanish and likely the prominence and commonality of Zapotec in community life is understated in the data. Many young people, such as my research assistants, understand far more Zapotec than they can speak. In front of anyone other than family, many teens and young people claim they do not know any Zapotec. Pride in the language is being restored in a few Oaxacan

${ }^{33}$ For discussion of what it means to be "indigenous" and the challenges of identifying who is indigenous, see Trine Lunde's (2009) dissertation, "Escaping Poverty: Perceptions from Twelve Indigenous Communities in Southern Mexico." 
communities; Guelavía is not one of them. School instruction is in Spanish; curriculum is completely devoid of Zapotec.

The vast majority of Guelavían adults are married. Marriage takes two forms in Mexico, legal and religious, but the Health Center data do not distinguish between the two. Mexicans can be married por iglesia (through the church), por ley (through the law-legally), or both. While the difference is important in the legal sense, many Mexicans consider it inconsequential, especially if their marriage took place in the church—most often in the Catholic church—and, therefore, perceived as "married" in the eyes of God (as explained by countless Mexicans). INEGI registered just two marriages in Guelavía in 2008 and zero divorces ("Matrimonios y Divorcios," 2008) extremely low numbers for a town of approximately 2,400 residents. These low numbers are likely due to the lack of formal registration of marital status with the state government. Additionally, the Health Center survey combines married and living together into one category, "casados o unidos" (married or united [living together]), with the only remaining category as solteros (single). Survey results showed that 94 percent of Guelavíans age 20 and over are married or living together; neither divorced nor widowed were available as responses to the marital status question. Likely this high figure included widows and widowers and women with husbands who had left for the United States and never returned.

Guelavíans' livelihood no longer comes primarily from arts and crafts as it did in the past (Cohen \& Browning, 2007; Zafra \& López-Rocha, January-April, 2009). Guelavíans devoted to basket weaving were categorized as part of the artisan 
community. The Health Center data show that only 6 percent of Guelavíans claim artesano (artist or craftsperson) as their occupation. Even though Guelavía was known for handmade straw baskets—-mostly utilitarian rather than artistic-a few of the minute 6 percent are engaged in the production of red pottery, rug weavings, and alebrijes, ${ }^{34}$ in addition to basketweaving.

In the Health Center data, every household was asked of all members' "occupation," even children. By not inquiring only of adults, the data are skewed but still offer insight to the general work life of Guelavíans. In addition to the 11 percent who were "students," a surprising percentage, 54 percent, chose ninguna (none) as their occupation. Assuming that includes children and young adults that are not students and may also not be working, the high percentage also includes amas de casa (homemakers) as well as men that were not working at the time of the survey. Oddly, to this researcher, maintaining the family's home is not an occupation, yet estudiante (student) is. The Health Center survey form is supplied and mandated by the Mexican federal government and shows a typical, supposed emphasis on education with little respect or acknowledgement of the essential, challenging, and burdensome role of wife and mother as a homemaker.

Setting aside from the two-thirds of residents who responded that they do "nothing," according to the Health Center data, as well as students, the remaining 35 percent responded to their "occupation" as the following:

${ }^{34}$ Alebrijes are brightly painted, ornamental, whimsical figurines. 
Table 1: Health Center Occupation Data

\begin{tabular}{l|c}
\hline Occupation & $\begin{array}{c}\text { Percentage of } \\
\text { Respondents who } \\
\text { Have an Occupation }\end{array}$ \\
\hline Agricultura (agriculture/farmer) & $44 \%$ \\
\hline Obreros (laborer in factory or workshop/employee) & $9 \%$ \\
\hline Comercio informal (informal commerce, merchants) & $9 \%$ \\
\hline Jornaleros (laborer) & $8 \%$ \\
\hline Conductores de vehículos (taxi/mototaxi/bus drivers) & $7 \%$ \\
\hline Artesano (artist/craftsperson) & $6 \%$ \\
\hline Empleo particular (private company employee) & $5 \%$ \\
\hline Profesionistas (professional) & $5 \%$ \\
\hline Comercio formal (formal commerce, merchants) & $5 \%$ \\
\hline Empleados federal (federal government employee) & $2 \%$ \\
\hline Total residents who claimed an “occupation” & $\mathbf{1 0 0} \%$ \\
\hline
\end{tabular}

Source: Guelavía Health Center survey, December 2009

Three features are striking in the Health Center occupational data: 1) the large percentage of residents who claim to have no occupation even considering that a portion of the 54 percent are children or teens; 2) the excessively small percentage of working Guelavíans that self-report as professionals, which are most often defined by graduation from prepa (high school) or some level of college or trade school; and 3) the low percentage of working residents, just 24 percent, at the most, that receive a regular paycheck from an employer. ${ }^{35}$ Likely, a significant portion of

35 This figure is calculated by summing obreros, $9 \%$, empleo particulares, $5 \%$, profesionistas, $5 \%$, and empleados federales, $5 \%$. These are the professions that most likely draw a consistent bi-monthly paycheck although several of these positions likely have irregular schedules and less than full-time employment. 
that 24 percent has only sporadic work that is neither reliable nor full-time throughout the year.

One likely probability derived from the Health Center occupational data is that few Guelavían women report having an "occupation." Agricultura (farmer), obreros (laborers), jornaleros (laborers), and conductors de vehículos are maledominated labor activities. It is likely that no women participate in the combined 68 percent of these reported occupations. In addition, artesanos (artists/craftspersons), profesionistas (professionals), and empleados federales (federal employees) are also male-dominated occupations, just not to the extent of those previously mentioned.

The Health Center data also show that Guelavíans rely heavily on the federal health care system, as do most rural Oaxacans as well as numerous urban Oaxacans. Just one resident of the 2,430 surveyed in the Health Center data has health care offered to government employees. Just 2 percent have IMSS health coverageinsurance offered by an employer to regular, longer-term and likely stable employees (indicating a job in the formal sector and more likely to receive a regular, bi-weekly paycheck). This suggests that the previously-stated maximum of 24 percent of working residents who may receive a regular paycheck is considerably lower. The vast majority of Guelavíans, 98 percent, have only basic, rudimentary care provided by the federal government health care system.

The government-funded Guelavía Health Center, located just a block from the municipal building in the center of town, employs a full-time, local nurse with a high 
school education and a medical intern finishing her last year of medical school. The Health Center sees a constant stream of Guelavíans with a wide variety of ailments and health-related needs. While there is some mention and discussion in the general media as well as government publicity that residents who are able to pay for various services are expected and required to pay, thus generating a small amount of revenue in each facility for the program, I never observed a single patron who paid for any service, medication, or treatment obtained at the center.

In terms of education and literacy, San Juan Guelavía is typical of rural Oaxaca with high illiteracy and low education completion rates:

Table 2: Education Completion Rates in Guelavía

\begin{tabular}{l|c}
\hline Education & $\begin{array}{c}\text { \% of } \\
\text { Residents }\end{array}$ \\
\hline Illiterate & $14 \%$ \\
\hline Attended elementary school without completion & $49 \%$ \\
\hline $\begin{array}{l}\text { Attended middle school (6 } \\
\text { without completion }\end{array}$ & $30 \%$ \\
\hline 9 years or less of education & th grade) \\
\hline
\end{tabular}

Source: Guelavía Health Center survey, December 2009

INEGI education statistical data for Guelavía correlate with the Health Center data. Health Center data do not offer average grade level completion as does INEGI but does show the high rate of illiteracy and low rate of education beyond Mexico's educación básica obligatoria (obligatory basic education) mandated by the Mexican

\footnotetext{
${ }^{36}$ This figure also correlates with the very low percentage of likely regular wage earners with steady incomes since higher education correlates with salaried positions (Pagán \& Sanchez, 2000).
} 
federal government--9 years of schooling. INEGI shows the average grade level completion of Guelavía students as 5.6 years-1.3 years, 19 percent, lower than the average for the state of Oaxaca and three full years, 35 percent, lower than the average for the country (Instituto Nacional de Estadísticas Geografía e Informática).

This Health Center data are offered to create context for the surveys and interviews conducted for this dissertation. Additionally, the Health Center data offer an opportunity for triangulation to compare and contrast data as well as integrate observations, experiences, participation, and the commonplace, casual encounters with Guelavíans.

\section{Conclusion}

Due to the inductive nature of this study, a multi-strategy, mixed-method approach presented as a case study was most appropriate and suited to the inquiry of this research. The process of triangulation is well suited for this case study approach. This research project uses a secondary data set—the December 2009 Health Center Population Census—and two primary data sets: 1) structured, random surveys of every eighth home; and 2) open-ended interview. Observation, casual and informal conversations, and participation in events and activities are used to understand the larger context of Guelavían women's actions and reactions to male migration. 


\section{Chapter 4: Guelavían Women and Male Migration}

\section{Introduction}

How do women act and react to male migration? This question is best differentiated by generation since women in their 20 s tend to respond differently to male migration than do women in their 60s. The survey instrument gathered demographic data that could easily be segmented by age. The quantitative data gathered through surveys were supplemented by qualitative responses. Questions about husband or partner's migration status, remittances (or lack thereof), savings, and women's belief of men's future emigration plans, for example, were followed with open-ended questions inquiring as to why women thought what they thought. The quantitative data allowed correlations by generation, husbands' migration status, and women's role in decision making, among other data, while the qualitative responses provided richness, depth, and complexity. As an example, asking women with absent husbands if they received remittances and the average amount was valuable. If, however, wives did not receive remittances from her U.S.-based husband, the qualitative responses as to why- "Why do you think you do not (or did not) receive remittances"-were critical in revealing women's suspicion of men having relationships in the United States that negated remittances. As another example, women whose husbands remained in the home were asked if they thought their family would be economically advantaged if their husbands emigrated. The quantitative data show that women did not think their family would be better off but it was the qualitative responses as to why they thought that that reveal that women 
choose, often, to dismiss the "economic" portion of the question and show that they prioritize family over economics. The strategy of using a survey that combined quantitative data responses with open-ended questions offered the sought-out rich data of women's realities for valued use in this research project.

From the survey data, an overall picture can be drawn using the sample data of the 71 random survey responses. The three individual and three two-person interviews supplemented the survey data by exploring the "why" rather than settling solely for the "what." Observation, participation, and numerous and routine casual, informal conversation also played a critical part in the findings of this research project.

Women have varied experiences, views, opinions, and actions and reactions to male migration based on generation. Younger women were most likely to have experienced male migration, had most often participated in the migration decision of their husband, and had most often influenced a husband into staying within Guelavía rather than considering the emigration path.

Although younger women tend to have a stronger partnership or a more dominant role in the marriage than do older women, unmistakably, the decision to leave Guelavía is made by the husband. Once absent, the choice to return from the U.S., when to return, and if to stay in Guelavía upon return are all fully the domain of the husband-leaving women as by-standers in decisions that intricately impact their own lives and the lives of their children. 
Men's primary obligation is as economic provider. The findings of this research show that one-third of men that emigrated failed to fulfill that role and left stay-behind wives to become "mujeres abandonadas" (abandoned women)."37 Although women not receiving remittances believe, for the most part, that lack of work for her husband is the reason for the omission of remittances, many women suspect that men have another relationship and/or are spending their income on themselves. This worry and fear of women whose husbands are absent is transferred to women whose husbands have never emigrated. Women whose husbands are in the home are impacted by women whose husbands have left them as mujeres abandonadas.

Women's strategies for keeping men at home are multi-faceted often including women generating income to "help" the family and emphasizing the notion of "sufficiency" in order to keep the family intact. Dividing off family land and constructing and owning their own home contributes to women's notion of "sufficiency":

"Aunque aquí gana poco, estamos juntos."

(Even though here he earns little, we are together.)

“... aunque tenemos poco dinero, aquí estamos bien."

(... even though we have little money, we are fine here.)

37 The term "mujeres abandonadas" (abandoned women) can most closely be aligned with "leftbehind women." Researchers tend to use "left-behind" women whereas Mexicanas, themselves, use "mujeres abandonadas." At this point forward in this research, mujeres abandonadas will be used as this most accurately describes Mexicanas view and perception of their own situation. 
If women are able to portray their vision of their lives as "sufficient" in terms of material goods and income, they are more able to convince men to remain within the home.

\section{The Women of Guelavía}

Based on the sample data gathered from random surveys of every eighth home in Guelavía, women who were surveyed live in households of an average of 3.8 members. This figure coincides closely with 2010 INEGI figures of $3.5\{$, , Censo de Población y Vivienda 2010\}. Based on survey data, 85 percent of women are casada (married) with 7 percent living in unión libre (free union—civil union or living together). The distinction between the two categories is unimportant to women. While "married" and "living together" are clearly-delineated categories to the typical U.S. citizen, the distinction in Mexico is blurred and ill-defined. It is common to be introduced to "mi esposa" (my wife) or "mi esposo" (my husband) only later to discover that he or she is not formally or officially married. However, living together is limited to younger women: 
Table 3: Civil Status of Women in Guelavía

\begin{tabular}{l|c|c|c|c|c|c|c|c}
\cline { 2 - 9 } & \multicolumn{6}{c|}{ Women's Age Category } & \multicolumn{2}{c}{} \\
\cline { 2 - 10 } & \multicolumn{2}{c|}{ Under age 35 } & \multicolumn{2}{c|}{ Age 35 to 50 } & \multicolumn{2}{c}{ Over age 50 } & $\begin{array}{c}\text { Total } \\
\#\end{array}$ & $\begin{array}{c}\text { Total } \\
\%\end{array}$ \\
\hline Married & $\begin{array}{c}17 \text { of } \\
22\end{array}$ & $\mathbf{7 7 \%}$ & $\begin{array}{c}29 \text { of } \\
30\end{array}$ & $\mathbf{9 7 \%}$ & $\begin{array}{c}14 \text { of } \\
19\end{array}$ & $\mathbf{7 4 \%}$ & $\mathbf{6 0}$ & $\mathbf{8 5 \%}$ \\
\hline Living together & 4 of 22 & $\mathbf{1 8 \%}$ & 1 of 30 & $\mathbf{3 \%}$ & -- & -- & $\mathbf{5}$ & $\mathbf{7 \%}$ \\
\hline Divorced & -- & -- & -- & -- & -- & -- & -- & -- \\
\hline Single & 1 of 22 & $\mathbf{5 \%}$ & -- & -- & -- & -- & $\mathbf{1}$ & $\mathbf{1 \%}$ \\
\hline Widowed & -- & -- & -- & -- & 5 of 19 & $\mathbf{2 6 \%}$ & $\mathbf{5}$ & $\mathbf{7 \%}$ \\
\hline
\end{tabular}

Source: Author's survey of 71 randomly-selected Guelavía households, May 2010

None of the women over age 50 lived in a "free union"; 18 percent of women under age 35 claimed to do so.

"Divorce," in its legal and social definition, is not an acceptable civil status for women in rural Oaxaca. Divorcio (divorce) was an option on the survey yet none of the 71 women claimed it as their marital status. In 2008, Mexico officially registered 14 divorces for every 100 marriages. Oaxaca registered the fewest divorces of the 31 states at just three divorces for every 100 marriages ("Matrimonios y Divorcios," 2008). Three likely scenarios contribute to Oaxaca's extremely low divorce rate. First, divorce is not fully culturally acceptable and even less acceptable in a rural setting than in an urban population (with Oaxaca ranking as the most rural of all states in the republic). Secondly, with a very low rate of official, governmentregistered marriages, there are fewer "official" marriages that can end in divorce. Third, the process of acquiring a divorce is not easily accessible to rural populations. The steps to obtain a divorce usually require the assistance of an attorney- 
professionals that only operate in urban settings. Additionally, the process of filling in paperwork and acquiring proper documentation is an impractical expectation for many un- and undereducated women, some illiterate, with little understanding of the official and formal process as well as the unmanageable expense.

It is important to recognize that women self-identified their marital status in the survey-gathering process. The 85 percent of women who identified as "casada" (married) were engaged in "marriage" at an average age of 20.8 years; husbands, 24.7 years. The average marriage in Guelavía has lasted nearly 20 years. In Guelavía the social stigma of being divorced weighs heavily on Mexican women, especially rural Oaxacan women who view their options for a new relationship if their current or dissolved relationship fails as non-existent. Even a few women who had long been abandoned by U.S.-bound husbands still consider themselves married. The reality that marital status may not accord with assumptions about behavior challenges researchers' propensity to neatly classify participants. While much migration research categorizes women as "stay behind" with the underlying assumption that the husband is remitting and supporting his family or that a husband who has returned is an active family member once again, as Stephen (2007) clarifies, the categories are not so easily defined nor do they necessarily remain static. 
In the survey data, very few women self-reported as soltera (single). MariElena, $^{38} 29$ years old and living in a small home with only her 73 year old mother, was the only woman of the 71 that specified her marital status as single. MariElena did not work for income, nor did her mother, and it was unclear as to how she and her mother supported themselves. Not surprisingly, similar to Howell's (1999) observation of the correlation between higher levels of education and delayed or absence of marriage, MariElena's nine years of formal education is nearly four years higher than the average for Guelavían woman.

Self-report marital status may not accurately describe women's lived experience, as illustrated by Sara and Elysa, two Guelavían women whose husbands had emigrated, left them behind, and never returned. "Mi esposo se fue por dinero y por otra mujer y ya no regresó" (my husband left for money [income] and another woman and did not return) declared 43 year old Sara. Sara called herself casada (married) but quickly added that she felt as if she were divorced. Sara chose not to answer the years of marriage nor contribute any demographic data about her "husband." She was just 17 when she married and had finished just three years of elementary school. She earned income for the home by selling tortillas within Guelavía. She, unlike the large majority of women in Guelavía, stated that she worked more than 50 hours per week, a stark contrast to MariElena, who also had no husband to support her. Sara chose to answer several of the questions as if her

${ }^{38}$ All names have been changed to protect the privacy and identity of the women of Guelavía. 
"husband" was living in the United States, though it appeared that they no longer had any type of relationship or communication.

Elysa, whose husband also emigrated to the United States and did not return, embodied a woman scorned, her bitterness and anger of her husband's long-ago betrayal still fresh. Fifty-four year old Elysa responded to the question of marital status as widowed, adding and clarifying:

“... porque mi esposo se fue. Ese animal me dejo sin dinero y sin nada. Ya tiene mucho tiempo que me dejo."

(... because my husband left. That animal left me without money and with nothing. It has been a lot of time since he left me.)

Elysa's husband had left for the United States 26 years prior with the intention of making their lives better, economically, by crossing the border and sending remittances as soon as he acquired work. From the day he left Guelavía, Elysa never heard from him again. Anticipating the follow up question, Elysa offered that she knew he was alive and that he was with another woman since other Guelavíans living in Los Angeles, the primary U.S. destination for Guelavíans, had seen him numerous times with another woman and had reported back to Elysa.

Additional challenges were to come for Elysa when her son and daughter-inlaw, who had two very young children at the time, chose to also leave Guelavía for Los Angeles. The couple left both children in Elysa's care. At the time of the interview, Elysa's grandsons were 10 and 12 years old and had been raised to believe that Elysa was their mother rather than their grandmother since their parents, Elysa's son and daughter-in-law, had only sparse conversations with Elysa 
and rarely sent money for their sons' support. Elysa was the one who chose to tell the boys that she was their mother rather than their grandmother to help allay their pain of betrayal and abandonment of their parents. While her son and daughter-inlaw had never communicated with their children since their departure, it seemed just as relevant to Elysa that they also had never sent remittances, a particularly acrimonious betrayal for Elysa. Her income for her two boys and herself came from maintaining a small, apparently minimally-profitable store in a front room of her home-identical to a few dozen of tienditas (small stores or shops) throughout Guelavía.

Elysa spoke several times of her own desire to leave for Los Angeles in order to seek a better life; she clarified that it would not be to find her absent husband. She confided, however, that she recognized that she was too old and too poor to seriously consider crossing the border. Although Elysa's situation was dire and the stress of raising the boys in poverty was notable, Elysa was determined to give her grandsons a better life. She was committed to keeping the boys in school as long as possible even though—or possibly because-Elysa had just four years of education. At 10 and 12 years old, the boys were in $3^{\text {rd }}$ and $6^{\text {th }}$ grades, respectively. Finishing $9^{\text {th }}$ grade, middle school, is mandatory in Mexico, but not universally adhered to. A few children with less than $9^{\text {th }}$ grade were not attending school in Guelavía. For Elysa's two boys to be in school with her clear expectation of their finishing middle school or higher was not a small feat. 
Every woman surveyed considered herself to be a housewife or homemaker, irrespective of marital status, work status, or work hours. Ama de casa (housewife/homemaker) does not appear to be consistently defined across Mexican urban and rural environments. In casual conversations with numerous Oaxacans in various urban and rural environments, I inquired as to Oaxacans' personal definition of "ama de casa." Responses ranged from "a woman who does not work and cares for the family" to "a woman with children who takes care of the house" to "any woman with a family." Using myself as an example—a single woman, living alone but with a grown daughter that few knew about, working full time through the Internet and volunteering outside of the home-I asked several Oaxacan friends if they would consider me to be an ama de casa. The responses tended toward "no" with rare exception. Yet, in Guelavía, even women who worked full time, who did not have children, who lived alone, and the one single woman all considered themselves amas de casa.

The important designation of "mother" and "wife" in Mexican culture coincides with taking care of the home. For a woman to self-report as the home caretaker whether she works outside of the home or not is culturally vital if she is a mother and/or a wife. This is a crucial, impactful, and clarifying label particularly for rural women. The distinction and priority that claiming oneself as-first and foremost—a homemaker limits women's opportunities in the work force, in education, and in envisioning opportunities to coordinate and sync the roles of wife 
and mother with the roles of work force participant and/or advanced-level student simultaneously.

\section{Households, Male Migration, and the Women of Guelavía}

Migration, especially male migration, is a fairly commonplace economic strategy for families in Guelavía. Every eighth inhabited home was surveyed about migration status of the husband or partner of the home. Despite the impression created by anecdotal stories and comments of colectivo drivers, health center personnel, and random women in the local mercado describing a very high rate of male migration, the majority of women surveyed, 54 percent, had spouses that had never left (anchored husbands) for the United State, as shown in the table 2, below:

Table 4: Husbands' Migration Status in Guelavía

\begin{tabular}{l|c|c}
\hline Husband's migration status & $\begin{array}{c}\text { \% of } \\
\text { Respondents }\end{array}$ & $\begin{array}{c}\text { \# of } \\
\text { Respondents }\end{array}$ \\
\hline Anchored husbands & $54 \%$ & 36 \\
\hline Returned husbands & $33 \%$ & 22 \\
\hline Absent husbands & $10 \%$ & 7 \\
\hline In other parts of Mexico & $3 \%$ & 2 \\
\hline & $\mathbf{1 0 0 \%}$ & $\mathbf{6 7}^{*}$ \\
\hline
\end{tabular}

Source: Author's survey of 71 randomly-selected Guelavía households, May 2010

* Four women were widowed, single, or did not report a husband's migration status.

Two women had husbands that were living in other parts of Mexico-not previously mentioned in anecdotes or experiences expressed by Guelavíans during casual conversations. Maria, age 47, answered the survey question of her husband's migration status as if he had migrated to the United States. He had not sent 
remittances due to his recent departure three months earlier. At age 52, Maria's husband was much older than the majority of husbands that emigrate, especially international migration rather than domestic migration ("Migración," 2010). Only 5.7 percent of emigrants from Mexico to the United States are age 50 and over ("Migración," 2010) Near the end of the interview, Maria suddenly realized and quickly conveyed, that her husband had not emigrated to the United States but instead that he was living in Ensenada, Baja, Mexico. Whether misunderstanding, misrepresentation, or simply not hearing the question correctly, this example, in combination with many women's lack of knowledge of husband's living situation, housemates, work environment, and even, on occasion, the town in which he resides conveys the impression that "absence" is perhaps just as critical of a factor in women's experience of male migration as is destination. In many women's experience, when husbands are absent from the home, they are simply absent. With absence a more significant factor than destination, husbands currently in the U.S. and husbands in other parts of Mexico were combined resulting in 9 percent of surveyed women with "absent" husbands. Thirty-three percent of surveyed women had "returned" husbands and 54 percent of surveyed women with "anchored" husbands—husbands who had never left Guelavía for international migration destinations. 
The differences by generation of male migration are notable as shown below:

Figure 2: Migration Status of Husbands of Women Surveyed by Generation

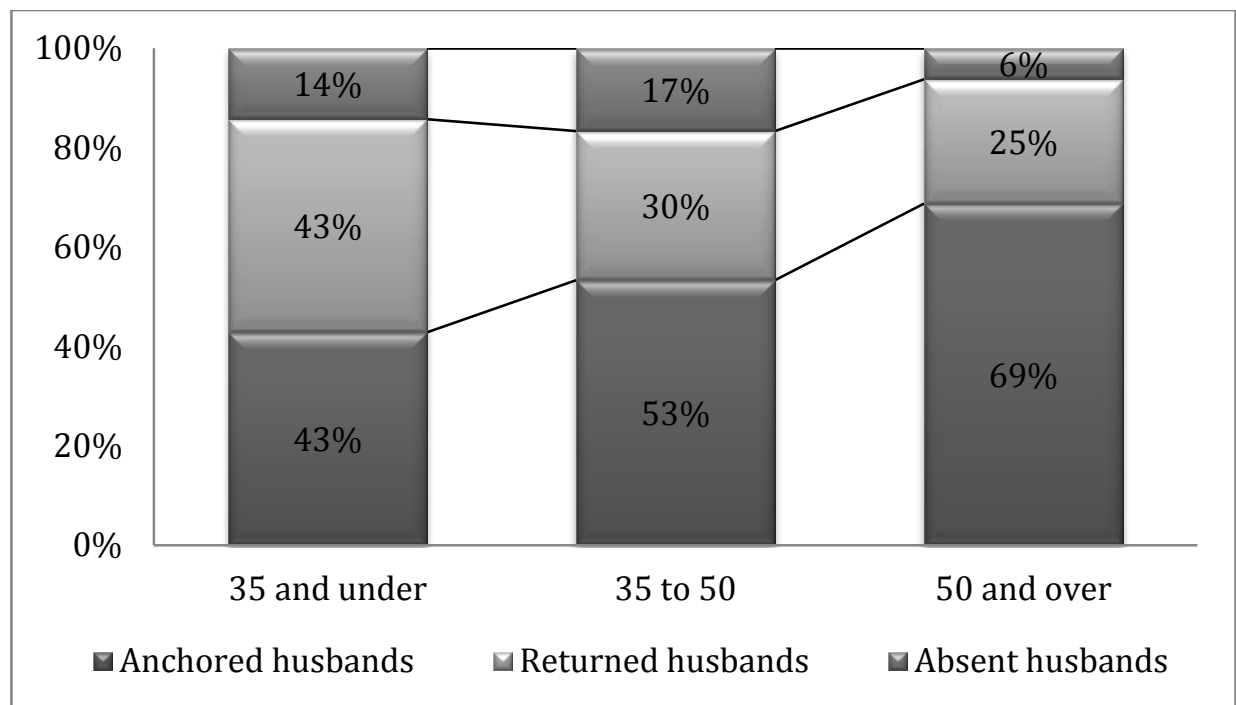

Source: Author's survey of 71 randomly-selected Guelavía households, May 2010

Women age 35 and under have had much more experience with migration of spouses than have older women. In combining returned husbands and absent husbands, 57 percent of surveyed women in the youngest age category are living with or have lived with male migration compared with 47 percent of women ages 35 to 50 and only 31 percent of women age 50 . This substantial difference in generation demonstrates the increased level of male migration from the state of Oaxaca during the 2000s (C. Hernandez, State Population Council, personal communication, February 20, 2008; Cohen, 2004; Lowell et al., 2008). ${ }^{39}$

\footnotetext{
${ }^{39}$ Survey results are derived from women's age, women's perspective, and women's responses. It is not assumed that men's age at emigration correlates with women's age or that both are in the same category; however, it is close. When piloting the survey, men's birthdate was asked. When the first two women were unable to answer the question and a third ran back into the house to ask her husband the date of his birth, I chose to delete the question. Men's average age at the time of marriage, however, was four years older, 24.7 years compared to women's 20.8 years. Therefore, it is
} 
The survey data imply that husbands are leaving Guelavía at a higher rate, even if a significant number of husbands have returned, voluntarily or involuntarily. Guelavía also includes a significant number of abandoned and vacant homes where it appears that entire families have left as well as empty homes in various stages of construction inferring that income is being used to construct homes that will be used as future residences for currently absent migrant families. The survey data suggest that women are still remaining behind and that male emigration appears to have grown throughout the 2000s even though some men do return. It is important to recognize, however, that some of the women with male migration experience were migrants themselves and both, or the entire family, returned to Guelavía.

\section{Decision Making and Migration}

Many migration scholars describe an assumption of a unified household migration strategy but fail to support that the presence of one. In Guelavía the migration decision appears to lie almost exclusively with the husband, especially for older women. In survey responses and interviews, women initially spoke of some level of equity in the decision process. It became clear in further conversation that migration decision making is not a collaborative process. Younger women appear to have a somewhat stronger voice in a more collaborative process than did their mother's generation, but not substantially.

safe to assume that men's age falls just minimally above women's. However, the position of the survey and this research is from women's experience and women's age at the time of emigration, not necessarily the age of their husbands. 
Survey and interview data imply that women are completely omitted, however, from decisions of length of stay as well as remigration. If men return to Guelavía, the choice to leave, once again, appears to be a decision exclusively that of the husband. Generational differences appear to make little difference as those decisions appear to lie solely with the husband, absent or returned.

Similar to Salgado de Snyder's (1993) findings, the survey data for this project disclosed that slightly more than half, 54 percent, of women perceived that the decision to emigrate was made solely by their husband. Forty-six percent of women responded that they "both" had participated in the decision. Two factors could not be controlled for in this survey data: 1) Some of the women with male migration experience had, themselves, emigrated and returned thus assuming they were part of the decision, and 2) In a few of the surveyed households, husbands had emigrated with his nuclear family or other family members prior to marriage and therefore, she was not part of the family nor a participant in the decision making process.

All of the 13 percent of women with absent husbands were married or in a relationship when their husband emigrated. Among women with absent husbands, age is significant in migration decision making: 
Table 5: Generational Difference in Male Migration Decision Making

\begin{tabular}{l|c|c|c}
\hline \multirow{2}{*}{$\begin{array}{l}\text { Participation in the } \\
\text { migration decision }\end{array}$} & \multicolumn{3}{|c}{ Women's Age } \\
\cline { 2 - 4 } & $\begin{array}{c}\text { Under age } \\
\mathbf{3 5}\end{array}$ & $\begin{array}{c}\text { Age 35 to } \\
\mathbf{5 0}\end{array}$ & $\begin{array}{c}\text { Over age } \\
\mathbf{5 0}\end{array}$ \\
\hline $\begin{array}{l}\text { Felt she had participated } \\
100 \%\end{array}$ & $50 \%$ & \\
\hline $\begin{array}{l}\text { Felt the decision was made by } \\
\text { the husband, alone }\end{array}$ & & $50 \%$ & $100 \%$ \\
\hline
\end{tabular}

Source: Author's survey, May 2010, of women with absent husbands

Veronica, a 46 year old Guelavían wife of 12 years who operates her own small food stand in Guelavía's mercado, communicated her extensive conversations as well as arguments about her husband's aspiration to cross the border for a more favorable work life in the United States. Although the discussions were extensive and often with both participation of both Veronica and her husband, the emigration decision was solely her husband's.

Veronica offered her strong, opinionated views of male migration in an openended, individual interview demonstrating much more emotion on this topic than on any of our previous informal conversations. In her individual interview, Veronica revealed that her husband had left to cross the border various times only to be apprehended by border control agents while fellow travelers escaped and succeeded in crossing over:

"La migración lo descubrió y paz para otros."

(Migration [border patrol] discovered him and peace for others [fellow travelers])--implying that her husband was picked up by border patrol while others that were with him were able to cross without problems (in peace). 
It was not just the concern of border crossing that invoked emotions for Veronica, but the process of arriving at a decision to leave. Veronica's language was lucid in describing the decision to emigrate-a decision made solely by her husband. Veronica spoke of always being adamantly opposed to her husband's departure yet he proceeded to leave Guelavía and cross the border multiple times. She referred to the necessity of emigration as economic, to support their son in his future educational needs. But immediately after speaking of his decision to leave as economic, Veronica voiced doubt as to his real motivation. She did not feel their economic situation warranted an extreme decision such as emigration with the result of breaking up the family. The first time Veronica's husband decided to leave, Veronica began working outside of the home. "Le apoyo trabajando," (I helped him by working). She believed that working outside of the home 50 hours per week or more would be sufficient to keep her husband anchored and at home in Guelavía. She conveyed her belief that her income generation would deter the need to emigrate and would eliminate the complete disintegration of the family (expressed by Veronica as "se desintegra completamente").

Veronica emphasized that she was never in agreement with her husband's decision to leave. She did not believe that a set, defined length of time-one year, two years, five years-would be adhered to due to the fact that there is no "dinero suficiente" (sufficient money) emphasizing that there really is no point that you have enough money and at which time he would decide to return. 
Veronica was skeptical of her own husband's motivation as being solely economic as well as skeptical that most Guelavían men left exclusively for economic reasons. This skepticism may contribute to women's lack of involvement in the decision of a husband to leave the home for the United States. Many women's language was elusive and indirect in discussing why men leave-always emphasizing the economic priority but often including accompanying messages, anecdotes, or examples that added elements that appeared to be rather unknown to women about men's decision to leave. Conversations with women in surveys, interviews, and informal conversations often alluded to concerns of other relationships in the United States, men's lack of family responsibility other than economic, and men's desire to be burdened with no one other than himself. Women routinely started these conversations with discussing men's supposed economic provider role and family obligation but quickly supplemented these culturallycorrect statements with their own theories, worries, and suspicions. Women's responses coincided with Ahern et al's (1985) discussion that when interviewing husbands, they tended to justify their trips to the United States with generalized statements of family obligation. The culturally-correct role that men play and women acknowledge and support is quietly yet simultaneously accompanied by women's suspicions and skepticism of men's motivations for leaving. Men may not elicit nor respect women's participation in their decision to emigrate if there are unspoken motivations in addition to the constantly-stated economic priority. 
Veronica's explanation of her husband's economic motivation for attempting to cross over the border into the United States and her language of her own lack of participation in the decision paralleled the discussion of Sulema and Lulu, two acquaintances that were interviewed together but separately from Veronica. The two women's language about their husbands' emigration decision paralleled Veronica's language. The three women of similar age-Veronica, 46; Sulema, 50; and Lulu, 50-all spoke of the emigration decision as being solely of their husbands'.

Sulema and her boyfriend were in their early 20 s when the two left together for the United States in the late 1980s. Sulema gave birth to two children while in the U.S. and the family returned to Guelavía a few months after the birth of her second child. Less than a year later, her husband left Guelavía for the United States once again, with Sulema remaining behind with their children. "El dice [que] 'me voy a ir allí, a lo mejor podemos progresar un poquito'” (he says 'I am going to go there [to the U.S.]. Maybe we can progress a little.'). Rather than directly answering the question of who made the decision about his emigration, Sulema spoke that "he said" he would go. In 1990, "se habia ido ir al norte y me dejo acá" (he had gone north and left me here [in Guelavía]). When asked about her usage of "me dejo acá" (he left me here), she clarified or changed it—questionable which was her intentto "me quedé aquí" (I stayed here). The change in grammar suggests, as well, a blurring of the line between women who stay behind and women who are left behind. After this change in grammar-and possibly of intent--Sulema quickly added that she had initially wanted to return to the United States with her husband. 
Her husband made the decision that he would go alone. He promised her that he would be away for just one year. Sulema's husband returned one year later and has remained in Guelavía since 1991.

Lulu, age 50, used similar language, expressed similar views and opinions, and tended to corroborate and validate much of Sulema's story while communicating her own. Lulu and her young husband, ages 17 and 18, respectively, lived with her mother-in-law. It is common in Guelavía, as in pueblos throughout Mexico, that when children marry, the groom's parents go to the authorities of the pueblo and request a small plot of land on which the couple can build their home or provide a portion of their own land on which the couple can build a home. They often share a common area with one or the other's parents putting the newlyweds' home a short stone's throw from the parents of the bride or of the groom.

In Guelavía, it is tradition that a husband's parents divide their land or go to the municipal authorities and request a piece of land for the newlyweds. In the case of Lulu and her husband, this did not happen. In the interview, Lulu communicated her mother-in-law's message shortly after they married: "Nos dijo que ya no nos iba a dar esa casa y nos quedamos sin casa" (told us that she was not going to give us a house and we remained without a home). Lulu's husband decided to go the United States to earn money for them to build or buy a home. Her husband emigrated and returned as many as five or six times, building a home during his stays in Guelavía and having it built while he was away. The couple and their teenage and young 20s children still reside in the home the couple built. 
Holding to tradition, Lulu's daughter and son-in-law received a small plot of land from the son-in-law's parents. The intent is to retain the couple in Guelavía by their building their own home in the community, thus tying them financially, psychologically, and supportively to the community. Lulu, as well as her daughter, contribute the younger couple's stability and continued commitment to Guelavíarather than emigrating to the United States-to the acquisition of the small piece of land. Even though the land was gifted by the daughter's in-laws, Lulu was integral in the young couple's securing the land. Lulu's motive, in part, was to keep the couple, including the husband, in Guelavía. Lulu did not want her daughter to have to endure the stresses and challenges of male migration that she endured.

In general, women in the youngest age category, 35 and under, have different experiences with the migration decision. While the decision to emigrate fell to the husbands of middle-aged Veronica, Sulema, and Lulu, younger women participate more often in the decision, yet remaining fairly minimal.

Alejandra, a 27 year old stay-at-home mother of two boys, spoke of the migration decision of her husband having been made by both; however, her language and further discussion in an individual interview suggested that the decision was, in fact, made by her husband. Alejandra conveyed that she and her husband had no other option than for her husband to leave for the United States due to their dire economic situation, while also suggesting that the couple had considered no other options and viewed emigration as the only option. 
Married while in their late teens, Alejandra and her husband were "más como hijos de la familia," (more like children of the family) than a grown-up, mature, married couple. Neither had remunerated work when the opportunity arose for her husband to go to the United States, offered by her husband's cousins who had crossed the border years prior. While Alejandra was in support of his departure due to their ominous economic situation, she was also against the decision due to the fracturing of their relationship, at least physically_-"no quieres separarte de tu esposo" (you don't want to separate yourself from your spouse).

Not all women, even of similar age in a similar locale, have a similar history or recount analogous stories (Stephen, 2007). Simona, 48 years of age, spoke not only of being included in the decision for her husband to emigrate but also of involving the children, at least by asking their opinions. "Aquí ya no había trabajo" (here there was no work) and that "les pedimos su opinión a los niños" (we asked our children their opinion). She stressed that the decision for her husband to emigrate was a family decision.

Simona's husband had a 10-year history of emigration to the United States prior to their meeting and their marriage at age 27 for Simona and 28 for her husband. Shortly after their wedding, Simona's husband emigrated once again in 2000 and, as of 2010, had not returned to Guelavía. According to Simona, the two spoke daily over the phone. After 10 years in the United States, her husband continues to send money, primarily for the education of the children-"manda 
poquito, lo suficiente para que los niños vayan a la escuela" (he send a little, enough for the children to go to school).

Although the decision to emigrate was made by the two of them, with the children consulted and the decision affirmed, the decision to return appeared to be held solely by Simona's husband. At the time of the interview, her husband's plans to return to Guelavía had very recently changed. He had plans to return at the end of 2011 but her husband had recently "nos pidió tener paciencia" (asked them to have patience) while he continued working in the United States. His reasoning, as communicated by Simona, was the family's continued need for income due to their daughter entering university and the lack of work for him in Guelavía. During the conversation Simona offered that she wanted him here, in Guelavía. Her responses, her body language, her emotions, and her interactions with Lulu during their twoperson interview, clearly portrayed that she had reluctantly acquiesced to her husband's decision to delay his return but that she was not necessarily in agreement.

\section{Absent Men-From a Woman's Perspective}

Why do husband's leave? Of 28 women that responded to why their husbands had emigrated, 27 women responded that is was for trabajo/dinero (work/money). Just one woman, age 68, commented that in 1985 her husband "fue a conocer" (went to get to know [visit] the United States). Although they were married at the time, her husband went to the United States with his family and 
stayed for only six months. He did work, however, and the small amount that she received in remittances was used toward the construction of their home. This woman was one of the only women who reported that remittances and/or savings were used for something other than everyday sustenance.

\section{Remittances (or Not)}

According to the women of Guelavía, nearly all men-96 percent-left Guelavía for work and to earn money because "no hay nada aquí" (there is nothing here), "no hay trabajo" (there is no work), or "no habia trabajo" (there hadn't been any work) - all routinely heard throughout Guelavía as in the majority of pueblos in Oaxaca. Yet 33 percent of absent husbands do not currently or never have sent remittances. One woman made it a point to stress that her husband had been "muy responsable con sus hijas y conmigo" (very responsible with his daughters and herself)—seemingly an important aspect to emphasize as it was a marked contrast with some other women's experiences.

Women whose absent husbands send remittances had sometimes waited several months after the spouse's departure before receiving remittances for the first time as shown in the figure below: 
Figure 3: Length of Time Women Waited for Remittances

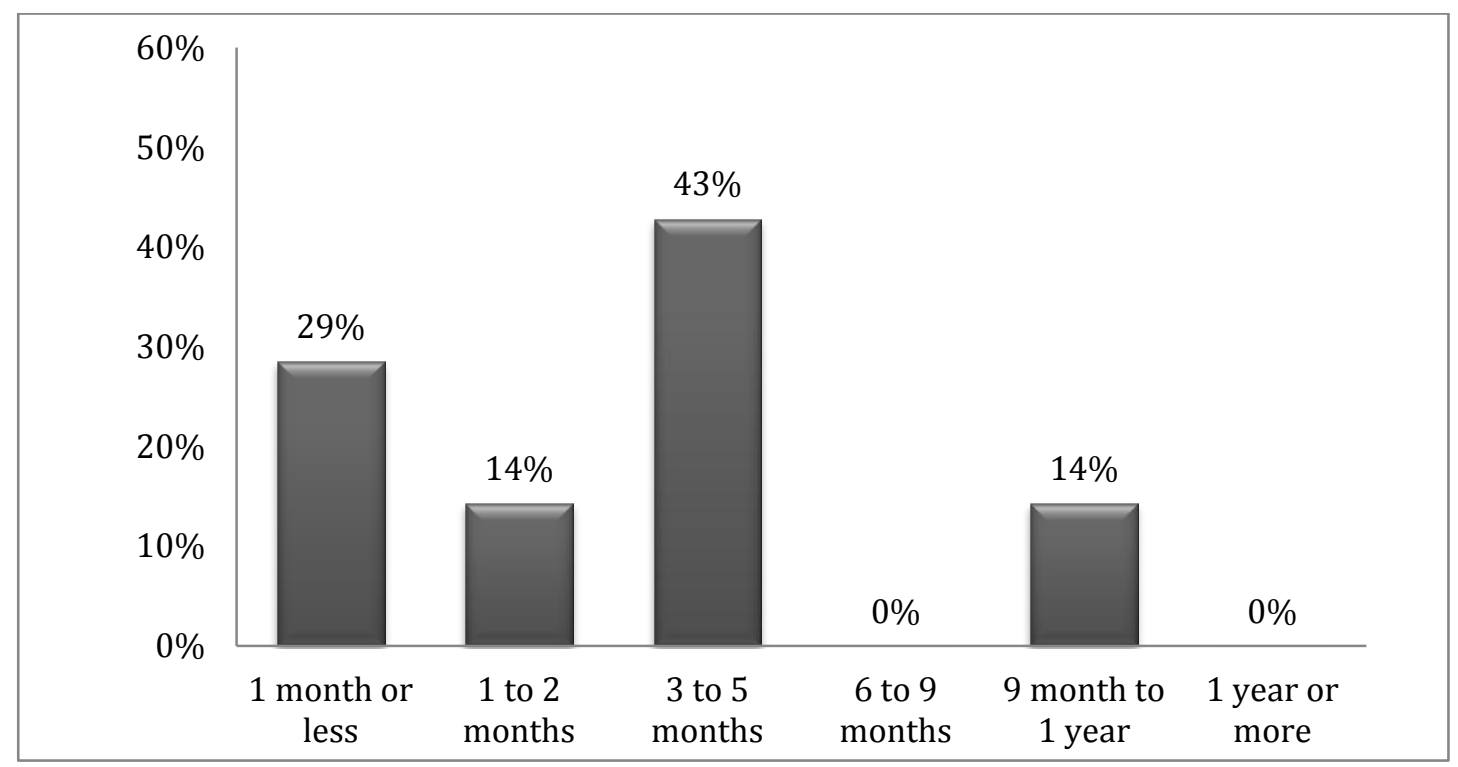

Source: Author's survey, May 2010, of women with absent husbands

Of absent husbands that have been away from Guelavía for more than one year, 33 percent, continued to send approximately the same remittance amount while 67 percent sent less than the previous year. Of the husbands that were away in 2008 and 2009, a full 84 percent sent less in remittances in the latter year, likely related to the economic crisis in the United States that began in 2008 and eliminated many jobs in construction, a primary area of Mexican migrant jobs. However, women appear to be ignorant of men's lives while away, including their income and how they may spend their money. In surveys, interviews, as well as casual conversations, women expressed a nearly complete dearth of information about where exactly their spouses lived, with whom, what exact type of job he held, how much he earned and how much and on what he spent what portion of the income, and even in some cases, in what city he resided. The diminished economic situation in the United 
States that spread to Mexico may only partially explain the lessened remittance amounts that women received since women have almost no knowledge of men's lives while away.

Although 96 percent of husbands left Guelavía for higher income opportunities in the United States, average remittance amounts were low based on financial needs of a typical Guelavían family. As shown in Figure 4, the largest group, 57 percent, received between $\$ 100$ and $\$ 250$ monthly over the previous six months:

Figure 4: Average \$US Monthly Remittances of Women with Absent Husbands

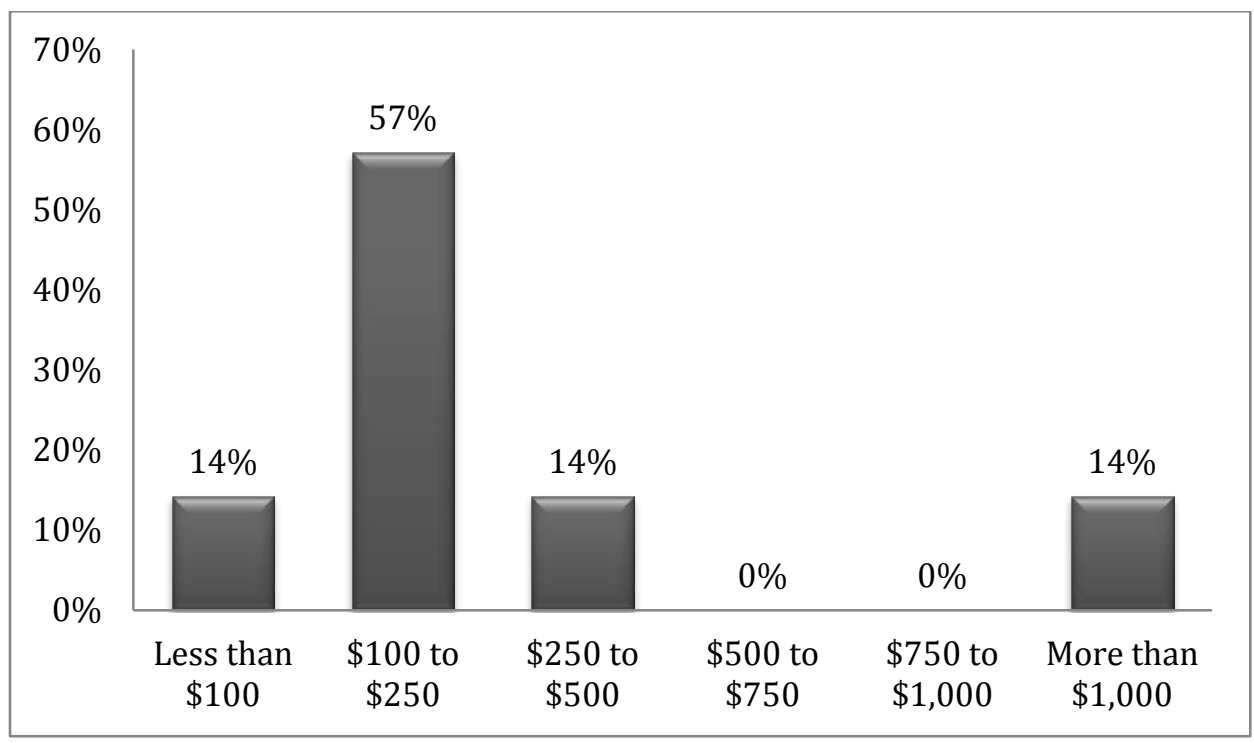

Source: Author's survey, May 2010, of women with absent husbands

With husbands absent from the home, women potentially have a major voice in how remittances are used, yet, even absence does not diminish husband's influence. Eight-six percent of women replied that both she and her husband together made the decisions of how remittances were to be used with only 14 percent responding that she alone made the decisions. This difference may be 
attributable to more accessible and economically-feasible communication methods in 2010 than in any year prior. The prevalence of cell phones in both the United States and Mexico as well as cell phone company plans that include the entire United States and all of Mexico now allow easier transnational communication whereas in the past the cost was prohibitive for most Guelavíans. The Internet also offers ease of real-time communication yet very few women in Guelavía are computer literate or have computers in their homes and Internet availability is also unlikely for Guelavían absent husbands. ${ }^{40}$ INEGI 2010 shows that only 43 of Guelavía’s 869 homes, just 5 percent, include computers and none of those have Internet connectivity ("Censo de Población y Vivienda," 2010)

For women who received remittances, comprar comida (to purchase food) was the primary use of money arriving from the U.S.; education for the children was cited as a secondary priority. Remodeling a home, constructing a home, buying animals, and paying debts were third-level priorities. None of the women surveyed mentioned that remittances were used to start, enhance, or expand a business. However, if husbands return with a quantity of savings, the perceived usage shifted slightly from a priority of daily food for meals and education expenses-although still mentioned often and a continued priority—to enhanced emphasis on larger

\footnotetext{
${ }^{40}$ San Juan Guelavía has one Internet café that offers computers to the public for approximately 10 pesos per hour, a fairly reasonable rate. In numerous trips to Guelavía and many, many hours spent in the town, I encountered the store open only three or four times. In all of the casual conversations that I had in Guelavía, I never encountered a women, teenager, or young wife with a computer and Internet in her home. While the Internet offers ease of retaining at least an audio and possibly video relationship with an absent family member, the Internet still appears to not have bridged the digital divide between the middle to upper socioeconomic, educated, professional levels and those who remain in poverty with lesser education.
} 
expenses-home construction and improvement, purchasing tools, and starting a business. Women identify the decision of spending savings that her husband returns with as a responsibility of both.

A third of the surveyed Guelavían women were partners to men that had lived in the United States and had returned. Of those, 68 percent, were married to their current spouses at the time of their departure-the remainder having lived with their families of origin. For this 68 percent of women with returned husbands, decision making and usage was similar to women with absent husbands as shown in Table 6 below:

Table 6: Remittance Decision Making

\begin{tabular}{l|c|c}
\hline Remittance decision making & $\begin{array}{c}\text { Absent } \\
\text { Husbands }\end{array}$ & $\begin{array}{c}\text { Returned } \\
\text { Husbands }\end{array}$ \\
\hline Husband made the decision & $0 \%$ & $6 \%$ \\
\hline She made the decision & $14 \%$ & $19 \%$ \\
\hline Both made the decision & $86 \%$ & $75 \%$ \\
\hline & $\mathbf{1 0 0 \%}$ & $\mathbf{1 0 0 \%}$ \\
\hline
\end{tabular}

Source: Author's survey, May 2010, of women with absent husbands and returned husbands who were partners at the time of departure

Women with absent husbands perceived the reason as to why they were not receiving remittances was their husband's lack of work two though one woman thought her husband did not send money because of another relationship that he currently has. Of women with returned husbands, a high percentage of women suspected or knew that their spouse chose not to send remittances due to another woman and/or relationship while away. In combining women with absent husbands 
and returned husbands, a full two-thirds believe the lack of remittances was due to a lack of income as shown in Figure 5. The statistics of surveyed women also shows that 23 percent believe that the lack of remittances is due to a female relationshipanother woman-in the United States. ${ }^{41}$

Figure 5: Wives of Absent and Returned Husbands and Why They Believe that Husbands Do Not Remit

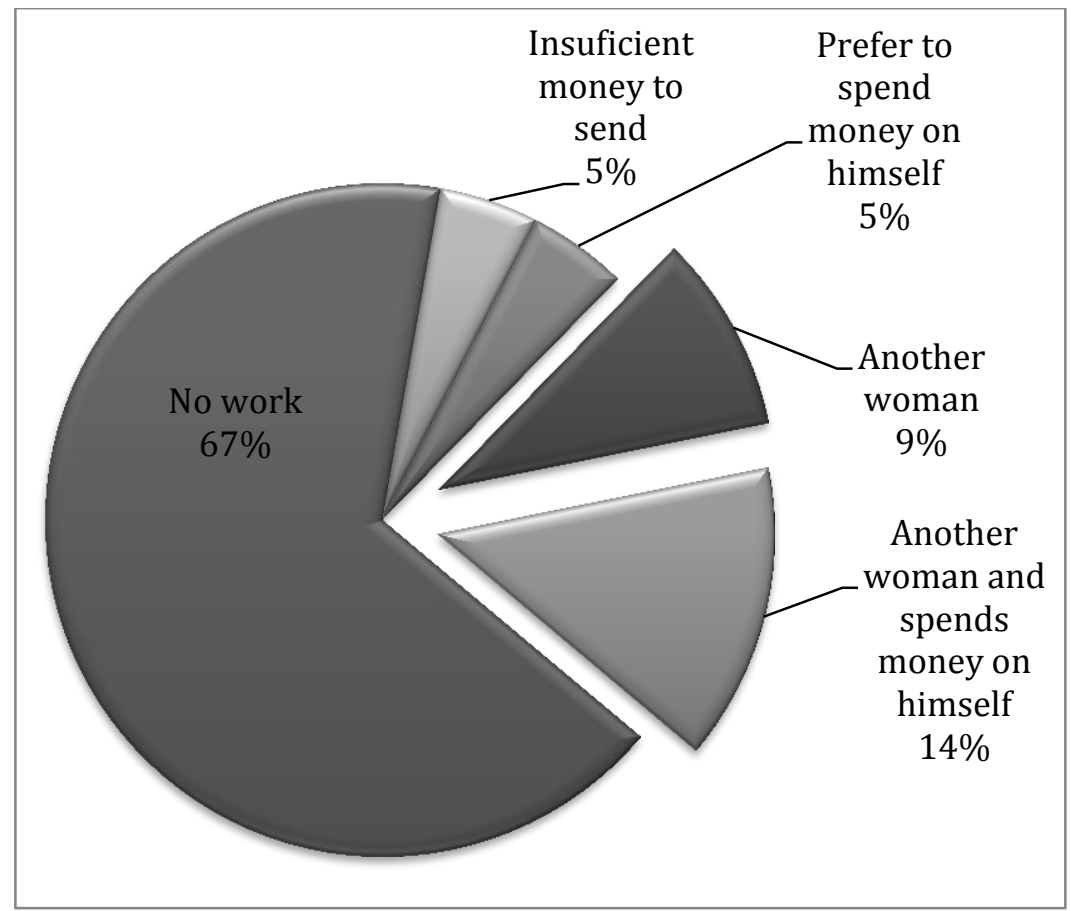

Source: Author's survey, May 2010, of women with absent and returned husbands

Simona's comment was typical of surveyed and interviewed women:

“... el dice que muchos con los que convive y con los que trabaja ahí ya tienen otra familia"

( ... he [her husband] says many [of the men] with whom he lives [in the U.S.] and with whom he works, have another family [there, in the U.S.]).

${ }^{41}$ Two responses about "another woman" to the question of why women thought that they do not or did not receive remittances were offered: 9 percent responded "Another women," and 14 percent responded "Another woman and spends money on himself." 
Simona went on to say that her husband often tells her that he continually thinks about her and their children. Simona's acknowledgement that men routinely have relationships when they are in the United States-with clarity and emphasis that her own personal situation is not one of such-was typical. This coincides with the woman previously mentioned who made a point in emphasizing that her husband had been very responsible with her and their children ("muy responsable con sus hijas y conmigo")—emphasis not needed if it was the norm.

Women's worries extended to comments that their daughters may find themselves in a similar role and situation. Twenty-three year old Mercedes, a young mother of three children under age 5 whose husband had spent his teenage years in the U.S. with his parents, commented:

“... ella se quedaría con responsabilidades y en EEUU hay mas mujeres"

(... she [her daughter] would remain [in Guelavía] with the responsibilities and in the U.S., there are more women).

\section{Returning with Savings (or Not)}

Seventy-five percent of surveyed women with returned husbands responded that she and her husband made joint decisions about remittance usage. A much larger percentage, 92 percent, stated that the two made joint decisions about savings with which her husband had returned. Every woman surveyed reported using both remittances and a portion of savings for daily sustenance-primarily food for the family. Savings, however, were used for larger and more substantial 
purchases than were monthly or sporadic remittances. Approximately half of women surveyed cited savings used for construction or remodel of a home. One woman, of fifteen women who had received savings from their returned husbands, stated that a portion was used to start or enhance a business. One couple bought "toros" (bulls) and one couple used husband's savings for the couple's wedding. Belem was married at age 16 , four years prior to the survey. In anticipation of their wedding, her then-boyfriend spent $1 \frac{1}{2}$ years in the United States earning and saving specifically for the expenses of their wedding in Guelavía. Guelavían weddings, as in most rural Oaxacan communities, are usually elaborate, expensive, and result in a nearly pueblo-size fiesta that lasts three days. Belem and her husband, currently ages 20 and 26 respectively, have two children, ages 3 and 1, and the family lives with her husband's father and sister. Although Belem spoke of her husband working in Tlacolula in construction with a schedule of 60 hours or more per week, Belem was the only woman who spoke of her husband having plans to emigrate, once again, to the United States.

Women with absent husbands thought that if their husbands come home with savings, the money would be used similarly as women with returned husbands—for the most part, larger, more substantial purchases and expenses. Construction of a home, un millar de ladrillos (a pallet of bricks-assumed to be used for home construction), business start-up, children's education, and pagar algunas deudas que tenemos (pay some debts that we have). While daily sustenance was cited as an important use for potential savings that would eventually arrive, 
savings also offer a sum of money that can be used for investments to enhance the quality, stability, and/or security of family's lives to a greater extent than traditional, routine remittances appear to do.

\section{Emigrating Once Again?}

Ninety-two percent women with returned husbands, 12 of 13, did not think that their husbands would leave again. One woman expected that her husband would emigrate soon and one other spoke of her husband vacillating between si (yes) and no. Belem, whose husband's savings had been used for their wedding, expected that her husband would cross the border again soon while she stayed behind with their two young children living in the home of her father- and sister-inlaw. Belem was not supportive of her husband's impending departure. Although Belem expressed that they had jointly decided for her husband to emigrate the first time as well as how to spend remittances and savings, it appeared that this future decision was being made by her husband rather than being a joint decision.

Lupe, age 40 , had received remittances in the short time that her husband was in the United States in 2000. While she was one of the women who spoke of her returned husband likely spending money on another woman and on himself rather than returning to Guelavía with savings, Lupe expressed wanting him to leave again for the United States. She mentioned that her husband was not accustomed to the ways of the United States and that he did not like it while he was there, so much so that he does not want to go back. However, their economic situation prompted Lupe 
to admit that she'd like him to leave for the United States once again due to a dire economic situation. Although Lupe worked outside of the home cleaning houses in the city and her husband as a laborer, their two and zero years of education, respectively, kept their earning potential relatively low.

The 92 percent of women whose husbands had returned that thought their husbands would not emigrate again, citing their husbands' desire to stay with their children and families, the challenges of crossing the border, a negative experience in the U.S., and the lack of work in the U.S. as the primary reasons for their husbands' decision to remain in Guelavía.

\section{Anchored Husbands-From a Woman's Perspective}

According to their wives, men do not want to leave their family. Anxiety about finding work in the U.S. and the danger of crossing the border were also commonly cited reasons why their husbands have chosen not remain anchored in Guelavía. The range of reasons that women offered for why their husbands had chosen to remain in Guelavía is summarized in Table 7 below: 
Table 7: Women's Reasons for Men Remaining in Guelavía

\begin{tabular}{l|c|c}
\hline & Percentage* $^{*}$ & \\
\hline Does not want to leave the family & $\mathbf{7 4 \%}$ & 26 of 35 \\
\hline No assurance of work in the U.S. & $\mathbf{6 3 \%}$ & 22 of 35 \\
\hline Danger of crossing the border & $\mathbf{5 1 \%}$ & 18 of 35 \\
\hline The children need their father in the home & $\mathbf{2 9 \%}$ & 10 of 35 \\
\hline Lack of network or assistance & $\mathbf{2 6 \%}$ & 9 of 35 \\
\hline Fear & $\mathbf{9 \%}$ & 3 of 35 \\
\hline High expenses in the U.S. & $\mathbf{6 \%}$ & 2 of 35 \\
\hline Lack of money to emigrate & $\mathbf{6 \%}$ & 2 of 35 \\
\hline
\end{tabular}

Source: Author's survey, May 2010, of women whose husbands had never emigrated from Guelavía

* Women could choose all answers that applied as well as offer their own responses so figures do not add up to $100 \%$.

Women question if their families would be better off economically if their husbands were to emigrate. Despite higher wages offered in the United States, more than half of women in each age category expressed that their family would not be better off as shown in Figure 6 below: 


\section{Figure 6: Women's Responses to "Economically Better Off" if Husband Emigrated}

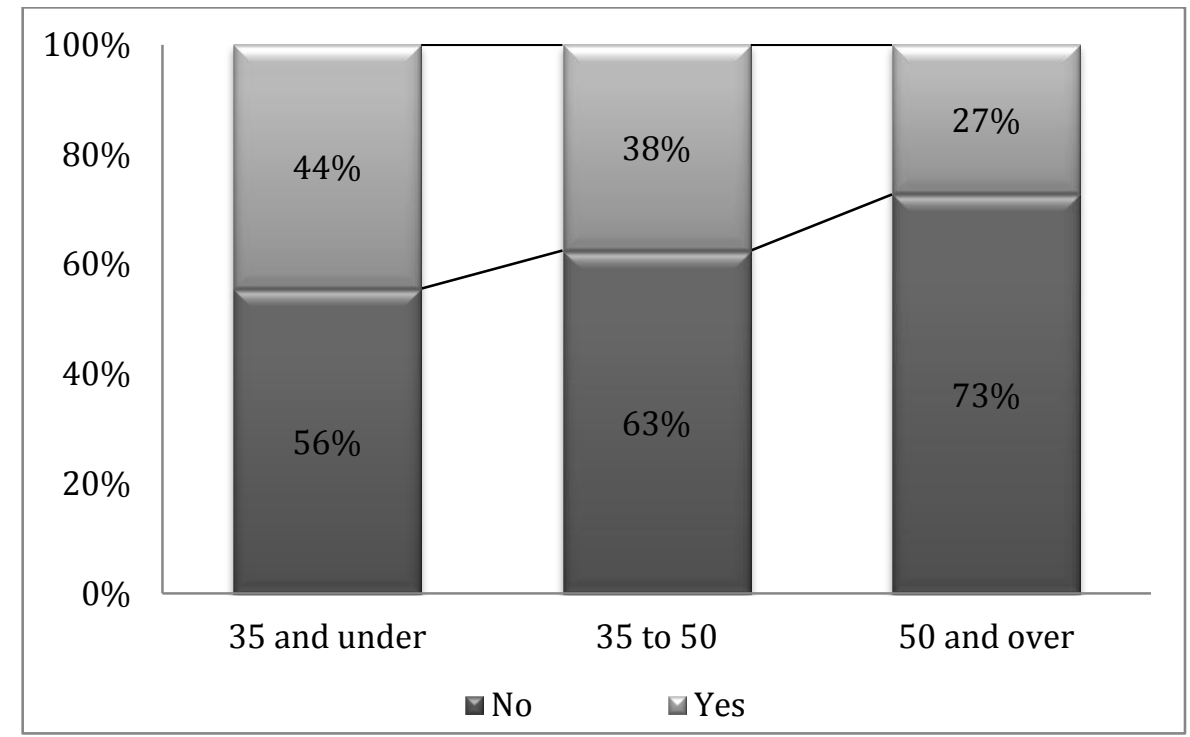

Source: Author's survey, May 2010, of women whose husbands had never emigrated

Responses that families would not be economically advantaged if their husbands were to leave were strongest among women age 50 and over. Seventy-three percent of women age 50 and over stated that "no," their family would not be better off, while just over half, 56 percent of women age 35 and under stated the same. Therefore, 44 percent, of women age 35 and under thought that their family would be economically advantaged if their husband lived in the United States. Some of the difference is likely attributable to perceptions of the limited potential for enhanced earnings in the U.S. labor market for men over age 50 .

Also significant is the difference between women's opinions in the middle and lowest age categories. In general, younger women appear to have a greater voice in husbands' decision to go or to stay but they also recognize that having a spouse in the U.S. would improve the economic situations of their families. Since 
most migration from Guelavía occurred in the last 10 to 12 years, it is primarily younger women that are most aware of the economic benefits that the U.S. could bring.

Perhaps surprisingly, there was no correlation between husbands who were not working and women's opinion of their family being better off if their husbands were in the United States. Perhaps women view their husband's non-working status as unlikely to change if he resided in the United States.

A key question in the survey was simply, "Por que piensa así" (why do you think that), as a follow-up to the inquiry if they thought their family would be economically advantaged if their husband were residing in the United States. It appeared that only a handful of women observed the "economically better off" portion of the question since the majority responded to a broader question of if their family would be better off, in general, if their husband were absent from the home. All of the women that answered "yes, our family would be better off economically if my husband were in the U.S.," responded in terms of money or work being more abundant if he were away. "Aquí no hay trabajo ni dinero" (here there is no work nor money) and "allí se gana mas dinero y ahorraríamos mas" (there [the U.S.] you earn more money and we would save more) were common responses for nearly all women that responded "yes." Even though the economic crisis in the United States yielded unemployment rates of 8.5 to 10 percent during 2008, 2009, and 2010, women still responded that work would be secured by their husbands if they were there, especially younger women. "Tendría un trabajo mas seguro" (he 
would have a more secure job) was a common response even in the midst of economic instability in the United States in 2010.

Two primary responses were common in regard to why women thought their families would not be economically better off if their husband lived in the United States: 1) staying together as a family was a stronger priority; and 2) the notion of "sufficient" overrode the notion of economically advantaged. A 43 year old woman's simple response encapsulated many women's sentiments. To the question, her response was "yes” but she added: “... tal vez, pero aunque tenemos poco dinero aquí estamos bien" (maybe [the family would be economically better off], but even though we have little money, we are fine here). Many women prioritize family: "Queremos estar unidos, ser una buena familia, y para educar juntos a nuestros hijos" (we want to be together, to be a good family, and to educate [raise] our children together). Keeping men anchored at home and in Guelavía for the solidity and continuity of the family was a commonly-expressed priority for women in Guelavía.

Similarly, another commonality involved the notion of "sufficiency"accepting the standards of earnings and material possessions commonplace in Guelavía as being "sufficient."

"Con lo que gana, es suficiente."

(With what he earns, it is sufficient.)

"Con lo que gana y con lo que tenemos, es mas que suficiente." (With what he earns and with what we have, it is more than sufficient.) 
Perceiving family income and material possessions as "sufficient" offered a strategy for women in retaining husbands in the home. If women desired little, men's responsibility for providing more was diminished, thus, men may remain anchored in their homes with their family.

Two additional themes emerged from the responses of women whose husbands had never emigrated. One, described here as the worry of the influences of the U.S., was typical:

"Que tal que me deja sola y cambia de forma de pensar" (Perhaps he would leave me alone [in Guelavía] and change the way he thinks.)

Secondly, women's responses were strong about other potential female relationships in the United States accompanied by the possibility of being forgotten:

"A veces se van y ya no regresan."

(Sometimes they [husbands] go and they do not return.)

"Seria igual o peor porque muchos hombres se olvidan de sus esposas."

(It would be the same or worse because many men forget about their wives.)

Women with anchored husbands are very cognizant of the risks that accompany emigration. None of these women had personally experienced emigration of their spouses-all having anchored husbands-but the stories and experiences of other women had strong impact on them.

Irrespective of the risks, a small portion of women with anchored husbands expected that their husbands would soon be leaving, for the first time. Women in the 35 to 50 age category responded at the highest rate that their husband did, indeed, 
have plans to emigrate. Only 11 percent of women age 35 and under with anchored husbands responded that their husbands had plans to emigrate, but 19 percent of women ages 35 to 50 responded that their husbands would soon be leaving for the United States.

\section{Threats, Risks, and Fears of Male Migration}

If you are a woman with an absent but "responsible" and communicative husband residing in the United States, one of your important roles is to defend your husband and the decision he made to emigrate. These women are stay-behind wives and acknowledge themselves as such. If you have an absent husband who fails in his economic role as provider and forgoes communication, you are a mujer abandonada (abandoned woman). Women worry—for themselves if their husbands are absent as well as for their daughters whose future husbands could leave them as mujeres abandonadas. As women with absent or returned husbands communicate their experiences and their concerns to female family members, neighbors, friends, and acquaintances, women with anchored husbands take on similar concerns, worries, and fears.

Questions on the subject of mujeres dejadas or abandonadas (Spanish version of "left behind" or "abandoned" women) were intentionally omitted from the survey as well as the open-ended interviews due what was perceived as inappropriate and too culturally sensitive. The subject nevertheless arose without provocation or 
inquiry during survey gathering, interviews, and in casual, informal conversation. ${ }^{42}$ Women with absent husbands, returned husbands, and even women with anchored husbands expressed the risk of potentially becoming one of these women in the face of male migration.

Threats and risks cited by women about their husbands' previous or potential emigration focused most heavily on men's infidelity when absent with the larger risk of lack of remittances or even lack of return.

Marilu, age 53, whose husband was previously in the United States and whose children reside on both sides of the border, spoke frankly of her belief of numerous husbands from Guelavía that have or have had other families in the United States. She conveyed her belief that nearly all men have other relationships while away, a bold and possibly insulting and/or worrisome statement as Simona, with whom she was interviewed, has a husband who currently resides in the U.S. Carefully choosing her words on the delicate topic, Marilu spoke of "mujeres abandonadas" (abandoned women) while in the presence of a stay-behind wife. Simona quickly agreed with Marilu's summation, adding her estimation that approximately half of all men who leave ultimately abandon their wives.

Women also acknowledge that the risks of male migration may create challenges for their own personal lives, as well. Erika and Elysa spoke of the risk that migration inflicts on the relationship when women encounter another male

\footnotetext{
${ }^{42}$ Considerable thought, discussion, and research went into the decision to omit previously-included survey questions regarding these terms and this theme. After considerable reflection and numerous discussions with various Oaxacans, all questions were omitted.
} 
relationship. Their discussion centered on three themes: one, that men often come back and drink too much and use violence against their wives when they had not previously or they are much more possessive when they return; two, women become more independent and do not want their husbands when they return; and three, women, too, cheat on their husbands when their husbands are absent. Both women spoke openly and extensively of these three themes appearing to adamantly place the blame on the phenomenon of emigration rather than on women or men's actions or reactions.

Both Erika and Elysa recounted anecdotes of husbands who had not been physically abusive prior to departure and returned as men who physically violated and abused their wives. While wives must adjust to expanded responsibilities while husbands are away, both Elysa and Erika spoke of men returning and expecting to regain control over their wives-regaining the control that they had had previously. While male dominance and female submission play a major role in much of Mexican culture, women appear to be more cognizant of men's dominance when husbands are away and subsequently return.

Women possibly fail to remember the submissive role they played in the relationship while the husband was away or perceive the potential for change which has not been realized. Yet Erika's verbose ramblings about her husband disallowing her from leaving her home without permission, forbidding her to visit her dying mother in another part of the state, and prohibiting her from working outside of the home displayed excessive control by an anchored husband who had never left 
Guelavía. Rather than the control, the submission, and the domestic violence, perhaps women risk and fear change. A husband who has always maintained a controlling and chauvinistic demeanor within the home and throughout the marriage is one thing; a husband who changes due to the influence-or as the "consequences of migration," as Elysa phrased it—is another. It was common for women to blame migration for the problems, changes, strains, or struggles in their relationship rather than the relationship or the specific involved parties.

The consequences of migration for women include a wife's added responsibilities and independence. While these can enhance women's esteem, their sense of self, and their confidence in maintaining their household, their family, and potentially their own business or job, these enhancements can also be a source of worry and risk. Alejandra conveyed that telephone communication with her U.S.based husband is frequent but it is not the same as living in the same home. For eight years Alejandra has handled every facet of the home from raising and disciplining two sons alone-one from just four months of age when her husband left—-to home construction to striving for a peaceful communal sharing of a courtyard with her mother-in-law. She also recognizes that her husband has lived on his own without someone to inquire as to where he is going, what he is doing, and how he spends his money. He, too, is accustomed to living his own life without her. She shared that she knows her responsibilities of "la ropa y la comida" (the clothes and the meals) will be greater when he returns. Alejandra's worry about her 
husband's impending return to Guelavía and their home was palpable due to his scheduled arrival just one week after her interview.

Alejandra's situation was representative of the risks that women take and are expected to endure when husbands emigrate. Alejandra received an average of more than $\$ 1,000$ per month from her U.S.-based husband, more than any other woman surveyed. Her home, as previously mentioned, is unassuming in its unpainted concrete façade but one of the grandest in stature. Alejandra cares for the home and raises their children. But the tradeoffs that Alejandra has appeared to have endured are extensive. Three aspects were particularly striking during the survey and in an individual interview with Alejandra.

The first aspect that struck me came upon arrival at Alejandra's home. While Alejandra remained calm, chaos seemed to surround her. Through the yelling and harsh tone of her mother-in-law in the background and the screams and tears of her children, Alejandra maintained a veneer of calm peppered with mild irritation. Her manner struck me as trying to appear calm and collected in front of a stranger while within the midst of a storm.

Secondly, Alejandra was the only women to be interviewed who quickly and firmly declined to be interviewed with another woman. She agreed to participate in an open-ended interview only if it was an individual, private interview. In her individual interview, Alejandra appeared forthcoming and open to all questions even expanding in areas that appeared to be of most interest to her. Her portrayal of 
heightened concern for privacy and confidentiality was a departure from other women interviewed or surveyed.

The third facet that struck me in speaking with Alejandra was her demeanor. Alejandra portrayed a serious, solemn tone and manner and an all-prevailing demeanor of anxiety. She was open and talkative but frank, serious, and guarded. Alejandra seemed beaten and worn down. Her challenges with living within a very short stone's throw of her mother-in-law's home caused her great dissatisfaction and discontent. She elaborated on the difficulties that her living situation caused her but, simultaneously, spoke of having resigned herself to the fact that it was unalterable and one she had come to accept. As the only son in the family, her husband was economically positioned as the caretaker. While he had promised to "care" for his mother, likely the physical and possibly emotional care fell to Alejandra. Throughout the interview Alejandra vacillated between relating the challenges her situation presented while justifying the male migration path that she and her husband had apparently chosen. The couple were very young when they married and, with without economic or social resources—no jobs, no house or material possessions, little education, little family support—emigration seemed their logical, possibly only, choice. From a 16 year old teenage bride to a 26 year old stay-behind mother, Alejandra had clearly matured but she portrayed and communicated that she was enduring a life that she had not envisioned nor anticipated. She had spent nearly all of her married life as a stay-behind wife- 
raising, educating, and nurturing her children-all the while enduring her motherin-law and the situation that she'd married into.

Not only did Alejandra experience the risk of tolerating male migration as a stay-behind wife and mother, she was now preparing herself for the risk of his return-in just one week. Alejandra had grave concerns as to how he would fit back into the family with one child that he barely knew and another who was only 2 when he left. She also worried about how their relationship would need to be reconstructed as well as his future work opportunities. The couple had savings, unlike many Guelavían families, so they could allow his work plans to be unsettled until he readjusted to Guelavían life. This was of concern to Alejandra who expressed that she believed that her husband will now and into the future reside with the family in Guelavía but also communicated that if a feasible work situation did not materialize, she feared that he will, once again, leave for "el otro lado." Alejandra's communicated worries paralleled those of Veronica, whose husband had unsuccessfully attempted to cross the border. Veronica spoke of emigration in the following way:

“... se desintegra totalmente la familia, total porque si bien cuando estamos juntos funciona más o menos pero ya una vez que falta un integrante resulta una desintegración total."

(... totally disintegrates the family because things are fine when we are together, it functions, more or less, but when one member is missing, it results in a total disintegration.)

Veronica worried about her husband's possible sudden departure and, as a result, the disintegration of her family. Her son needs both parts-a mother and a 
father-expressed Veronica. Veronica was willing to suffice with the material things, the food, the humble abode, the lifestyle that the two of them have created. With her working 50 hours or more per week, highly unusual in Guelavía, her husband continued to dangle the possibility of his likely departure. This clear and continued rift between the two had taken its toll on Veronica's marriage. While Veronica remained adamant about her insistence of her husband remaining in Guelavía, her realistic fear and preoccupation was that he will, one day soon, depart again for the United States and she will witness the disintegration of her family.

When envisioning a life without her husband in the home, Veronica's worries were similar to those of others. Women who have not experienced the extended absence of a spouse were well aware of the risks of male migration; women with anchored husbands were well aware that their status could change.

Simona articulately conveyed her worries and fears-border crossing, insufficient work, changes in lifestyle—all common for Guelavían women who were surveyed and interviewed. Simona expressed that she had both fear and worry prior to her husband's departure. Undocumented as he crossed the border, likely as are all Guelavíans, Simona's worry of his capture and potential incarceration weighed heavily on her. Just as concerning, however, was the potential of unemployment due to his undocumented status and his lack of English impeding his potential for employment. During his years in Los Angeles, her worries dissipated due, in part, to his job stability in holding the same position that he acquired upon his arrival eight years prior. 
Simona's actions when her husband left for the United States were to accept, handle, and manage the role of both mother and father simultaneously since her husband "me quedaría a cargo de los hijos" (he would leave me in charge of the children). She expressed her life without her husband in the home as "muy difícil" (very difficult), adding "porque la tengo que hacer de papa y de mama y tomar decisiones yo sola" (because I have to do that of the mother and the father and make decisions alone). Discipline, as expressed by Simona and other women, is primarily a responsibility of the father/husband; in Simona's case, she now is the disciplinarian, a role she resents and dislikes.

Simona's primary worry of a husband who has been away for years is in agreement with the worries of Alejandra-how will her husband fit back into the family after a lengthy absence. Simona spoke of her raising the children in her way and that they are older now with much time having passed during their father's absence. She expressed concerns of her children's reaction when their father attempts to direct them, discipline them, and raise them and her husband's place in a family that's changed during the many years of his absence. Women are aware that gender and cultural norms shifted while a husband was absent from the home and living in the United States and they are unclear as to which of those norms will be shifted back, which will have to be renegotiated, and which have changed permanently. Bever's work (1999) suggests that gendered roles changed necessarily while husbands were absent but, for the most part, returned to previous patterns, divisions, and power structures once the husband returns to the home. Many 
women in this study supported that view, communicated their own and others' experiences in a shifting back to traditional roles and patterns, and Simona, as well as other women, worried that the likely shifting of roles and norms would challenge the couple when her husband returned.

Marilu delicately but firmly expressed her opposition for a family to choose emigration as a strategy for economic livelihood. Marilu was interviewed with Simona whose family and/or husband had chosen the emigration strategy. Marilu, the wife of a returned husband who herself had lived in the United States during one of her husband's stints away, has children living on both sides of the border. Marilu, as expressed by Simona, worried about the next departure primarily of her two adult children that live in Guelavía as well as the lack of work to keep them embedded in the community.

Guelavía has traditionally been known as a farming and artisan community. According to numerous Guelavíans, the lack of rain has made farming more challenging than ever. It is routine to hear Guelavíans mention, as well as comments in open-ended survey comments and interviews, that the land is too arid for crops and that climate change is responsible for inadequate rainfall, the only means of watering crops. Older residents mention a time when the small stream that runs through Guelavía was filled with water throughout the year; now, it only contains water during the rainy season of August and September and sometimes, not even then. The small, local mercado is filled with fruits or vegetables that are imported primarily from the city of Oaxaca through a distribution chain. Only a small portion 
of the garlic, epazote (an herb used in traditional Oaxacan cooking), and cilantro are locally grown. Nearly all of the vendors in the local mercado are women, likely as high as 95 percent. The women take pride in the non-organic nature, shiny appearance, large size, and unblemished exterior of the produce that they sell commenting proudly that the variety of produce that they sell is not grown in Guelavía and that, proudly, it comes from the city. The female merchants in the mercado do not take pride in presenting or selling the produce grown in and around their own community by their own husbands.

Of the 71 women surveyed, 40 percent responded that their husbands were "campesinos" (farmers) when asked, "Qué tipo de trabajo hace para ganar dinero?" (What type of work does [your husband] do to earn money?). This suggests that farming remains a substantial income-producing economic activity in Guelavía although farming on small plots of land, as is the case in Guelavía, and on arid lands is widely recognized as minimally profitable and primarily a form of sustenance for the family. Forty percent of husbands as farmers is in sync with the Health Center data of 44 percent of all working residents as farmers. Forty percent of husbands of surveyed women work as albañiles (loosely translated as construction or masonry workers), 15 percent were chofers (taxi drivers, with one husband who drives a mototaxi), 23 percent work in restaurants, 2 percent in arts and crafts, and 2 percent as mercantes (merchants). ${ }^{44}$

\footnotetext{
${ }^{43}$ Taxi drivers averaged a high level of education in relation to the general population of Guelavía. The eight taxi drivers, including the mototaxi driver, averaged 11 years of education compared to 6.5
} 
Absent husbands' work is approximately the same as men's work in Guelavía-construction and agriculture, with just one absent husband working in a restaurant. Women often expressed their worries and concerns about their husband's readjustment from the United States to Guelavía, citing a readjustment from their U.S. labor environment to Guelavía with its low wages as a central concern. It appears that men transferred their skills from Guelavía and used them in a U.S. environment. However, women are concerned about transferring their U.S. skills back to Guelavía with Guelavía’s limited opportunities, unstable work schedules, and low pay. One anchored husband with whom I spoke spent approximately 50 percent of his day's wages as a construction worker on public transportation expense to Tlacolula and food during his work hours. Women's concerns of their spouse's potential discontent with the Guelavían labor environment appear warranted. Women worry that their discontent will invoke a circular migration pattern rather than their husbands remaining at home in Guelavía.

In addition to a challenging labor environment upon potential return, many women surveyed and interviewed expressed concerns about border crossings, lack of work in the U.S., other relationships their husbands may have, expansion of their own responsibilities, raising and educating their children alone, and lack of work when and if their husbands return. Sulema and Lulu, two 50 year old women with

years for all surveyed husbands. Excluding the mototaxi driver, taxi drivers averaged 11.7 years, an average of five addition years of formal education.

${ }^{44}$ The total of husbands' income-producing activities equals slightly more than 100 percent due to rounding. 
returned husbands who were interviewed together, quickly discounted the importance of the generalized worries of women. Both women were stay-behind wives in the 1980s and 90s. They chided women who claim to have worries current day compared to the stress and strain they experienced in a different era. Citing communication only through letters that would take weeks to arrive, they both discounted women's need to worry in this current age. When their children were sick or when someone had died, they had no one to converse with or with whom to share the bad news. Lulu's brother had died crossing the border and the family in Guelavía was not alerted until many weeks later, with her husband in the United States notified even later. Yet, immigration policy was vastly different with little focus on apprehension compared to modern day. Based on survey and interview data, based on generation, some worries are lessened while others are elevated.

Sulema and Lulu also freely conversed about their similar experiences of their husband's departure. The two women elaborated on the stories of the decision to emigrate-a decision made by each of their husbands both in a similar, fairly haphazard way. They spoke as if their husbands simply arose one day and off they went. There was very little planning, discussion, or conversation. Both women spoke somewhat flippantly of current-day couples' excessive planning for their wedding and then the eventual departure of the husband. Lulu expressed that in their time they didn't think about where they would live, with whom they would live, how they were going to survive, or what material possessions they would have; "si hay casa o no hay casa" (if there was a house or there wasn't a house), they 
simply married. Sulema and Lulu both spoke of the era that men from Guelavía began emigrating, in the mid-1980s. Wives remained behind without discussion, without a voice, without a vote. Discussion, voice, or a vote was not expected of women and was not their role. They both expressed that now, younger women converse with their husbands about where they will live, with whom they will live, and if the husband, or both, will emigrate. The generational differences expressed by Sulema and Lulu were substantial and appeared to be noted and recognized as a substantial difference from women in the early 50s to women in the 20s and $30 \mathrm{~s}$.

There is, however, little noted generational difference in women's burdens and responsibilities. The three age categories displayed differences among women's experiences in the 1980s, 1990s, and today but far more similarities than dissimilarities. Small shifts have occurred-women play a larger role in decision making and communication across the border is easier today than in the past but women's concern of their husband's impending border crossing is indisputably more worrisome today than in decades past. Women's burden, responsibility, and concerns seem to have changed little and stay consistent across age categories. While change has occurred, more has stayed the same.

\section{Keeping Men at Home}

Luz, a 26 year old mother of one who holds a part-time job has not experienced marriage with an absent husband. The young couple has, however, had numerous and even recent discussion on the topic of male migration. An important 
component of keeping a family from potential disintegration as a result of male migration, expressed by Luz, is the securing of a home. Luz emphasized in an individual interview as well in casual conversation, that she believed when a couple has their own home, they have little, valid reason to leave Guelavía. She recounted a portion of a discussion that she and her husband had just had a few days prior to the interview.

“... aquí, por lo general, los papás les regalan a los hijos un terrenito y ya ellos hacen su casita y pues todos tienen. Por eso, nosotros no lo vemos muy necesario ir a buscar a otro lado si aquí podemos tener esas cosas."

(... here, in general, parents give [or gift] their children a small piece of land and there they make their home and all have that. Because of that, we do not see that it is very necessary to look at the other side [to go to the U.S.] if here we can have these things [the house and the land].)

Luz's home shares a small courtyard with her mother, father, and two younger siblings. Her mother made sure that her daughter and son-in-law were given a piece of land through pueblo authorities in order that they maintain stability in Guelavía and have little motivation or reason to emigrate. It is most common that the husband's family divides their land or shares space with the new couple but Luz's husband's family is not from Guelavía so the land came from her parents instead of his. Whether Luz's or her mother's overt strategy for reducing the possibility of their leaving Guelavía, it appears to be working as neither Luz nor her husband have intention of leaving. 
According to the 2009 Health Center survey, 99 percent, 796 families, in Guelavía own their own home; only five families rent. Families in Guelavía build their homes poco a poco, little by little. Few, if any, families obtain commercial financing, nearly all paying cash as they go for construction materials and labor. Due to this method of construction, many homes are simple with small additions being built only as money is acquired and saved. Many homes are literally built and paid for wall by wall and window by window. Homes in Guelavía are quite humble but Guelavíans do not have a monthly rent or mortgage payment. While Luz was the most vocal about the lack of "need" to emigrate when a family likely does not have any housing costs, many women concurred in lesser-opinionated terms. Several women, Luz included, expressed that keeping the family together was a higher priority than obtaining a higher material lifestyle.

The value that Guelavían women place on keeping the family unit togethermost often with the traditional role of the wife in the home and the husband as economic provider and child disciplinarian-is validated throughout women's responses to their family being economically advantaged if their husband were residing in the United States. Many women's responses had little to do with the economic viability of having an "absent husband," and more to do with the dissolution of the family:

"Es mejor estar juntos" (it is better to be together)

“... estamos juntos y así estamos bien” (we are together and due to that, we are fine) 
"Aunque aquí gana poco estamos juntos" (even though here he earns little, we are together).

The concept of sufficiency appears to also play a part in keeping men at home. Women's perception of "sufficient" may impact the likelihood for husbands to emigrate. Women's persistent comments about the little that their husband or their family earns as "sufficient" — primarily with the added response that they are able to remain as a complete family—speaks to the priorities of many women with anchored husbands as well as a few who had returned husbands. Many women saw the continuation of the family unit as a priority over the enhanced income opportunities likely offered in the United States. Keeping the family unit intact was achieved by some women through the concept of feeling that the little they had was "sufficient."

Comments by 26 year old Alejandra displayed a maturity and possible shifting perspective gained through her eight years as a sole head-of-household. Her husband fulfilled his economic provider role in the United States. Alejandra expressed, in a general manner, that her initial worries just prior to her husband's emigration, were for the material things that she or the family lacked:

“... las preocupaciones, muchas veces, son las cosas que quieres tener y pues a veces ya tienes uno, ya tienes otra cosa, o también las preocupaciones son, por ejemplo, son con los niños."

(... the worries, many times, are the things that you want and sometimes you want one thing or you want another thing or, also, the worries are, for example, worries about the children.) 
Alejandra expressed that her attitude, opinion, and worries had changed during her husband's absence. They'd shifted from the severe deficiency of material things and daily sustenance to caring for her children alone. Her primary concern for her husband's return in a week, was if her husband would have the same feelings for their younger child that he knew only for a couple months as he did for the older child which he knew for a few years. Based on the size and quality of her home and the more-than-adequate furnishings as well as through conversation, Alejandra's worries had clearly shifted from the basics of survival and sustenance to more psychological and emotional. In her own young but wise way, Alejandra expressed her own lessons learned. In the interview, she openly expressed her skepticism of when "sufficient" would be acquired —and who would determine when sufficient had been reached. She asked, aloud, at what point would a cohesive, collaborative family living within one home would be enough.

Families with a husband and wife living in the same home rarely include two full-time incomes as most wives in Guelavía provide unpaid work within the home. Yet, some women use their own work with their own income as a strategy in helping deter emigration of their husbands. A small percentage of Guelavían women work for income-usually referred to by women themselves as "help" or "assistance" to their husband's primary income. Some women use their income as a strategy for keeping men at home. They also use it as an economic backup plan in the possibility that remittances never arrive or that they end up as a mujer abandonada. 
Veronica was an example of both strategies simultaneously. First, emphasizing the importance of keeping the family together with her son's need to have his father in the home, Veronica intended to either guilt her husband into remaining (and not making yet another attempt to cross the border) or to have realized the fundamental needs of his family. Secondly, finding an avenue for income for herself with the intent of lessening her husband's "need" to emigrate, Veronica thought she was supplanting her husband's economic "need" and his quest to go to the United States. Veronica's response when the interview began and the subject of male migration was introduced was immediate: “... por esa razón, yo le apoyo trabajando" (for this reason, I help him by working). Few women work for income in Guelavía, fewer still, work 50 hours or more as does Veronica. Although Veronica expressed pride in ownership of her small stand in the mercado and mentioned her desire and preference for financial independence, her usage of language continually emphasized her income role as "extra" and "supplemental." Veronica recounted that she had boldly told her husband that she would work and help financially support the home and proceeded to open her stand five years prior. Her primary motivation was to financially help support the home and, thus, eliminate the need for her husband to leave. She was unsuccessful at least in her primary motivation. Her husband still proceeded to leave Guelavía several times. At the time of the interview, Veronica was unsure if her husband would remain or if he would go but she suspected that he would, once again, try to cross the border even against her wishes. 
Veronica, however, expressed that she was resigned to his decision and felt that she had done what she could and that the decision was primarily left in his hands. 


\section{Chapter 5: Women, Work, and Male Migration}

\section{Introduction}

The focus of this chapter is on work, primarily women's work, in relation to male migration. Who works in Guelavía, what women do for work, and how their work is perceived are the major themes explored, followed by suppositions as to why few women in Guelavía claim to work for income. The gendered division of labor is described within the context of how work is understood and realized in Guelavía as well as men's role in controlling or influencing women's work. A short assessment of government and non-profit programs in Guelavía is included with respect to income earning and home production activities by women. Women may be obligated to begin earning or increase income for the family in order to replace income lost when a spouse has ventured north (Pessar, 2005). While newly- or increased women's income may be an interim measure until remittances are forthcoming, women's income may also become the only form of income if her husband fails to return, leaving her a mujer abandonada (an abandoned woman).

Women's work, whether induced by male emigration or simply the potential of male emigration, is based in gender role ideology. Traditions, culture, and attitudes of proper gender roles, responsibilities, and behaviors of women and men in economic activities in Mexican society are fundamental in all aspects of women's "work for income." Culturally-defined roles influence which women work, the type of work they perform, where they work, how much they work, and, possibly most importantly, their perception of their own work as "extra," "temporary," or 
"necessary and required." Men control women's world of work with only slight generational differences.

This chapter begins with the culturally-sensitive challenges of investigating women's work, recognizing that work inside of the home caring for the family is respected and noteworthy, but unremunerated. The challenges of inquiring about "work" are directly followed by survey findings on remunerated work for women in San Juan Guelavía. A discussion of women's gendered types of work, location of work, and hours of work follows with comparison and contrast to men's work. Findings include the fact that women without a husband in the home are primarily the women who work.

\section{Oaxaca Women's Work and Guelavía}

Inquiring about women's work in southern Mexico requires thoughtful reflection, understanding, and sensitivity to the cultural setting. The primary question in regard to women's work on the random survey instrument was intentionally short and to the point-“Trabaja por dinero?" (Do you work for money?). Nevertheless, the straightforward nature of the question still led to responses such as, "Todos trabajamos por dinero" (all of us work for money), as if "work" equates to "earning money" and therefore, the women implied, the question was redundant. The challenge in appropriately phrasing the question was twofold: 1) to incorporate women who work for income within the home; therefore, "Do you work outside of the home" would not have included these women; and 2) to 
acknowledge that women who care for the home and the children while not compensated are performing respected work. "Trabaja por dinero?" was received by women as intended. A few of the responses showed women's clarity on the difference between paid work and work inside the home: "Yo solo recibo el dinero que mi esposo me da para el hogar" (I only receive the money that my husband gives me for the home), "Trabajo en mi hogar para mi familia. No gano dinero." (I work in my home for my family. I do not earn money.), and "Solo me dedico a mi casa y a mi esposo" (I just dedicate myself to my home and my husband).

Thirty percent of women surveyed responded that they "work for money [or income]." When women age 70 and over were removed from the statistics-the oldest age of nearly all government or private retirement programs-the percentage of women who worked was only slightly higher, 31 percent. The youngest woman who worked for income was 26 years of age-with nine women younger than 26 who did not work-and the oldest, 53-with 16 women from 54 to 79 who did not work. The largest percentage of women who worked for income was women ages 35 to 50 ., worked at the highest rate, as shown below: than women age 35 and under. Women ages 35 to 50 were 35 percent more like to work than women ages 35 and under and seven times more likely to work than women age 50 and over: 
Figure 7: Women Who Work for Income, by Age, May 2010

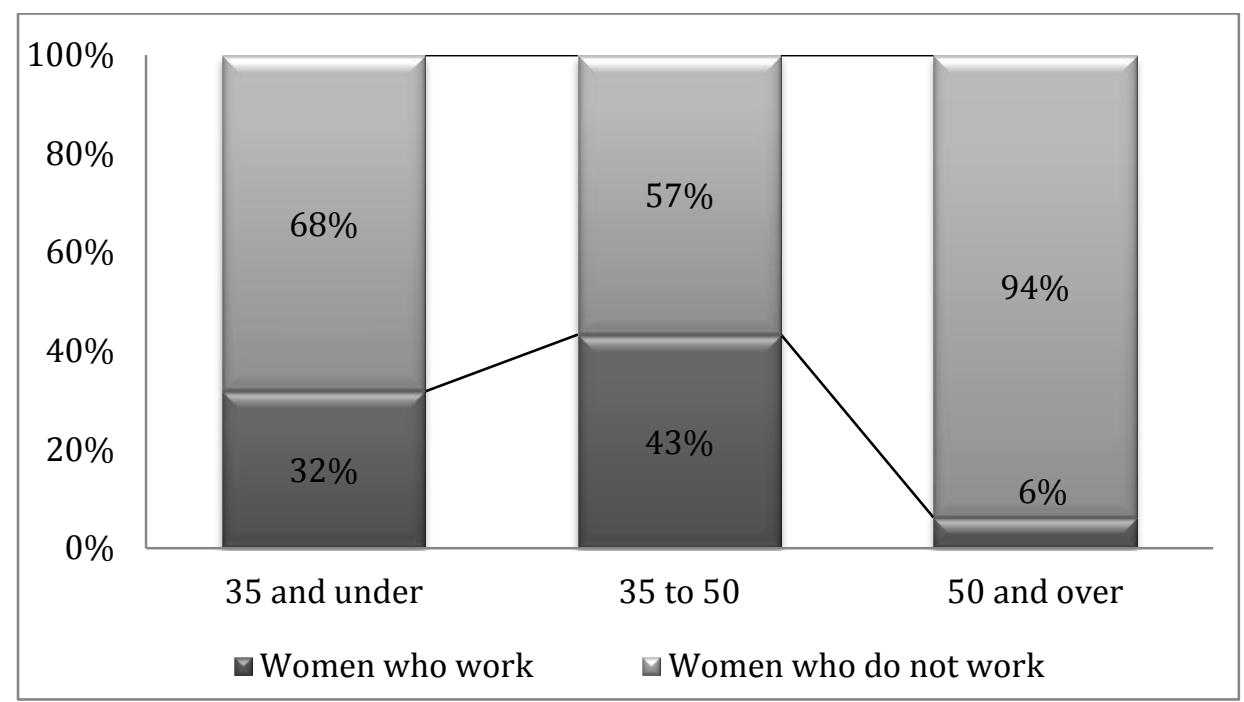

Source: Author's survey

Elysa, the woman whose husband had left her 26 years earlier and was raising her two grandchildren as if she were their mother, was the one of 16 women ages 50 and over who was working for income. Elysa was also one of only five of the 71 women surveyed who responded that she worked 50 or more hours per week. Her small store was situated in a front room of her home. With considerable competition and few customers noted, her small store appears insufficient to provide for her family. ${ }^{45}$ Elysa's 50 or more hours of reported work coincided with the store's open hours. Elysa simultaneously handled product questions, store transactions, social interactions, and domestic chores. Stocking the store, attending to customers, caring for her grandchildren, and even cooking and serving comida, the main daily meal, were handled simultaneously within the same environment. The flexibility of Elysa's situation accommodated the multiple roles that this

${ }^{45}$ Erika, the other woman interviewed with Elysa, also maintains a tiendita in her home, just a few blocks away. 
mother/grandmother fulfilled, but the store did little to sustain the small family economically. During her interview, Elysa commented several times on the family's dire financial situation, often mentioning her desire to go the United States while concurrently acknowledging that she would never actually be able to go due to lack of finances.

Elysa viewed her work situation as borne of necessity, due to being a mujer abandonada. If women have a husband in the home, women's work is primarily in the home (Gledhill, 1995; Pagán \& Sanchez, 2000). Without a husband, most women must work. Elysa eloquently explained the sentiment expressed by numerous women about the defined gender roles of work in and out of the home. Erika, the woman with whom she was interviewed, readily agreed:

... las mujeres que no trabajan por dinero, es porque están trabajando en la casa, haciendo tortillas, lavando su ropa, limpiando su casa. Ahí nadie les paga porque por que [sic] tienen un marido que les da el dinero cada ocho días, los sábados. Pero las mujeres que salen a trabajar fuera porque no tienen dinero por eso salen a trabajar. Por ejemplo, yo tengo una tiendita. Entonces yo abro mi tienda porque la abro porque quiero que vengan a comprar para que yo tenga dinero.

... women who do not work for income are working in the homemaking tortillas, washing clothes, cleaning the house. There [in the home], no one pays them because they have a husband that gives them money each week, on Saturdays. But, women that leave to work outside [the home], do so because they do not have money; it is because of that that they go out to work. For example, I have a small store. I open my store because I want others to come and buy so that I have money.

This passage, as well as multiple others that were similar in content and tone, offers three important declarations of gendered work in Guelavía: 1) Married 
women with husbands in the home tend not to work for income due to required domestic work; 2) Men usually control the money; men always control the money if the woman does not earn her own income; and 3) If women work for income, they work out of necessity, not for pleasure or fulfillment.

While the survey question was phrased in terms of working for money, some Guelavían women responded to the question as if all women work, ignoring the notation of remunerated "work." The distinction between paid work-work that generated income-and work in the home appeared blurred and somewhat unimportant. "Aquí la mayoría trabajan" (here, the majority work) or "todos trabajan" (everyone works) were phrases often included within the same short conversation as "aquí, no hay trabajo" (there is no work here) or "no hay nada aquí" (there is nothing here [referring to the severe lack of work]). These contradictions can be explained by women's understanding of work. Work in Guelavía is often identified by physical or spatial location or movement—physically planting or plowing a field, physically ironing or washing clothes, or physically being in another location such as a retail store where someone pays for your presence and responsibilities. While everyone may work doing either paid or unpaid work, there is very little paid work offered by employers, especially within Guelavían boundaries. The majority of women who work in Guelavía are self-employed while the majority of women who work outside of Guelavía work for employers. 


\section{A Que Se Dedican Los Guelavíans? (What Do Guelavíans Do for Work?)}

Guelavía has a public high school devoted to a focused curriculum of sustainable agriculture with a secondary curriculum focus of computer technology. With this, combined with Guelavía being an agricultural community, it was logical to include campesina (farmer) as one of the checkbox options on the survey as well as trabajo domestico (domestic work) and comerciante (commerce, merchant), two work activities mentioned frequently in casual conversations in Guelavía. None of the women surveyed answered that she worked for income as a campesina. Many women offered that they raise chickens and guajolotes (wild turkeys) but none maintain any type of garden and none considered themselves to be campesinas. The Guelavía climate is mild, and fruit and vegetables can be planted and harvested throughout the year. I visited 90 to 100 homes during surveys, interviews, and casual visits and never witnessed any type of garden plot, even though at least a small amount of space was available in all Guelavían homes due to the rural nature of the town. Two primary reasons appear to be: 1) the tradition in Guelavía is to sell fruits and vegetables imported from large middle merchants that bring produce into Guelavía from the city to be sold at the local mercado; and 2) falta agua (a lack of water) to sustain crops. But the primary reason women are not campesinas (farmers) - or at least claim not to be --is the social stigma of being viewed as one of meager resources-income, skills, education, motivation, among others. Although, due to gendered roles, women would continue to deny their status as campesinas, the opportunity for income replacement by raising fruits and vegetable to allay the 
need to purchase the same items is an opportunity overlooked by Guelavíans and women, in particular. Cultivating a small patch of land could easily be incorporated into women's domestic lives-especially the 69 percent that are not working for income-without impacting the time, energy, commitment, or priority of the devotion to the home.

Early conversations with Guelavíans in the streets, in stores, and in taxis indicated that Guelavían women work most often in trabajo domestico (domestic work) in the city of Oaxaca. However, survey data showed only 10 percent of women do domestic work. The majority of women, 67 percent, work in some form of commerce--in the local mercado or in one of the numerous small stores that sell sundry items, clothing, shoes, or tools. For example, one woman interviewed owns a small fresh juice and torta stand and another woman bought doughnuts wholesale produced in a nearby town and marketed and resold them locally through a loud speaker while walking the streets of Guelavía.

In addition to the 77 percent of women who reported commerce or domestic, other women worked as a nurse, a local librarian, a seamstress, and two women worked in restaurants. Eight-six percent of women surveyed worked within Guelavía, 14 percent worked in the city of Oaxaca, and no women worked in Tlacolula, the nearest city. Comparably, only 61 percent of husbands worked in Guelavía, 25 percent in the city of Oaxaca, and 14 percent elsewhere, primarily the United States and other parts of Mexico. 
Of all husbands that worked, women reported that 94 percent worked fulltime, 40 hours or more per week, with 68 percent working 50 hours or more. In comparison, only 43 percent of women surveyed who worked for income worked 40 hours or more per week, with 29 percent working 50 hours or more. Considering that the majority of women, if not all, maintain the home and care for the children, shorter work hours outside of the home is likely expected. Lulu mentioned that women do not have anyone with whom to leave their children if women do work outside of the home. Sulema, with whom she was interviewed, added, “... por eso es que no trabajan muchas mujeres aquí. Siempre son responsables por los niños y por la casa" ( $\ldots$ because of that [not having anyone with whom to leave their children], many women here do not work. Women are always responsible for the children and for the home.)

\section{Which Women Work?}

Survey data appear to support Elysa and Erika's assertion that women work much less when a husband is in the home. In her own, separate interview, Luz commented that "la mayoría de mujeres que trabajan en el pueblo son solas" (the majority of women that work in the town are alone). Luz was not referring to "solas" (alone) as women with a "single" marital status, but instead, as women without a husband in the home-women with absent husbands. Most of the women who are referred to as sola (alone) are women whose husbands have emigrated, most often to the United States, and may or may not return. 
The following table shows the significant difference between women who work and women who do not work differentiated by husband's migration status:

Figure 8: Women's Work by Husband's Migration Status, May 2010

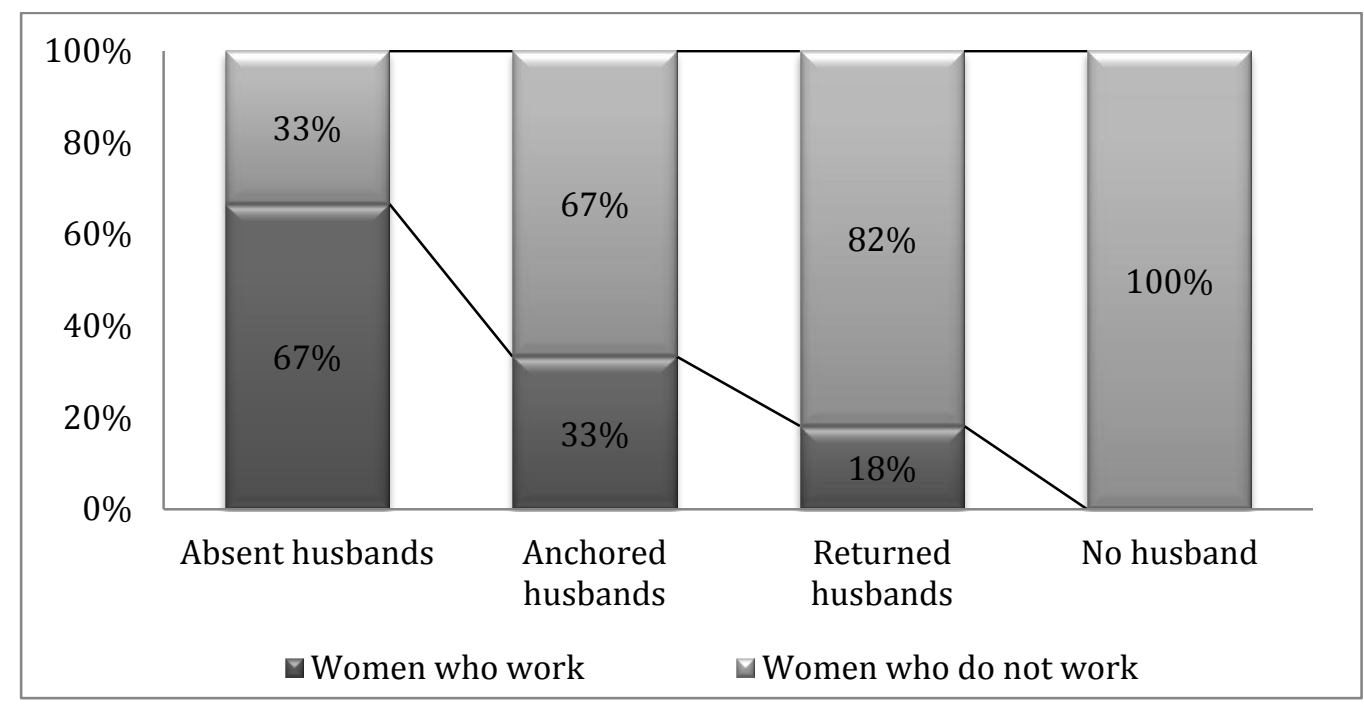

Source: Author's survey

The percentage of women that work that have absent husbands is two times the percentage of women with anchored husbands and nearly four times that of women with returned husbands. It may initially appear to indicate that women with absent husbands are working while simultaneously receiving remittances from their U.S.-based husbands, but for some of the women their "absent" husbands failed to ever send remittances or communicate. One-third of absent men had failed to send remittances and had no communication with their wife who remained in Guelavía. Also the number of women with absent husbands is just 13 percent and women without husbands is only 6 percent, both fairly small numbers when calculating 68 women of working age. 
It may be expected that women with absent husbands would be younger since most men emigrate while in their 20s or early 30s-73 percent of all Mexican migrants are age 35 and under while 91 percent are age 50 and under ("Migración," 2010). However, the average age of women with absent husbands was 41 ; women with anchored husbands, age 42; and women with returned husbands, 38.

Ninety percent of women surveyed age 70 and under had husbands who worked. The few husbands who did not work at the time of the survey ranged in age from 43 to 72 . When women stated that they, themselves, did not work, no explanation as to why was offered nor perceived as necessary. When women answered that their husbands did not work, an immediate explanation always followed: “No trabaja porque esta enfermo" (He doesn't work because he is sick) or "No tiene trabajo" (He doesn't have work). Since traditional, gendered Mexican culture defines men's role as one of economic provider while women tend to the home, the 13 percent of husbands that were not working-primarily due to illness or lack of available work, as explained by women-were defended by their wives for their lack of adequately fulfilling their role. The unprovoked responses as to why men were not working contrasted sharply with the rare explanations offered by women for their own lack of bringing income into the home. The few women who did voluntarily comment as to why they chose "No" to "Do you work for income?" focused on their women being within the home and that no one paid them for that work. 
Interestingly, husbands' work status is not correlated with the probability that surveyed women worked outside of the home. The percentage of working women with non-working husbands was nearly identical to working women with working husbands. When husbands were not working, 29 percent of their wives held income-producing jobs; when husbands were working, slightly more, 33 percent, of women worked for income.

Age and childrearing significantly impact women's work patterns. Women in the middle age category work at the highest rate. Since women marry at the average age of 20, childbearing is expected to come soon after. Women ages 35 and under are most likely to have children who need care in the home. As previously shown in Figure 7, 32 percent of women age 35 and under work while 43 percent of women age 35 to 50 work. Motherhood is the priority of Mexican women and work opportunities, if available and if pursued, are merged around this domestic responsibility of women.

Only 6 percent, just one of sixteen women ages 50 to 70 responded as working for income. None of the women ages 50 and over mentioned being retired which would most often require having worked for a wage or salary in stable, consistent employment. One woman, age 47, was a retired school teacher. Yet, retirement had little, if anything, to do with women's likelihood of working as women who worked averaged 44 years of age while women who did not work averaged just 40 years of age. 
Why do more than two-thirds of women in Guelavía not work for income when the majority of Guelavían families are in serious, dire, or at least challenging financial situations? In addition to the extensive domestic work of which women carry nearly all of the burden-many women commenting that women carry all of the responsibility of the home-and the male economic dependence that women have learned, traditionally and culturally, on which to rely (Benería \& Roldán, 1987), many women view low salaries and high expenses associated with work as lacking sufficient economic value.

In an interview, Marilu communicated her own situation, a typical example of women's salaries that barely cover expenses: "Me dedicaba a lavar y a planchar ropa y pues lo poquito que ganaba me lo gastaba en el pasaje nada más" (I worked washing and ironing clothes and the little that I earned was spent in transportation, nothing more). Marilu wondered aloud if the costs that women must endure simply to find a job accompanied with the high expense of transportation along with the cost of food while away is worth the small income that women's jobs generate. Leaving their domestic realm that gender division proscribes for women is too much of a tradeoff for many women for the small income that a job would generate. Marilu stated that all Guelavían women know that: "trabaja doble la señora" (women endure double work [paid work and domestic work]) when they work for income. No one picks up any part of women's full-time domestic burden when women work whether outside of the home or in. 
Several men, in casual conversations, mentioned women's lack of motivation to work and that Guelavían women, in general, prefer to stay within the home. Rather than pure lack of motivation, women are cognizant of that income opportunities for women, especially lesser educated women, only minimally cover expenses and if transportation expenses and/or child care expenses were required, the meager salary would be entirely consumed in expenses. Therefore, many women turn to work that can combine their domestic responsibilities with income generation. Guelavía women often have their children accompany them during their income-producing activity - to the library as the librarian, to the mercado as a vendor, or to an outside room of the home to make and sell tortillas, tamales, or corn on a stick.

One small business owner who had lived in the United States with his family for 15 years and had recently returned to his hometown of Guelavía to start his own business, spoke to me often of his inability to secure enough employees to plant and cultivate flowers on a plot of land that he owned. While this work was in Guelavía and the high cost of transportation would be avoided, several women expressed their lack of desire to work for what they had heard were very low wages. Women's aptitude in calculating and understanding the opportunity cost of having others care for their children, adding paid work to their domestic work, and meeting the expenses that accompany income generation (transportation, clothing, food) is acute. Since women's work is seen only as financial help for the family rather than perceived as rewarding, fulfilling, gratifying, or offering advancement potential, the 
perceived lack of motivation on the part of women is closely correlated with low wages and the opportunity costs that working for income presents.

\section{Women's Actions and Reactions to Paid Work}

"Pues, cuando trabajan por dinero, no es malo porque es una ayuda para la familia" (when they [women/wives] work for income, it is not bad because it is a help for the family) was a general sentiment commonly expressed by women. Women's sole rationale for participating in paid work was for income generation. Among dozens and dozens of comments about how women's work is only and specifically intended to financially assist with economic survival of the family, were just two comments aside: “... me gusta mi profession" (I like my profession) and "... sigo trabajando porque también me gusta ser independiente económicamente" (I continue working because, also, I like to be economically independent). Respectively, the first comment came from one of the few women-possibly the only woman-who holds a formal, professional, stable job with a consistent bi-weekly paycheck, benefits, and paid vacation. Her government position offered much more than most—possibly all—other women surveyed. With most women working at what they perceived as insignificant, uninteresting, and unfulfilling jobs, there is strong correlation between higher educational attainment and fulfilling and/or stimulating paid work and certainly professional work. With 12 years of education and a high school graduate, Azucena, acquired four more years of education than the average woman in Guelavía. Azucena's comment of liking her profession was the 
only one that showed any sentiment about women's work other than motivated entirely by economics.

The second comment, from Veronica, who maintains her own small stand in the Guelavían mercado, was accompanied by short commentary that when her husband does not have consistent work, she helps support the family. She also added that her priority was, in fact, the money that her work generated. Veronica also mentioned that the majority of women in Guelavía are economically dependent on their husbands and they believe that the man of the house is obligated to economically support the family. When women fully depend on men for economic sustenance-for their daily survival — they often fall into a submissive and passive role in the family.

Salaries in Oaxaca are low relative to the Mexico average. The average hourly income in Oaxaca is $30^{\text {th }}$ of 31 states at just 76 percent of the national average for Oaxacan men and just 73 percent of the national average for Oaxacan women (México Hoy, 2007, p. 71). In addition to the large disparity from the national average to the state average, women also a marked, gendered division of labor earning just 87 percent of the average Oaxacan male ("Censo de Población y Vivienda," 2010). The male/female average wage differential, low rural wages, child care costs, husbands' unwillingness to accept a portion of the domestic burden, and expenses required for generating income are reasons that many women in Guelavía choose to rely solely on spousal generated income. 
Women devalue and diminish the importance of their income-generating work as has been noted by other studies in the same region as San Juan Guelavía (Cohen, 2004; Stephen, 2007). In interviews for this project, every woman described her own work or the work of women, in general, as extra, a help to the family, or simply assistance to her husband. Alejandra, the woman with two children in the home, the mother-in-law across the patio, and a husband in the United States, expressed vividly her view of why women in Guelavía do not work for income:

... a veces por el machismo del marido. A veces el marido no las deja trabajar, porque he visto casos de que quieren trabajar y el marido no las deja trabajar o hay casos también de que el marido quiere que lo apoyen y ellas no tienen motivación. Ósea también hay casos, o a veces por los niños no tienen quien te apoye con los niños.

... sometimes [women do not work for income] due to the husband's machismo. Sometimes the husband will not let them [the wife] work because I have seen cases that they [wives] want to work and the husband will not let them or there are cases, also, that the husband wants the help of the wife [with her working] and women are not motivated to work. There are also cases that, because of the children, they [women] do not have help to care for them.

If a wife is permitted by her husband to work and/or has the motivation, her work will only be considered as help to the primary economic provider role that the husband fulfills. This disadvantages women in the sense that earnings often are associated with power both within and outside of the home. As long as women perceive their own work as nothing more than a "help," women remain subordinated within the home and within society at large. Alejandra's expressed sentiment about the reasons why many women do not work or that when they have their husband's permission and are motivated to work, their work is nearly always 
considered as extra was echoed by every woman interviewed as well as commonly heard in informal conversations. Twenty-three years after the publication of Benería and Roldán's (1987) The Crossroads of Class and Gender: Industrial Homework, Subcontracting, and Household Dynamics in Mexico City, Mexican women's role remains first-and-foremost as wife and mother with necessity to justify remunerated work. Women continue to stress their income-generating activities as a need of the family and helping out the husband with his economic provider role. When there is not a man in the home, women justify their work as necessary, required, and outside of the realm of choices since they must work since there is no husband. Little has changed in regard to Mexican women's work even for younger women. More significant than age is education. The only women that spoke of work as anything more than "necessary" and "a help" were the few more educated women that equated to more professional-type wage positions.

Alejandra's description of men's machismo nature in controlling women's work was a general comment rather than a reference to her own situation. Alejandra's husband had been away in the United States for all but a few months of their ten year marriage. In her interview, Alejandra conveyed that she took the opportunity of the absence of her spouse to work for a small amount of income. On the weekends Alejandra covered a small table with prepared food items for sale from the doorway of her home. Even though Alejandra received a relatively high average amount of remittance dollars, as offered in her self-report survey, she mentioned in her individual interview that she imagined a life for herself and her 
two children without the assistance of remittances. Alejandra had found a method of surviving even if remittances were to cease, her own method to "defenderse", defend herself (Howell, 1999). She also commented that money that a husband earns, in general, may often be insufficient and the little that a wife may earn would be a help to the family. Her comments were consistent with the reasoning of all other women who received remittances as well as those who did not. When the topic of needing to ask permission to work was discussed in Alejandra's interview, she replied that "yes" she had asked for permission even though she had an absent husband.

Nearly all interviews indicated that women interviewed and Guelavían women, in general, must ask husbands for permission to work, or that they would do so if they were in the position of needing to work. Only one woman, Luz, the 26year-old part-time employee of the municipio of Guelavía with an anchored husband, clarified that it was not permission that she asked of her husband in order to pursue an income-generating job, but instead, "fue un comentario que yo le hice. Yo le dije que a mi me gustaría trabajar." ( . . . it was a comment that I made to him. I told him that I would like to work.). Luz continued that she does what she wants to do and her work for the municipio was something that she chose to pursue. Although Luz spoke of the partnership of her relationship with her husband and of her independence, she, along with the majority of all women, spoke of her work being a help to the family, nothing more.

Luz's youth would appear to show generational differences in women's need to ask permission to work or, in some cases, even the need to ask permission to 
leave the home. Luz's marriage appeared to be one of more equality yet she appeared to have little help, if any, from her husband with housework. Luz had so little help that, in fact, she elaborated on the lighter domestic burden of women with absent husbands. Although her husband had never emigrated, she mentioned that a husband in the United States could result in considerably less domestic work.

Luz conveyed various conversations that she and her husband had had about emigration, women's work, and education. The conversations were described as being open, congenial, communicative, and with a level of equity and respect within the home. Luz appeared to have a much less submissive role in the household than the majority of Guelavían women.

On the other end of the spectrum, no woman of any age spoke of as unequal, submissive treatment within the home as did Erika, 17 years older than Luz. At one end of the spectrum could be Luz's comments of independence and telling her husband of her need and desire to work rather than needing permission to work or leave their home, with the other extreme as the emotional, convoluted, submissive treatment, experiences, and stories told by Erika, a mother of two young daughters with an anchored husband.

Erika's home was controlled by two residents: her husband and her motherin-law. Erika's life was dominated by the two adults in her home with Erika appearing to be as subordinated as any women that I spoke with in Guelavía. Erika elaborated on her husband and mother-in-law's control over her life, her decisions, and even her connection, or lack thereof, with her own family in a town several 
hours away. Erika's husband told her when and if she could visit her family, if she could work outside of the home, if she could leave the home and walk in the streets, and if she could have conversations with other women outside of her own home (men, of course, would not be discussed since that would be outside the realm of considering). During the interview, Erika recounted experiences with excessive emotion, animation, anxiety, and frustration. Her tears, emotional outbursts, and long-winded ramblings were met with compassion and empathy by Elysa, an acquaintance with whom Erika had agreed to be interviewed. The two women were fully cognizant of the submissive role that many wives play-including one currently, the other in the past by the husband who had left her 26 years earlieryet both conveyed an attitude of resignation and of irritated acceptance of this engendered role that women play.

A few months prior to the interview, Erika had come across an opportunity to sell doughnuts produced by in a nearby town. Multiple fights with both her husband and mother-in-law were provoked by Erika's absence from the home but even more so by her "unexplained wanderings in the street" as mentioned by Erika. Selling doughnuts requires "wandering the streets" to essentially sell doughnuts door-to-door. The continual fights forced Erica to give up the job and remain in the home.

Prior to the interview, an initial visit for survey gathering proved interesting as Erika's husband met my research assistant and me and appeared to attempt to control the conversation. This proved to be an important visit for both my research 
assistant and me to be present together. As Nohemí persisted in asking the survey questions, I was able to distract her husband from within earshot with questions about plants he had throughout the yard and construction materials he had usedanything to keep him away from the survey conversation with his wife. During our conversation, Erika's husband's complaints were numerous: losing his job in nearby Tlacolula due to his boss embezzling money from the government; spending more than half of his daily wage on transportation and food; and, the dire economic situation of his family.

From this researcher's perspective, the family's dire economic situation appeared to contradict his insistence that his wife not work outside of the home. Erika's husband wanted to retain spousal control and provide sustenance for his family while simultaneously controlling his wife-a task likely unmanageable if his wife were to be employed outside of the home. Erika maintained a small, minimallyor un-profitable store with very few products offered for sale. The family's financial situation became clearer with Erika's comment that the 20 or 30 pesos that she initially made selling doughnuts for a day was a big help for the family. Twenty or thirty pesos would, in fact, only buy a few avocados, a large bag of beans, one large box of generic cereal, or only one or two large garafones (large jugs) of drinking water. A help, yes, but such a minimal help that the effort and responsibility would be questionably worth the aggravation. But, with

Erika's husband also spoke of wanting to go to the United States-perhaps related to my being from the United States and an obvious U.S. citizen—although, 
financially, he had no chance of doing so. Erika's husband's dominant, controlling manner had limited the family's economic opportunities-he did not have work, he could not emigrate to the U.S., yet he would not allow his wife to work outside of the small store that she maintained, only occasionally opened, and likely generated minimal profit.

In the survey and interview data, generational differences do not appear to impact men's control over women's work decisions and strategies. Educational level, however, does appear to play a role-possibly the educational attainment of both the wife and the husband. It was rare to hear a woman with high school experience speak of a husband with excessive control. On the other hand, it was common to hear stories that related to a submissive wife role by women with five years of less of education. Erika had six years of education; her husband, just four, but women with considerably less years of education also spoke of a routine and persistent control that husbands have over women's labor choices.

Although women's experiences are not homogenous by generation, by husband's migration status, or by level of education, some generalizations can be made about women and work in San Juan Guelavía. As mentioned by several Guelavían women, when a husband is absent, women have a higher tendency to work for income. Secondly, if women work, it is out of necessity and is viewed as help for the family or as assistance to the husbands' dominant economic provider role rather than ever as fulfillment or self-actualization. This is, in large part, due to the low-skilled opportunities offered to women with little education as well as low 
wages paid for “women's" jobs. And third, men's dominance over women's decision making of working for income hinders women's economic opportunities and impedes potential independence. Most women recognized the independence that their own income did or would hypothetically generate, but low wages, high expenses, lack of help with domestic tasks, and men's right to control impedes the possibility of women working in most circumstances.

\section{Programs and Policies: A Help or Hurt?}

Government programs and policies also fail to achieve just wages for women in Oaxaca and specifically, in Guelavía. Women in Guelavía mentioned numerous government and NGO programs that had operated in Guelavía, all failing or moving to other locations. At the time of this project, there no government or non-profit programs operating that focused on women or women's work.

Three aspects appear to contribute to lack of success for income-generating programs and women. Government programs tend to begin early in a new Mexican president's term (which lasts for six years without the possibility of re-election). While new, large, high-profile programs that target income-generating activities are often liberally promoted through television, radio, and newspaper campaigns, Oaxacans rarely view these programs as they are often intended-short-term, startup assistance.

An example of a failed federal government start-up program is three weedfilled greenhouses on the outskirts of town. Multiple inquiries as to why the 
greenhouses were filled with weeds rather than functioning as their obviouslyintended purpose, every answer pertained to the greenhouses having been part of a government program that no longer existed. "The program ended," "After the program, there was no more money for seeds," and "I think they were built from a program that doesn't exist any longer" were common and continual replies.

Secondly, government and NGO programs tend to abide by, adhere to, and perpetuate gender norms by delivering services based on women's traditional work options rather than new opportunities. The most recent program to leave Guelavía was a women's embroidery program offered as a church-related project from a program in the city. The purpose was to teach women to embroider in order for them to generate income. The project helped perpetuate cultural limitations, problems in gendered-work opportunities, and lack of a vision of girls and women as contributing economic members of a household. Embroidery as an incomeproducing activity generates such a small profit that it has been abandoned by women in most communities.

Third, corruption impedes motivation, dedication, affiliation, and trust. INEA, Instituto Nacional Para La Educación de Los Adultos (National Institute for Adult Education), offered adult literacy courses during 2009 and 2010 in Guelavía. One woman commented on the beneficial offerings of the program but also commented on the overt corruption she had witnessed. Her role was to teach and tutor adults during her several months of required high school community social service. Her salary was determined by the number of students that passed their 
corresponding level of examination. She taught as well as tutored for several months. When the week of scheduled examinations arrived, she was suddenly and unexpectedly replaced by another instructor whom she later learned was a family member of the regional director. The reserved salary went to the replacement family staff member since she was the one who administered the exam.

None of the programs that have come and gone in Guelavía in recent years have focused on women living at lower socio-economic levels. None of the programs that were mentioned by Guelavíans target any specific group—none target only women nor "abandoned" women nor socio-economically disadvantaged men or women. None include programs related to the absence of a spouse. None reach women where they are and work to lift them up. And none offer workshops, courses, or challenge barriers of traditional careers and work for women. None offer opportunities for women in trades or construction that offer higher wages. Policies of many government agency programs or projects miss the opportunity to lift local residents above the poverty line-restoration of the San Juan Guelavía Catholic church is an unfortunate, yet typical, example.

The San Juan Guelavía Catholic church is the hub of many Guelavían families' lives. Weddings often take place in the church followed by three days of fiestas. Baptisms are an important symbol and time of passage for a young couple's children. Attending the numerous religious observances throughout the year is considered obligatory by the majority of families in Guelavía. The church was on the list of restoration projects for a collaborative project between the church, the state 
government, and the federal government. Imagined as a tourist attraction, the federal governmental project to restore the Guelavían church occurred slowly throughout most of 2010. While potentially serving as a slight draw for tourists to visit Guelavía, the project hired no local residents and had no female employees. Citing the need to use only experienced restorers-although the majority of the work appeared to be cleaning, removing, and replacing parts of the façade and the floor of the church—the government chose not to integrate the local community into a federal and state program as well as continuing the traditional gendered division of work where women would not be engaged in the types of better-paying positions required.

While the federally-funded Oportunidades (Opportunities) program is considered an education program rather than an economic program, the program does offer stable, reliable, albeit minimal economic assistance to families with children in K-12 education. Families receive a small bi-monthly subsidy with small increases as each child advances in school. Schools are required to monitor and report attendance of children enrolled in the program. Every woman interviewed acknowledged the economic assistance of Oportunidades as beneficial but they all added comments that the subsidy was too little--“... pero, de hecho, no alcanza” (... but, in fact, it does not reach [the money does not cover all expenses]) —even though the program is intended as a supplement not as income replacement. One interview participant, Veronica, conveyed her belief of the lack of motivation for women to work since they receive the small, direct subsidy from Oportunidades. She 
suspected that women often kept children in school solely for the subsidy through Oportunidades rather than dedication to educating their children. Other interview participants as well as women in casual conversations openly questioned why some families with larger homes - their primary way to judge the socio-economic level of other families in the community-were receiving Oportunidades subsidies when those families clearly (in these women's opinions) did not need it. 


\section{Chapter 6: Women, Education, and Male Migration}

\section{Introduction}

Male migration impacts women's worries and fears (including for women with anchored husbands), their burdens and responsibilities, and their work, but the impact of male migration on educational attainment is unclear. Little research on the topic of migration and education exists. Two dominant streams of the issue prevail: a small portion of remittances are reportedly used for educational expenses and, expectedly, used to keep children attending school at a higher rate and to advance educational attainment. Conversely, with husbands/fathers as the disciplinarians, a home with an absent father may be a home lacking discipline in children's educational achievement, attendance, and behaviors that may negatively impact success (Kandel \& Kao, 2001).

Attempting to correlate migration effects to children's educational performance is particularly challenging due to the following: 1 ) emigration is selfselective; 2) most often, families in the lowest and the highest socio-economic levels remain and do not migrate;46 3) parents prioritization of education cannot be properly controlled for; 4) opportunity costs cannot be easily calculated nor completely understood, analyzed, or realized; and 5) social networks—family members following other family members-strongly impacts and influences which families or which family members emigrate.

\footnotetext{
46 Those at the lowest level are unable to afford the estimated US\$3,000 to $\$ 5,000$ typical expense to cross the border with the assistance of a "coyote" and those in the higher socio-economic levels lack the economic need to emigrate.
} 
This case study of San Juan Guelavía provides four education-related findings. First, education is valued in Guelavía, as verbally expressed by women as well as indicated in a published article about the town, but only through $9^{\text {th }}$ grade and generally, not beyond. Educational opportunities at the high school level are minimally valued even though readily available and, in general, lack respect in the community.

Second, educational deficiency is generational. Mexico's emphasis on basic education completion since the passage of the 1993 General Education Law has significantly raised grade level completion of the 35 and under generation and has narrowed the gender gap of formal education levels of completion.

Third, school attendance through $9^{\text {th }}$ grade (basic education) is minimally impacted by opportunity costs-namely, the opportunity to work in lieu of school attendance. The impact of remittances may have a minimal impact on children staying in school at levels beyond $9^{\text {th }}$ grade but the impact is minimal and may be offset by the absence of the father in the home and the mother playing both parental roles.

Fourth, women's worries and fears of the confluence of advanced education (beyond $9^{\text {th }}$ grade), the negative societal influences of life outside of Guelavían boundaries, and the need or desire for girls to marry are confrontations to girls' educational attainment. These four challenges do not appear to be positively nor negatively correlated with male migration. Each of these four areas is addressed in 
this chapter with an initial discussion of the educational opportunities offered in Guelavía.

\section{Education in San Juan Guelavía}

Education is readily accessible in San Juan Guelavía; a major contracts to the several thousand small pueblos throughout the state of Oaxaca. Guelavía has a public elementary, middle, and high school as well as access to other public and private K-12 schools in nearby Tlacolula and in the city of Oaxaca. The prevalence of educational opportunities offers Guelavían families options-public school locally, public school just outside of the city, or the much-higher-cost private school option. Speaking from an economically rational position, most Guelavían families have but one feasible option—public school within Guelavía. Public school in Guelavía eliminates the high cost of private or public transportation, food expenses while away, and costs of tuition for private school.

Educación básica (basic education), defined by the Mexican federal government, comprises three levels of schooling: three years of pre-escolar (pre-

school), typically ages 4 through 6; six years of primaria (primary or elementary school), typically ages 7 through 12; and three years of secundaria (secondary or U.S. equivalent of $7^{\text {th }}, 8^{\text {th }}$, and $9^{\text {th }}$ grades), ages 13 to 15 (Plan de Estudios 2011: Educácion Básica, 2011). Since the 1993 General Education Law, Mexican parents have had the responsibility to send their children to school and their children have had the right to attend school through the $9^{\text {th }}$ grade, "basic" education. 
The 1993 General Education Law has impacted educational attainment levels for adults and children of approximate age 30 and younger.

Guelavía has public schools at each of the three obligatory levels as well as a public high school. The pre-school and the elementary school are well attended. The survey data show no loss of students to other public or private schools in the surrounding area. One hundred percent of families surveyed with children from ages 4 through 12 send their children to school; all were attending Guelavía public schools.

Attendance at the middle school level is slightly less. Survey data of the 71 homes in Guelavía revealed that two shifts occur as children pass from elementary school to middle school: 1) A small percentage of children do not continue from elementary school into middle school; and 2) A significant percentage of parents send their children to schools outside of Guelavía for middle school. Both shifts are considerably more pronounced when children finish middle school and move to high school. These significant shifts contrast with women's repeated emphasis of the high value that they place on their children's education.

\section{Middle School Heightened Risks and Education Value Revealed}

Guelavían early teens $d o$ attend school—thus, to some extent, validating women's high-referenced value placed on education. Just 7 percent of middle school age children, 13 to 15 year olds, were not enrolled in school with an additional 8 percent still attending elementary school instead of middle school, putting them 
below grade level and at risk for potential drop out. Although required by the federal government, middle school appears to be a divergent period for families, a time when children and parents are deciding if high school—accessible, but optional—is feasible, valuable, worthwhile, and/or achievable.

By the time one child hit middle school, one family had already either decided or accepted that middle school was not the path for their son. Trini, the mother of a 15 year old not enrolled in school, even though required by law through $9^{\text {th }}$ grade (age 15, possibly 16 ), has a family of three sons-ages 13,15 , and $20-$ with three more adult children-ages 23, 28, and 30-living in the United States. Trini married at age 15 , had a $1^{\text {st }}$ grade education, and spoke during the survey of dedicating herself to domestic chores and not generating income. Trini's husband, a farmer and basketweaver, married at age 20 , and has a $6^{\text {th }}$ grade education. He had been in the United States from 1991 until 2008 when he decided, due to lack of work, to return to Guelavía.

Trini spoke of her husband's departure from Guelavía as a means of lifting the family out of poverty with the small remittances received used first, according to Trini, for food and sustenance of the family, and second, for education. While the first priority may have been met, it appeared that the second was not fully realized. Trini's two older boys had completed $6^{\text {th }}$ grade but failed to continue on to middle school even though $9^{\text {th }}$ grade was federally mandated. Trini's 13 year old was attending his first year of middle school, possibly breaking the cycle. Surprisingly, Trini also revealed that neither of the two older boys, ages 15 and 20 and both living 
at home, worked for income, thus questioning the assumption that school dropout is accompanied by working to provide income for the family.

Trini responded to the question of the level of importance of education for their sons and for their daughters as did nearly all other women—as a " 1 " on a 1 to 5 scale, representing education as "very important." Of 71 responses, 95 percent of women offered their opinion of the priority of education as "very important" for their child or children. It must be recognized that I, as the researcher, am a white, U.S.-born, middle-aged, American Ph.D. student who was introduced by her Guelavían research assistant as a college professor. Although the majority of women had little or no understanding of a tesis doctoral (dissertation), doctorado (doctorate), or investigaciones (research), the notion that education was very highly valued to this researcher was obvious by the fact that I teach and was silently but readily communicated to women. It would have been unusual as well as considered somewhat disrespectful to offer any opinion of education other "very important."

While Trini's response that she highly valued education for her three boys tended to contrast with the fact that her 15 year old was not attending middle school even though it was required and her 20 year old had finished only $6^{\text {th }}$ grade, her comments explained more of the story. With Trini's three older children living in the United States, she saw the path for her boys as one of emigration rather than education. She had a goal for her youngest son to complete high school but saw the likelihood of all three emigrating as a viable and realistic option-a stark contrast to the majority of mothers, nearly all of whom commented on their desire to keep their 
children in Guelavía. Trini's comments about the challenges of keeping the boys in school when they fought against remaining in the educational system showed the struggles that mothers confront in disciplining children-a role typical of fathers. Trini's husband returned to Guelavía in 2008 after 17 years in the United States. While away, he sent only small remittance amounts while simultaneously missing the disciplinarian role of a traditional Mexican father.

The vast majority of 13 to 15 year olds, 93 percent, were attending school at the time of surveys in 2010. The shift for families from elementary to middle school does not necessarily impact if their children will attend school through the required $9^{\text {th }}$ grade but instead, where they will attend is the pertinent question. Surveys showed that all elementary-age children attended the local public elementary school. But when families are preparing for their children to move from elementary school to middle school, they look at opportunities outside the confines of Guelavía.

Children moving out of the Guelavía public schools to schools in Oaxaca and Tlacolula is evident as children move into $7^{\text {th }}$ grade, the first year of middle school. One hundred percent of elementary-age children in surveyed families attended the local school but attendance at the local middle school falls to 50 percent; 42.8 percent attended schools in Oaxaca or Tlacolula and 7.1 percent did not attend school.

Middle school attendance in Guelavía is differentiated by gender: 60 percent of girls attended schools outside of Guelavía while just 33 percent of boys attended schools outside of the pueblo. The high percentage of families that choose to send 
their girls, primarily, to schools outside of Guelavía for middle school is an indication of a family's eventual rejection of the local high school.

The trend of losing children from the Guelavía public school system in the transition from elementary to middle school is problematic due to families with resources having options while many families do not. More disruptive, disheartening, and discouraging to mothers' supposed value placed on education is the high dropout rate from middle school to high school, discussed in the following section.

\section{Teens and the San Juan Guelavía Bachillerato}

The presence of a publically-funded high school in a pueblo the size of Guelavía is unusual in the state of Oaxaca. The Centro de Bachillerato Tecnológico y Agropecuario (Technological and Agricultural/Livestock High School), known as CBTA, opened in Guelavía in 2001. CBTA offers an agricultural curriculum as its primary focus, with a lesser-emphasized computer curriculum, as well. In the first five years, CBTA had an average incoming class size of 33, with an average graduating class of 21 three years later (Zafra \& López-Rocha, January-April, 2009).

In recent years, as mentioned by a teacher as well as seperately by an administrator (personal communication, July 2009), graduation rates have declined. Teachers and administrators' primary concerns centered on the low proportion of students from Guelavía even though the high school is located in Guelavía. Slightly less than one-third of attending students lived in Guelavía (Administrator, personal 
communication, July 2009) with the other two-thirds attending from surrounding small towns. While Zafra and López-Rocha (January-April, 2009) comment that administrators consider the main causes of student dropout as "reprobación, migración y económicas" (failing grades, migration, and economic challenges) (p. 137), both the teacher and administrator, in separate, unrelated conversations, communicated the lack of motivation as well as lack of emphasis and priority on education, in general, of Guelavía. Findings follow that tend to corroborates this view.

Seven percent of 13-15 years olds were not enrolled in school; however, the percentage of teens not attending high school is substantially higher. Nearly threequarters, 71.4 percent, of 16-18 year olds in surveyed Guelavían families were not attending nor enrolled in any school.

The trend of girls attending school outside of Guelavía that begins in middle school advances considerably once girls hit high school. Of the 16 to 18 year old girls in surveyed families that were attending high school, 71 percent were attending schools outside of Guelavía whereas just 7 percent of boys were attending schools outside of Guelavía. More striking, however, is the difference between children attending and children not attending. Twenty-nine percent of girls age 16 to 18 were not attending any school, while 71 percent of boys were not attending as shown below: 
Table 8: Educational Attainment by Age of Teen Boys and Girls, May 2010

\begin{tabular}{|l|c|c|c|c|c|c|c|c|}
\cline { 2 - 10 } & \multicolumn{4}{c|}{ Ages 12/13 to 15/16 } & \multicolumn{4}{c|}{ Ages 16 to 18 } \\
\cline { 2 - 10 } & \multicolumn{2}{c|}{ Girls } & \multicolumn{2}{c|}{ Boys } & \multicolumn{2}{c|}{ Girls } & \multicolumn{2}{c|}{ Boys } \\
\cline { 2 - 9 } \multicolumn{1}{c|}{} & $\#$ & $\%$ & $\#$ & $\%$ & $\#$ & $\%$ & $\#$ & $\% *$ \\
\hline $\begin{array}{l}\text { Guelavía public } \\
\text { school }\end{array}$ & 2 of 5 & $\mathbf{4 0 \%}$ & 5 of 9 & $\mathbf{5 6 \%}$ & 0 & & 3 of 14 & $\mathbf{2 1 \%}$ \\
\hline Private school & 3 of 5 & $\mathbf{6 0 \%}$ & 3 of 9 & $\mathbf{3 3 \%}$ & 5 of 7 & $\mathbf{7 1 \%}$ & 1 of 14 & $\mathbf{7 \%}$ \\
\hline Not attending & 0 & & 1 of 9 & $\mathbf{1 1 \%}$ & 2 or 7 & $\mathbf{2 9 \%}$ & $\begin{array}{c}10 \text { of } \\
14\end{array}$ & $\mathbf{7 1 \%}$ \\
\hline
\end{tabular}

Source: Author's survey

* Due to rounding the figures are slightly less than $100 \%$

When looking at 13-18 year olds as one data point, the overall trend is notable and obvious-boys are not attending school; girls are not only attending school, they or their families are choosing schools outside of Guelavía that require expenses that would not be part of attendance at CBTA.

Figure 9: School Attendance of Boys/Girls Ages 13-18, May 2010

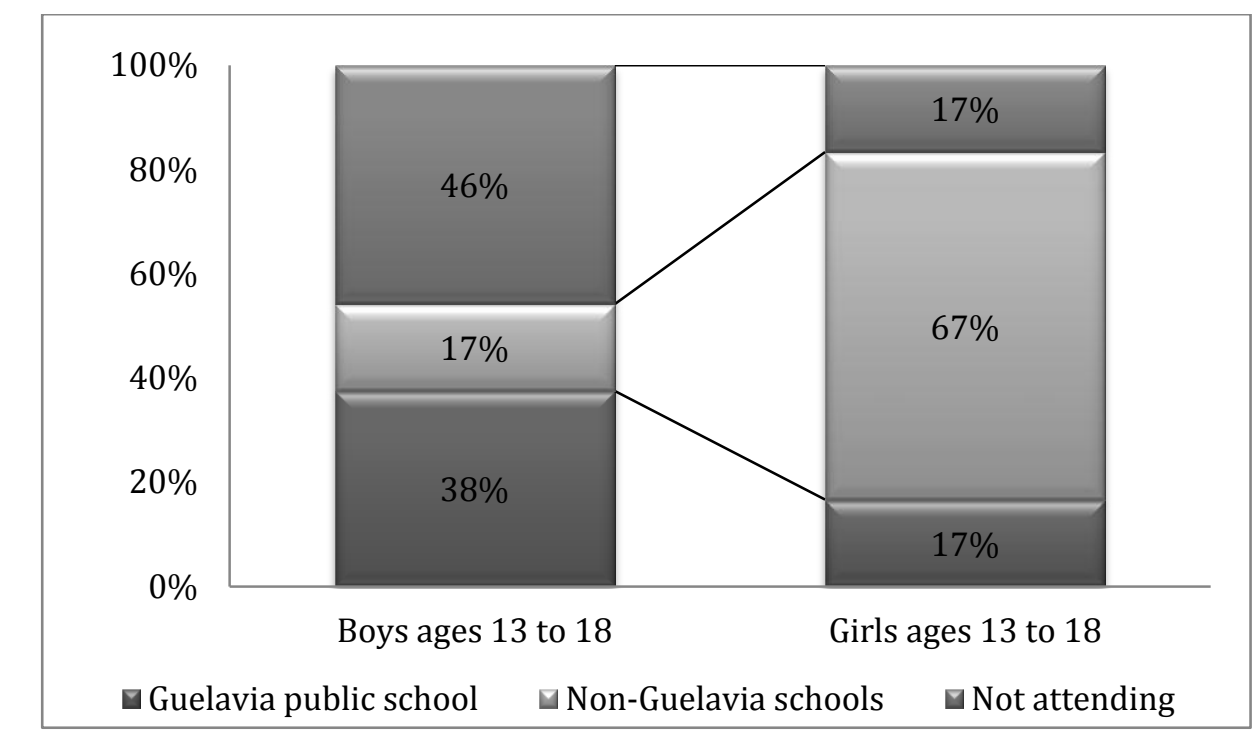

Source: Author's survey 
In association with the comments of the high school teacher and administrator, just 14 percent of 16 to 18 year olds from surveyed families were attending CBTA-exceedingly low for a small pueblo fortunate enough to have a public high school. The lack of interest relates to the curriculum. Several surveyed mothers commented on the lack of interest in the community of the agriculturebased program of CBTA. The organic, contemporary, research-proven planting, growing, harvesting, and farming methods offered by the high school are not valued by the majority of Guelavían families. The advanced-level farming curriculum has not infiltrated the larger Guelavían community in any positive way. Guelavían families view farming as their past. They fail to see farming—even with advanced, researched, newer methods-as their future. There was never an occasion that anyone spoke of the CBTA curriculum as offering potential as a future economic livelihood for anyone in the community. If women value education as clearly and as emphatically stated in their survey comments, they clearly do not value CBTA. The lack of support of the high school agriculture curriculum was discussed by all of the interview participants as well as mentioned in many survey comments.

Men are primarily self-employed in agriculture while very few women derive self-employment from agriculture (Pagán \& Sanchez, 2000). Survey data for this research project found no women professing campesina (farmer) as their occupation. An agricultural curriculum is not going to advance girls' opportunities for securing a regular wage-generating income since agriculture work is low-paying, requires little or no education, and contradicts the social norms of women's proper 
place in society. Additionally, farming as self-employment for women is a very unattractive, even unthinkable, option for women. CBTA's curriculum does not benefit girls in wage salary opportunities nor in self-employment and pushes girls out of post-secondary education entirely or, at the least, into private school options outside of Guelavía thus creating self-selection due to the expenses of transportation, time away from home, and additional expenses required for private school programs.

The factors related to low high school attendance at CBTA offered by Zafra and López-Rocha (January-April, 2009)—failing grades, migration, and economic challenges-likely have some impact on the low attendance rates by Guelavían teens, but the problems and challenges are deeper, more extensive, and primarily cultural. The primary factors related to low high school attendance at CBTA contradict proper gender norms. When women were asked, in both surveys and interviews, for their personal comments about CBTA, their view of the community's perception of the school, and their opinions as to why enrollment by teens from Guelavía is so low, all responses focused on the curriculum and the community's negative perception of the low quality of education delivered. None of the women commented on failing grades, on migration, or on economic challenges as the primary deterants to enrollment at CBTA.

The significant population of teens that are not attending any high school points to a larger societal and/or cultural issue in relation to Guelavía and education. Opportunity cost of educational attainment appears to play only a 
minimal role. Just 46 percent of 13 to 18 year old children of surveyed women that were not attending school were working. Women also responded that most of the 13 to 18 year olds that were working, were working in farming. To be a campesino in Guelavía implies the production of food for the family and working on a family's own land instead of for income. While both may occur in sync, production for sustenance of the family is much more common in Guelavía. The majority of the 13 to 18 year olds that were noted as campesinos would have been fulfilling that role even if they were enrolled in school. The social and community norms play a much more significant role in children lacking post-secondary education rather than the opportunity cost of income generation.

\section{Why Guelavían Teens Do Not Attend High School}

Findings from interviews, open-ended survey questions, informal conversations, attendance figures, and interviews with school personnel conflicted with women's stated priority of education for their children. On a 5-point Likert scale, women rated prioritization of education for their daughters at 1.03, "very important" with 1.2 for sons. Using qualitative data to assess prioritization, three findings stood out: 1) Guelavíans emphasize early marriage for their daughters, most often with Guelavían boys, 2) Mothers, specifically, desire to keep their daughters within the community and away from negative influences of the city, and

3) Guelavíans distrust of the value of the agricultural curriculum offered at CBTA, the local, public high school. 
These three findings cause challenges for girls and educational attainment. First, for most Mexican girls, marriage is an alternative to advanced education. Girls tend to marry by age 20, thus forgoing educational levels beyond high school. Secondly, Guelavía is located close enough to the city, an approximate 45-minute drive, but is separated and considered fairly isolated by many Guelavíans. The rural setting close to an urban hub offers knowledge of the city with associated concerns and fears. Comments are commonly heard about the negative influences of the city and strive to keep their daughters in the community so as not to engage in drinking, drugs, gangs, and promiscuity. Third, with an agricultural focus of the local public high school, girls are not actively engaged in school attainment beyond middle school unless parents have the resources to send them to private school outside of Guelavía.

Every woman interviewed commented on the lack of dedication and motivation of most parents to keep their children in school and/or engaged in school. Additionally, every woman interviewed commented on the importance that parents place on their daughters marrying, often at a fairly early age. Many women stated that marriage will keep their daughters in Guelavía and away from the negative influences of the city.

“... hay personas que lo prioritario es que se casen y todo y que tengan hijos" (... there are people that the priority is that they [girls] marry and have children)

“... aquí tenemos la idea de que te casas y ya no tenemos que ver nada en tu vida" (... here we have the idea that you marry and then we do not have to see anything in your life) 
“... ya no estudian, porque aquí dicen que de todas maneras se van a casar. Luego dicen ya no estudies." (... they do not study because here they say, in whatever way, they're going to get married. Next, they say they are no longer going to study.)

One research assistant commented shortly after survey data gathering on the hypocrisy of women's responses on education in comparison to the reality that she'd experienced while growing up in Guelavía. She commented on the impact of the researcher on the research. Paraphrasing, she offered: "We introduce you as a teacher, that you're doing research, that you're in a university program, you're from the U.S., you're white-you're all about education. That's the only reason they say education is a 1 out of 5 . They don't live that way, though."

\section{Migration and Education}

For the sake of this research, it would be beneficial to categorize the effect of male migration (father's absence) on the education of children. Numerous challenges arise in that attempt (some mentioned previously)—socio-economic level of the family, education of the parents, involvement of the father, presence of the father, devotion to education by the parents, remittances received if the father is absent from the home, remittances devoted to education if money does arriveamong numerous others. Survey and interview data, however, do suggest a few trends-understood within the context of the complexity of male migration. 
From survey data of families with children ages 13 to 18 , the likelihood of children's educational attainment is greatest in homes with absent fathers, followed by homes with anchored fathers, as shown below:

Figure 10: School Attendance of Children Ages 13-18, May 2010, by Father's Migration Status

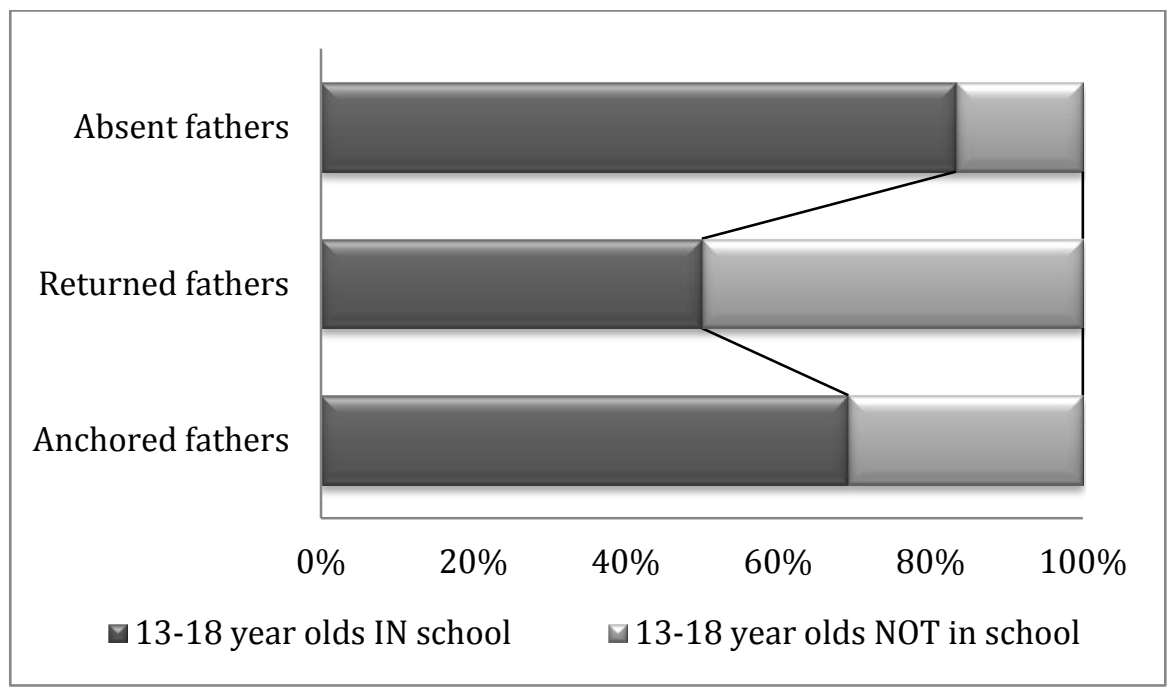

Source: Author's survey

While this data may suggest the possibility that homes with absent fathers receive remittances used for education expenses or to displace the need for children to work instead of attend school, it is important to remember that one-third of these homes have absent husbands/fathers who have lost contact, do not send remittances, and, therefore, have no father in the home as well as no economic support. Twenty percent of homes with absent fathers that include children ages 13 to 18 have children who are not attending school but do receive remittances. Conversely, several homes with parents with little education, a mother who does not work, and a father working in or around Guelavía have children that attend private school in the city. 
The distribution of 13 to 18 year olds who attend schools outside of Guelavía crosses the spectrum of homes-homes with absent fathers, returned fathers, inhome fathers, and even a 16 year old without a father living with her single mother and widowed grandmother. Children ages 13 to 18 that attend the Guelavía middle school and high school also come from all types of homes. There is little to suggest a correlation between fathers in the home, remittances coming into the home, and where children attend school. Children ages 13 to 18 that were not enrolled in school but were, instead, working for income also shows lack of correlation with homes with absent or present fathers and remittances. Emigration status of the father/husband plays a minimal, if any, role in children's educational attainment, where they attend school, and if they choose work over school.

\section{Education, Migration, and Deficiency}

The Consejo Nacional de Evaluación de la Politica Social (CONEVAL) (National Council for the Evaluation of Social Development Policy ${ }^{47}$ uses two indicators for measurement of deficiency in education: 1) population of 6 to 14 year olds not attending school, and 2) population of age 15 and over with less than $9^{\text {th }}$ grade completion (less than "basic education").

To accommodate two years of implementation of the 1993 General Education Law, it can be assumed that a Guelavían citizen born in 1980 or later (thus, age 15, finishing middle school, approximately two years after passage of the law) would be

${ }^{47}$ CONEVAL is a Mexican federal agency tasked with generating "objective information on the social political situation and poverty measurement in Mexico, allowing better decision making in the matter." See www.coneval.gob.mx/cmsconeval/rw/pages/quienessomos/index.en.do. 
considered "deficient" with less than Mexico's "basic education" (9th grade). Nearly all children ages 4 through 15 in surveyed families, 98 percent, were attending school. The 2 percent of children not enrolled is considerably lower than CONEVAL's data of 8.5 percent of 6 to 14 year olds not attending school (Consejo Nacional de Evaluación de la Politica Social, 2010). Data gathering methods, selfreport conflicts, and/or timing may play a part in the data discrepancy.

The more substantial finding of the survey data is the high rate of 15 to 30 year olds who are educationally deficient. Survey data show that Guelavía children are attending school through the $9^{\text {th }}$ grade irrespective of fathers' presence in the home and/or the receipt of remittances. The larger concern in regard to children's education is the high dropout rate prior to basic education completion by 15 to 30 year olds. Prior to the reforms of the 1993 General Education Law, education at all levels was limited with access in rural communities severely limited. Guelavía is no exception.

Survey data showed that of the 69 residents ages 15 to 30, 28 residents, 41 percent, had not completed basic education, $9^{\text {th }}$ grade. Educational deficiency was also calculated by husbands' migration status as well as two homes without fathers as shown below: 
Table 9: Educational Deficiency for Guelavíans Age 15-30, May 2010

\begin{tabular}{|l|c|c|c|c|}
\cline { 2 - 5 } \multicolumn{1}{c|}{} & \multicolumn{2}{c|}{$\begin{array}{c}\text { With 9th Grade } \\
\text { Educational Attainment }\end{array}$} & \multicolumn{2}{c|}{$\begin{array}{c}\text { Without 9th Grade } \\
\text { Educational Attainment }\end{array}$} \\
\cline { 2 - 5 } & $\#$ & $\mathbf{\%}$ & $\#$ & $\mathbf{\%}$ \\
\hline Homes with absent fathers & 9 of 9 & $\mathbf{1 0 0 \%}$ & 0 of 9 & $\mathbf{0 \%}$ \\
\hline Homes with returned fathers & 14 of 30 & $\mathbf{4 7 \%}$ & 16 of 30 & $\mathbf{5 3 \%}$ \\
\hline Homes with anchored fathers & 16 of 28 & $\mathbf{5 7 \%}$ & 12 of 28 & $\mathbf{4 3 \%}$ \\
\hline Homes without a father & 2 of 2 & $\mathbf{1 0 0 \%}$ & 0 of 2 & $\mathbf{0 \%}$ \\
\hline
\end{tabular}

Source: Author's survey

The data show a relationship between educational attainment and absent

fathers. The assumption would be that remittances are used either for the expenses endured even in a public education setting or that remittances may be used for daily sustenance in lieu of children having to work. A small sample set, adult children living in the United States that the survey did not capture, and homes with longterm absent fathers that have failed to remit cautions against that.

Of families with absent spouses, 33 percent had children living in the U.S., the majority in their mid- to late-20s. Thirty-two percent of families with returned spouses had children living in the U.S.-also, the majority in their mid- to late-20s. Although it is not possible to measure the impact of migration as an alternative to advanced levels of education for the families that have left Guelavía, it does appear that children living in the U.S. with parents in Guelavía are older than school age. While school administrators may believe that migration plays a role in lack of educational motivation and attainment (as cited by Zafra and López-Rocha [January- 
April, 2009]) or possibly interpreted as such by the authors, there is little evidence to support this in this research project. Survey data, interviews, or casual conversations or observation failed to support this assertion.

Opportunity costs of children participating in the workforce for income for the family rather than attending school appears to have only minimal impact on surveyed Guelavían families. Forty-two families had children age 20 and under. Only eight of those 42 families, just 19 percent, had children that worked instead of attending school-with seven of those eight at ages 17 to 20 . Only one of all children ages 16 and under was working rather than attending school—and that son had attended school through the $6^{\text {th }}$ grade but at age 16 , was working as a campesino rather than attending school. Children in Guelavía attend school at a high rateparents appear to value education over the opportunity of children earning income or working for family sustenance—at least through middle school.

In asking women's opinion of the probability that their daughters or sons would emigrate, women do not envision emigration as a strategy nor viable option for their children. On a 1 (very probable) to 5 (not probable) scale, the responses were nearly identical for both daughters and sons at 4.4 and 4.3, respectively. Eighty-four percent choose "not probable-5" or "little probability-4" for their daughters' potential emigration; 79 percent for sons. Several mothers who chose "not probable-5" responded that crossing the border was too costly, too difficult, or too dangerous. Several women commented that they viewed education as an alternative to emigration: 
... education was important "para tener opciones de trabajo y evitar la emigración" (to have options for work [a job] and to avoid emigration

How likely is emigration? “... depende de la educación que le estoy dando" (depending on the education that we give her)

“... darle educación para que tenga un trabajo y se quede aquí en Mexico" (... provide him education so that he has a job and will stay here in Mexico).

A few mothers were adamant that their daughters and sons will not emigrate whether their choice or the choice of the parents: “... el no quiere ir" (he doesn't want to go) and "aquí tiene todo lo que necesita" (here he has everything that he needs).

All of the mothers that chose the other end of the five-point range, "very probable-1" that their children would emigrate, commented that their children were born in the U.S., "tienen papeles" (they have "papers" meaning they would be legal and documented), or that they have family in the United States. A few mothers also acknowledged the reality of their children's potential departure: “... puede ser, possible" (it could be possible); "depende de que decisiónes tome cuando ya sea grande" (depending on decisions that he makes when he is older). The distribution of responses was fairly equally spread across homes with absent fathers, returned fathers, and never-left fathers. There appears to be little connection between husband/fathers' migration status, children's education, children working instead of attending school, or potential for emigration - at least from the woman of the home's view. 


\section{Gender Norms, Marriage, and Education}

Even though the 1993 General Education Law appeared to have little impact on nearly half of the 30 and under population as shown by the 41 percent that did not finished the required basic education, average grade level completion has increased substantially with age. Women surveyed averaged 5.3 years; their husbands, 6.5 years-a 19 percent difference. Not only has average grade level risen significantly by age, the gap between men's and women's average grade completion has also narrowed:

\section{Figure 11: Average Educational Attainment of Men and Women} by Age Category, May 2010

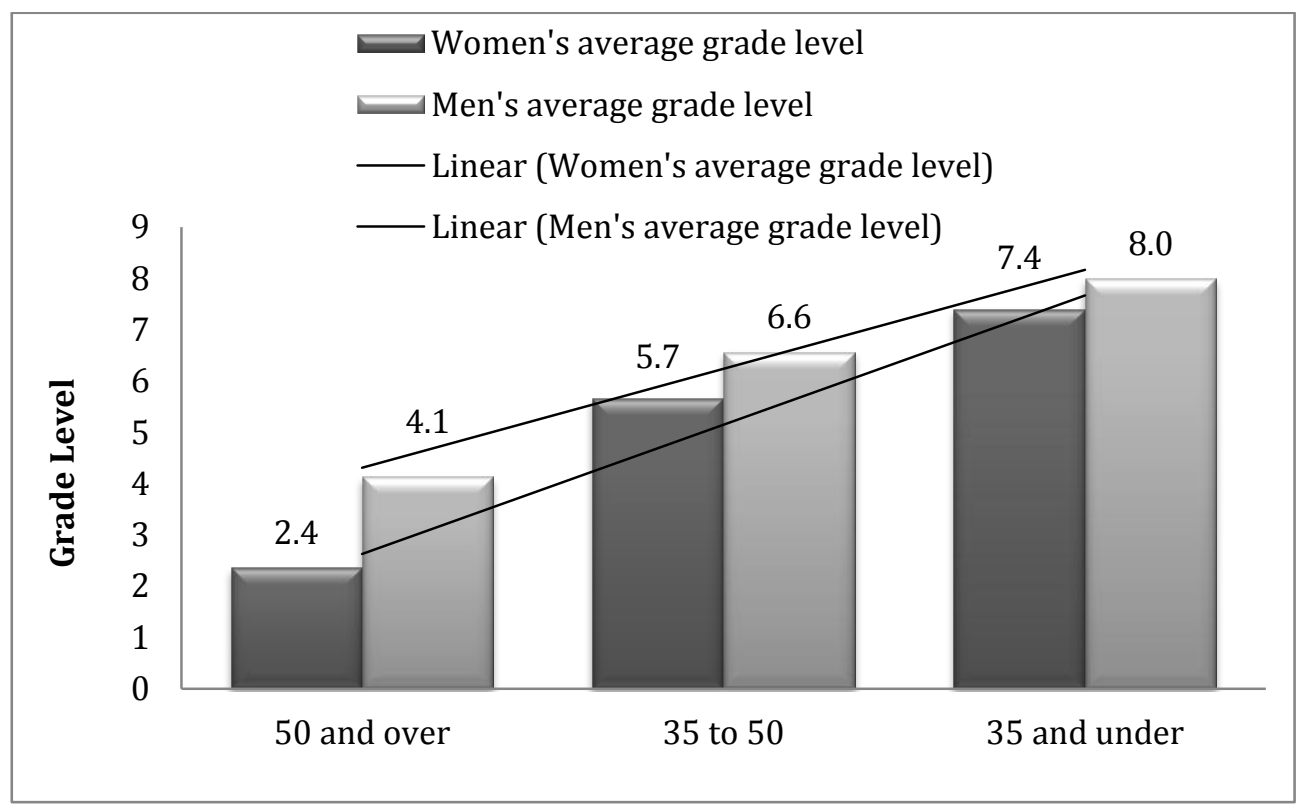

Source: Author's survey

The difference in average education level for women age 50 and over in

relation to men of similar age shows a 43 percent difference. For women ages 35 to 50 the difference drops to 14 percent with just 7 percent for women under age 35 . 
Girls, however, deal with gender norms that impact their education that boys do not. Every woman interviewed spoke of the pressure and expectation for girls to marry, most often expected in their late teens or early twenties. Women want a combination of four things for their daughters: education through basic education and possibly into high school; marriage; a stable job or career that supplements the family income; and residence that continues in Guelavía and not in the city.

The average age of marriage of all surveyed women was 20.8 years, men, 24.7 years. The differentiation among age categories of average age at marriage showed rather surprising results and shown below:

Figure 12: Women's Average Age at Marriage

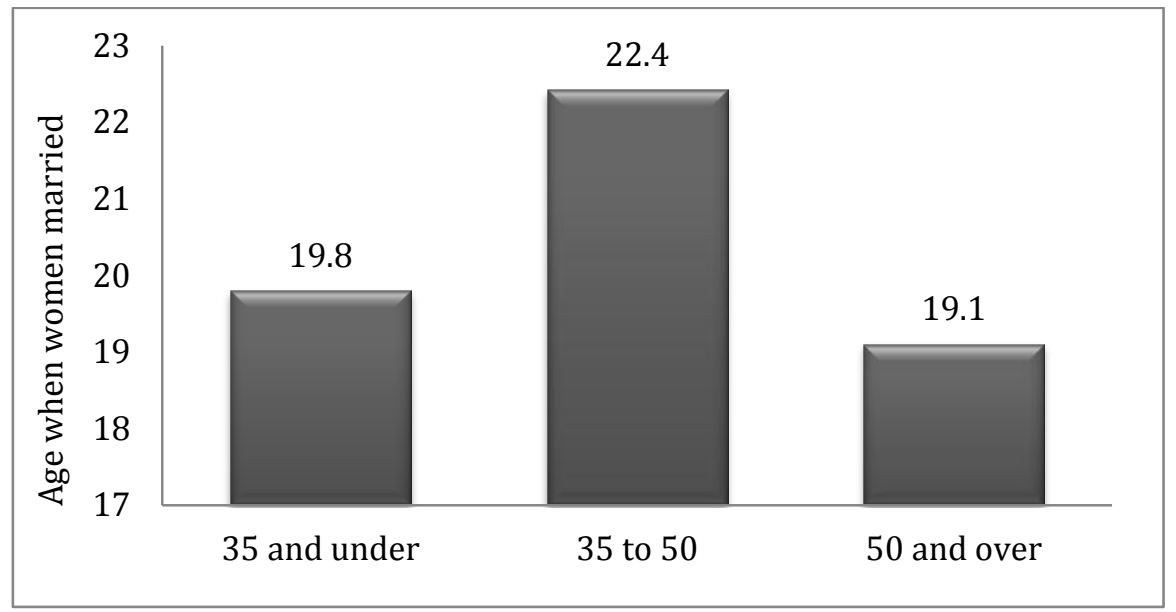

Source: Author's survey, May 2010

The shift in average age of marriage from 19.1 years for women ages 50 and over to 22.4 years for women 35 to 50 is not surprising due to generational differences in gender expectations, higher levels of educational attainment, and shifts in gender norms. That women in the 35 and under category married at an age of two-and-onehalf years earlier than women ages 35 to 50 is surprising. It is unclear why the trend 
of later average age at marriage since the same shifts in educational attainment and gender norms continued from the middle age category to the younger generation. Age that men married was slightly older but similarly differentiated by age at 24 years for 35 and under (women's age category), 26 years for 35 to 50 year olds, and 23 years for women in the 50 and over category.

The abundant array of comments during surveys, interviews, and casual conversation of girls' early marriage in Guelavía—often in lieu of advanced educational attainment—appears supported by the data. While education level has risen substantially by age, age at marriage has changed little and is two-and-one-half years younger for women 35 and under than for women ages 35 to 50. Education through $9^{\text {th }}$ grade is now routine and expected of girls and high school is more common than it has ever been in the past, but beyond high school, girls choose marriage rather than higher levels of educational attainment. It appears that generation still has little impact. Only one of 71 women surveyed, just 1.4 percent, had attended school beyond high school graduation. This woman had completed two years beyond high school and was working as a merchant in Guelavía. With a much higher percentage of girls enrolled in high school, it is possible that more than 1.4 percent will continue on beyond high school.

Higher levels of education for girls equates to a later age at marriage (Cohen, 2004; Hellman, 2008; Hirsch, 2003; Howell, 1999), both in rural and urban Mexico, is only minimally supported by survey data. Women ages 35 and under married at age 20 irrespective of their level of education. With women age 50 and over, none 
had more than elementary school and were married at a slightly younger age than women 35 and under. Only surveyed women ages 35 to 50 showed a correlation between higher levels of education attainment and delayed marriage as shown below:

Figure 13: Women's Education and Average Age of Marriage

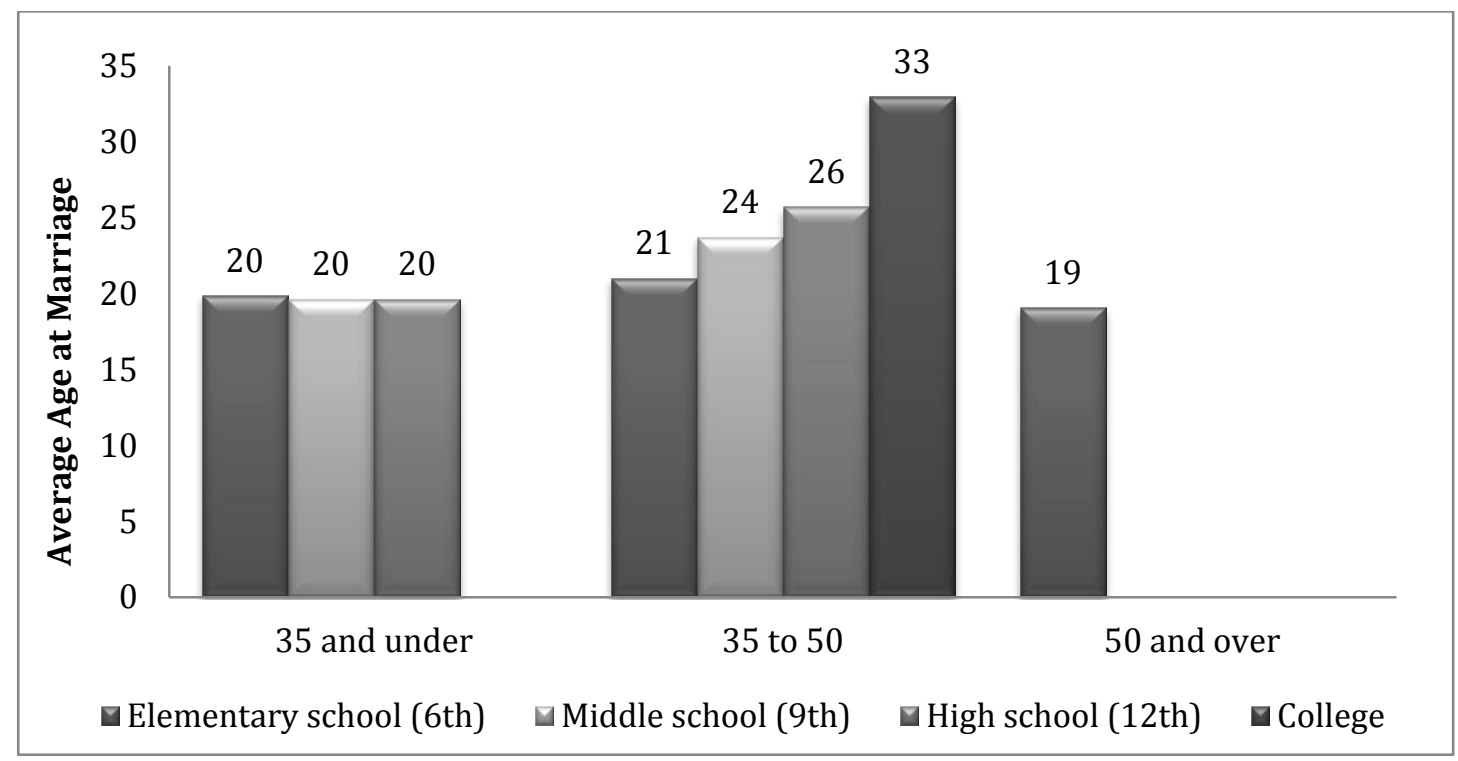

Source: Author's survey, May 2010

Survey data, women's comments in interviews and surveys, and conversations show that women prioritize marriage, motherhood, and possibly a following priority, education, for their daughters. Women want both their sons and their daughters to marry; however, women's comments as to why differed by gender. Women want their sons to marry for two reasons: to have a family and to keep them near (inferring their desire that their sons not emigrate nor even leave Guelavía). Women also mentioned their sons' responsibility to take care of a wife- 
acknowledging the pressure and responsibility that accompanies men's economic role in Mexican gendered society.

Women's responses of what they want for their daughters differed from what they want for their sons. For their daughters, women want a myriad of outcomes-a daughter who marries, who does not spend her adult life alone, has children and a home of her own, and a husband that does not emigrate.

Every woman interviewed spoke of the societal norm of girls and early marriage. High school and/or college (or carreras cortas) ${ }^{48}$ are the opportunity cost lost for girls that marry at an average age of just under 20 years of age. Veronica articulated the general comments offered by every woman interviewed: “... las obligan a casarse" (daughters are obligated to marry). In regard to whose responsibility it is to emphasize education and see that children are enrolled, Veronica added:

... los padres que se lo van transmitiendo a los hijos esa idea de que te casa, se te hace una gran fiesta. Esa es la realización máxima para ellas aquí.

... parents transmit these ideas [the importance of marriage] to their children and then they have a large party. This is the maximum realization for parents here.

The social status-securing wedding and three day fiesta is so important that Belem's then-boyfriend crossed the U.S. border and spent one full year working and saving money used exclusively for their wedding back in Guelavía. As mentioned prior, Belem was the only woman with a husband

\footnotetext{
${ }^{48}$ See Howell (1999) for more information on carreras cortas (short careers-shorter training careers such as secretarial).
} 
who had previously been in the U.S. that had plans to return. Belem, age 20 at the time of the survey, had married at age 16, had just 6 years of formal education, and had two young children. Her husband, with six years of education, was one of the few men or women that verbally acknowledged that his family's future would include a transborder relationship without an anchored father.

In general, parents choose marriage over education for their daughters with many daughters following the path emphasized and set by their parents. Mothers who send their daughters to schools in Tlacolula or Oaxaca know that their daughters have potential to be corrupted by drugs, alcohol, and the negative influences of the city. Women routinely articulated the negative influences that await young girls who leave the community and for this reason, many women find themselves ambivalent about their daughter's education beyond basic education. Women must decide: 1) send their daughters to a school they respect—-thus, not CBTA—and risk the negative influences impacting their daughters; 2) keep their daughters in Guelavía in a school with a curriculum that no female values (farming); or 3) encourage marriage as an "out" to the education dilemma thus avoiding the high cost, potential negative influences, and possibility of disconnect or remote geography from family that educational attainment could create.

Girls are caught; mothers are caught. Educational policies that have created educación básica (basic education) have created a shrinking gap 
between boys' and girls' average grade level attainment so much so that it appears that girls' average level of education will equal boys' within 10 years. But the federal and state education system and policies within that situated a high school with a male-oriented curriculum, at least from Guelavíans' perspective, continue to hamper girls' higher educational attainment and achievements, especially beyond high school. To continue their studies, income devoted to education has to be present-possibly coming from remittances-accompanied by the discipline that a father can implement in retaining a child in school. Girls who leave the community are likely to be corrupted, at least from mothers' perspective, with the chance of not remaining in Guelavía. The social, economic, and cultural factors impact girls in ways that do not negatively impact boys.

The impact of male migration on children's education and educational attainment is inconclusive and will remain nothing more than speculative due to the diverse and multitude of threads that influence both emigration and education. It appears that some small portion of remittances are devoted toward education expenses but, conversely, the negative impact of not having a father in the home appears detrimental to children's education beyond primary and especially beyond middle school. Mothers readily acknowledge that discipline is the role of a father and forcing children to attend school falls within the father's domain. 
What is not speculative are the impacts of social norms, cultural traditions, and gender implications on girls' education. Girls achieving ever higher levels of formal education is confirmed but where and in what areas of curriculum is strongly influenced by traditional gender patterns and roles. Girls who venture beyond high school risk rejecting the parental, community, and societal norm of early marriage. These challenges and decisions dominate the discourse of girls and education across the spectrum of where fathers live-absent fathers, returned fathers, as well as anchored fathers. 


\section{Chapter 7: Conclusion}

The embeddedness of values in social structure, gender norms, and cultural tradition of the rural Oaxacan context is disrupted through the process of male migration. This disruption impacts more than just the migrant and the migrant's family; a type of social osmosis transfers the worries, the fears, and the implications of stay-behind or left-behind women to women with returned husbands as well as women with anchored husbands who have never emigrated from the home.

Migration is an integrating-fragmenting process and phenomenon. Rosenau (2003) coined this integrating-fragmenting process as "fragmegration." Male migration and the impact on women may well be characterized by Rosenau's description of the chaos of fragmegration:

What is needed is a conveyance with many wheels that sometimes roll harmoniously in the same direction, that sometimes move crazily in contradictory directions, and that often lurch fitfully as some wheels turn while others are stationary. (Rosenau, n.d., p. 8)

Women's experiences in the face of male migration are well characterized as "some wheels turn while others are stationary" in that some migration experiences are "successful" while others are pure failures. Some women endure male migration with a benefit of remittances that help feed their family, send their children to school, and provide a roof over their heads while simultaneously assuming the atypical role of primary disciplinarian, interim economic provider, and in-law caretaker. Some women endure male migration with the typical and expected anticipation of a better, more stable economic life only to become mujeres 
abandonadas. And some women experience male migration through their own worries and fears—even though directly unassociated with the phenomenon—but take on the worries and fear experienced by other women.

Fragmegration, an integration and simultaneous fragmentation, is the norm of Guelavían life. The following offers a concluding synopsis of the fragmegration of women's fears and worries, women's work, and educational attainment in San Juan Guelavía.

Fragmegration, Male Migration, and Women's Fears and Worries The integration of Mexico and the United States through migration creates fragmentation of nuclear families. Often, as is the case in much of rural Oaxaca, families are fragmented through the male head-of-household pursuing his economic provider role in the United States while the wife or partner remains as the stabilizing force that holds the household together. The lack of open border policies or circular migration policies that support connected, integrated families creates worries for Guelavían women. Concerns are often concentrated in the areas of danger of border crossings, remittance receipt, and distress at becoming a mujer abandonada (abandoned woman).

Lack of open border policies or circular migration policies create mothers and grandmothers who raise, feed, clothe, educate, and discipline children alone. Women must often shift their primary role of mother and ama de casa (homemaker or housewife) to one of labor force participant. Women are often relegated to raising 
their grandchildren due to the inability of children's U.S.-residing parents to cross the border as well as the distress at their having to stealthily cross back into the United States after visiting with their rural Mexico-residing children. Lack of open border or circular migration policies create fragmentation and often dissolution of families.

The embedded social norms in rural Oaxaca call for decision making to primarily reside with the male in the family, and migration decision making, for the most part, follows these structured norms. Decision making in regard to emigration is only minimally impacted by age-younger women appear to have more impact in decision making than do older women. However, when and if men return from the United States appears to exclusively reside with the husband. The integration of lives lived on both sides of the border and the decisions surrounding leaving and returning cause fragmentation of nuclear family's daily lives.

Some women in Guelavía worry of husbands' return while others worry of husbands' potential departure. Men’s economic provider role prescribes Guelavían men to a primacy role of campesino (farmer)—an integration into the larger economy through remunerated work-with the simultaneous fracturing of families due to the near demise of income-producing rural farming in the community. Campesinos, always men in Guelavía, contend with inadequate rainfall and lack of value placed on locally-cultivated produce. Even with a local high school that teaches new and organic farming methods, "campesino" is not a valued profession, and women as campesinas appears non-existent in Guelavía. Guelavíans see farming 
as their past, not a path for their future, and never a path for their daughters. Thus, the potential of integration into the larger economy through modern farming methods by expanding the thinking, value, or role of "organic" or "local" cannot be realized within the current Guelavía context. For the most part, Guelavíans envision farming as a non-integrative practice in the larger economy nor as a valued income opportunity. Therefore, the fragmentation of families continues through men's emigration to the U.S., girls shifting education to the city and risking contact with negative influences, and women scrambling for income opportunities that do not compromise their primary role as "mother." Women with absent husbands worry if coming back to the local context will be a success and women with returned husbands worry if spouses will settle for the survival mechanisms of the "past"namely, farming—or leave, once again for a "better" future in the United States. The integration of the local economy into the larger collage collides with the local environment.

Women with anchored husbands do not escape the concerns of emigration. Women are cognizant of the economic benefits of male migration: remittances that contribute to feeding and sustaining a family, construction or repair of a home, or assistance for education expenses. But, the economic benefits are complemented with concerns: potentially another woman, lack of remittances sent from the United States, or ultimately, becoming a mujer abandonada. Women with anchored husbands implement strategies that retain men in the home but with recognition that their status could, at any time, potentially change. Strategies sometimes work, 
sometimes do not. The integration of the north and south sides of the U.S./Mexico border challenges women with anchored husbands with potential fragmentation of their family. The risks and threats of fragmegration at the couple and family level loom large even to women with anchored husbands.

\section{Fragmegration, Male Migration, and Women's Work}

Women's work in Guelavía is in the home. The priority of motherhood, secondarily of wife, is disrupted through the process of male migration since women often must enter the workforce or invent their own income-generating activities that challenge women's priorities. When men migrate, women's expectation of the integration of cross-border income generation by husbands may turn into turned into a delay of remittances or full evasion of husband's remitting responsibility. This integration of cross border reliance upon remittances is often disrupted by the fragmenting of communication among parties, relationships, and responsibilities. This integration of cross-border relationships disrupted or unsuccessful in the homes of some stay-behind women, shifted to mujeres abandonadas, is seen, witnessed, and experiences by women with returned husbands as well as women with anchored husbands.

Women who generate income for the family are, for the largest part, women without husbands in the home and/or women with children that are old enough to require less direct care or primarily self-sufficient. Women are challenged to retain their social and cultural priority of mothering when faced with economic 
uncertainty and insecurity. Meeting the economic challenges of a family-whether a family with a husband in the home or not—often means income generation coordinated with all domestic responsibilities. Coordination of motherhood, domestic caretaker, and work force participant creates disadvantages for women through limited and often low-paying opportunities. Based on the data in this research project, women continue to devalue their income-generating activities. This appears, in part, due to gender norms that place men in the income-generating role with the woman in the home. But an accompanying part is women's necessity of devaluing their work so as not to step on their priority or motherhood or step on the valued macho role of breadwinner.

Fragmegration is a recognized concept in Guelavía life. The integration of a globalized economy has increased accessibility and decreased the price of imported Chinese goods - primarily, in the case of Guelavía, plastic imported baskets—while fragmenting the local economy. Once an artisan and farming community, women no longer see arts endeavors nor farming as viable economic means to a "successful" future. Fragmegration can be seen in Guelavía in the lack of understanding of what their future livelihoods will look like while only minimally accepting the integration of their sons and daughters, their families, and their communities into a larger, even global economy. Migration—-primarily male migration—has forced integration into the larger society but Guelavían women often fight it. Their lives, their existence, their economy is often structured within the small confines of the Guelavían borders. The necessity of accepting the larger integrative context displaces 
Guelavían women's priority of motherhood, of stay-in-the-home wife, and women's generalized framework in society.

Data in this research project shows that women prioritize motherhood and work to "assist" husbands in their economic provider role. Yet, many mothers are cognizant of the need for them to generate income, much so for women with absent husbands who've not sent remittances but also for women whose husband's generate less than needed. But, with wages low with the trade-off of leaving their children and retaining full responsibility for the domestic realm, women are left with few options.

The few programs that have operated in Guelavía, such as the church-related embroidery program, have not offered viable economic opportunities to women. To learn to embroidery for income retains women in their same gendered role simultaneously earning very little income. NGOs or government programs could implement policies that would retain the values and norms of a rural Oaxacan environment while teaching skills to advance women in income-producing opportunities. The earlier example of church restoration in Guelavía--a collaborative project between the church, the state government, and the federal governmentcould have implemented policy to train and retain 25-30 percent of its staff as women, for example, possibly as half-time positions so women could retain their role of mother and wife. Programs with a focus of integrating women into the work force and into non-traditional, higher-paying jobs could be the beginning of women 
in Guelavía looking at work opportunities differently while simultaneously adhering to the traditions of rural Oaxaca.

\section{Fragmegration, Male Migration, and Education}

Fragmegration is evident in the implications of education in Guelavía.

Educational policies found it most appropriate to situate an agriculture-curriculum based high school in a rural "farming" community. Processes of the federal and state government that placed a public high school in San Juan Guelavía should have integrated the community with the larger educational priorities of advancing education throughout Mexico with a larger global emphasis on education. Educational policies that chose to situate an ag school in a farming community caused unexpected, undesired, and likely, unforeseen fragmentation of the Guelavían community.

Fragmentation is a part of the educational fabric of Guelavía since families that have sufficient income send their children to school out of the community and families without sufficient income either make their children "suffer" through the CBTA curriculum or allow their children to drop out or take their children out of school after $9^{\text {th }}$ grade.

The "farming" community of Guelavía lacks understanding or is reluctant to acquiesce to the newer and mostly organic farming methods of the curriculum of CBTA. With farming seen as their past, Guelavíans, for the most part, dismiss the value of a high school curriculum that teaches methods and courses that offer no 
value to them, their families, or the community. Although there is no clear indication, designation, or direction of the general Guelavían future economic path, Guelavíans are clear that farming, even organic, newer methods, is not it.

This lack of value on the curriculum of the local high school creates a dichotomy for families. What is the path for children after the obligatory educación básica (basic education through $9^{\text {th }}$ grade)? The survey and interview findings suggest that families are fragmented in their decisions and paths by two factorsgender and resources.

Boys tend toward one of three paths: 1) dropping out of school after middle school since the farming curriculum is of little value; boys, then, work to some extent in subsistence agriculture or sometimes, do not work at all; 2) continuing on to the public high school but with little infiltration of their learning into the larger community context; or 3) considering, possibly pursuing, emigration themselves either as older adult men or possibly with family members. The fragmegration of boys' lives and education is evident in Guelavía.

Girls offer a greater challenge. Integrating girls into the larger context of the state of Oaxaca or the country of Mexican means that mothers would have to contend with their hesitancies, their fears, and their aversion to integrating their daughter's into a life in the city. Guelavían women tend to devalue the agriculture curriculum at the local, public high school. Options for their daughters are situated within two factors: 1) overcoming their reluctance and fear of allowing their daughters to be part of a city context—which, to women, offers an environment of 
drugs, alcohol, gangs, and promiscuity; and 2) securing, saving, or gathering sufficient resources to send their daughters to public school outside of Guelavía, which involves substantial expense. In women's minds, the possibility of corruption-in various forms and affects—is strong. Women are caught between a rock and a hard place (or, in Spanish, entre la espada y la pared [between the sword and the wall]).

It is also relevant that if girls leave the community, women are unsure if they will return. Therefore, the decision to send a girl to high school in the city portends a likelihood that she will not remain in Guelavía as an adult. Data for this research project provided consistent comments by women of the priority of education for their daughters but with various comments, experiences, and observations to the contrary. Without readily acknowledging it verbally, Guelavían women, in general, see marriage—often to a Guelavían boy—as a viable path for daughters just a few years after they've finished their middle school obligation. Women ages 35 and under married at an average age of just under 20 years of age; no different—and in some cases, even younger-than their mothers and grandmothers.

Fragmegration is a part of all Guelavían women's lives regardless of migration status of their husbands, their marital status, their work status, or their level of education. This San Juan Guelavía case study offers an intimate and intricate picture of the dichotomies and challenges that women face in each of these areas. Guelavían women's lives are a study in fragmegration regardless of the migration status of husbands. 


\section{Contributions to Policy and Beyond}

The findings of this research project offer data and information that would be valuable to government—federal, state, and local—in policy formation and implementation. The data and information would also be of use to NGOs with ties to rural Mexican communities. Three primary arenas of contribution to policy include cultural gender awareness policy within anti-poverty programs, education policy in Mexico, and U.S. border policy.

\section{Cultural Gender Awareness Policy within Anti-Poverty Programs}

\section{Oportunidades}

An opportunity to use knowledge gained from this research project is in implementing policy changes in the Mexican federal conditional cash transfer program Oportunidades (Opportunities). Launched in 1997,49 Oportunidades is a "human development program" instituted to help "accomplish access to equal opportunities for better living, thus reaching human development and social welfare for its people" (“Oportunidades, A Human Development Program," 2010).

Oportunidades assists 6.5 million Mexican families in 187,000 localities, 99 percent of which are rural or semi-urban ("Programa de Desarrollo Humano," 2010).

Oportunidades is a conditional cash transfer program with interventions in health, nutrition, and education ("Programa de Desarrollo Humano," 2010). The state of Oaxaca ranks second, only to Chiapas, of Mexico's 31 states and the Distrito

\footnotetext{
${ }^{49}$ See Oportunidades' Web page at http://www.oportunidades.gob.mx/. Oportunidades was known as Progresa in the previous 2000-2006 federal administration.
} 
Federal in percentage of families enrolled in Oportunidades at 58 percent (“Oportunidades, A Program of Results," 2010). Oportunidades uses a "gender approach"50 in helping girls, boys, and teens maintain school attendance and incentives that "help families improve their socioeconomic condition providing the beneficiaries with the possibility to obtain better wages" ("Programa de Desarrollo Humano," 2010).

Recipients of Oportunidades' cash transfers are required to attend communal educative workshops, most often requirements for mothers and teens. This requirement offers an opportunity for policy and curriculum integration. Oportunidades could integrate material related to three primary program arenas with a gender awareness focus: 1) migration tendencies, strategies, and coping mechanisms of women and daughters based on the community's level of male migration and level of need pertaining to economic and psychological factors with recognition of the larger community of women even with anchored husbands; 2) a subsidiarity approach to challenging girls' and women's notion of "proper" gendered work; and 3) recognition of challenges that girls encounter in educational attainment understood by girls, boys, as well as parents.

One, if serious and intentional about its "gender approach," Oportunidades could construct and implement curriculum that recognizes, accepts, and acknowledges the impact of male migration on women within a community. The approach should integrate cultural gender roles at the local level with the intent of

50 "Gender approach" is a term used by Oportunidades on its own Web site as well as downloadable reports but the term is not described. 
uniquely catering to the wide array of indigenous groups in Oaxaca, the varying levels and severity of male migration, vastly different levels of education of women, and the array of roles women manage and maintain. Oportunidades could be enhanced through policy design to be more attentive to women's needs in regard to the stresses, worries, and burdens that male migration causes, or may cause, and how gender roles and norms are affected. Support within group settings in challenging the traditional and cultural gender norms should be incorporated into curriculum while driven at the local level.

Two, a subsidiarity approach to challenging girls' and women's traditional, proper-gendered work could enhance their economic opportunities. Institutional thinking and policy implementation would best be done in a subsidiarity manner that encompasses the traditions and culture of the immediate community. Shuman (1998) defines subsidiarity as "a pragmatic relationship among different levels of government. Subsidiarity posits that power should always be exercised at the level closest to the people affected by a decision" (p. 125). Implementation of policy, procedures, and programming in an institution such as Oportunidades, for example, would best be done at the lowest level, most likely at the level of local health clinics. "At the community level, decisions can be tailored to special local circumstances" (Shuman, 1998, p. 125). Implementation of curriculum that takes into account the local, perhaps indigenous community into expanding girls' and women's thinking of proper gendered work roles would respect the culture and community while expanding opportunities. Integrating women into the process at the local health 
clinic level would not be free of challenges but would offer a more communityfocused response. Pushing decision making and policy implementation down to the lowest level—a subsidiarity strategy and focus-would integrate women, themselves, into the process.

Women's work is inextricably linked to gender norms and role appropriateness. In Mexico, in general, and in Oaxaca, even more so, gender roles and women's work are intractably linked. "Separation of the role of structural and endowment factors has important public policy implications when designing policies attempting to reduce gender inequities in labor market outcomes" (Pagán \& Sanchez, 2000, p. 622). “Endowment factors," offered by Pagán and Sanchez, refer to "women having less schooling and work experience than men, and gender differences in other productivity-related characteristics" (p. 622). Women's work cannot be delinked from the endowment factors that challenge women. This creates an opportunity for a program such as Oportunidades to build curriculum that challenges girls and women to consider income-generating possibilities that do not necessarily follow strict traditional paths. As an example, presenting non-traditional career or work opportunities being explored by girls—construction, organic farming and distribution, historic building preservation, or taxi driving—could widen mothers' and girls' thinking of future economic opportunities. Using a subsidiary approach would help respect the local culture and traditions while possibly using girls as speakers and as examples from the same community that 
have crossed over the traditional gendered-work boundaries into careers and work positions that are not traditionally held by females.

Three, Oportunidades could integrate curriculum in their current workshop offerings that addresses challenges that girls encounter in educational attainment. Curriculum of this nature would also be best implemented in a subsidiarity approach. Oportunidades is in the unique position of having direct access to millions of teenage girls—as well as boys-through requirements of workshop attendance usually held in local health centers. By better understanding that girls from San Juan Guelavía, for example, confront obstacles to educational attainment—early marriage expectations, distrust of the value of the agricultural curriculum of the only local, public high school, and tracking girls into proper gender careers, to name just a few-the local health clinic could incorporate curriculum that helps girls, boys, and their parents think "outside of the box" in regard to educational opportunities as well as eventual careers. By using research such as generated by this project, administrators in charge of program curriculum could see that curriculum in Guelavía, as an example, could explore girls' opportunities in agricultural careers. It would also be feasible and pertinent to offer presentations by college-age young women who are engaged in non-traditional college majors as well as offering mentoring for girls who want to explore opportunities currently unknown to them. Higher education like agricultural-based careers through Universidad Tecnológica de Los Valles Centrales de Oaxaca in a rural setting a few hours away from Guelavía or Escuela Normal Bilingüe e Intercultural de Oaxaca that offers curriculum in both 
Zapotec and Spanish located just 10 kilometers from Guelavía are largely unknown to Guelavían high school students. Adding curriculum to Oportunidades' workshops that expose girls, especially, to educational opportunities and options previously unknown and unexplored could benefit all residents in Guelavía.

\section{Education Policy}

The second policy arena that this project could help inform is education policy. In the larger area of educational attainment this, research shows a fissure in education policy in omitting the needs and desires of a local context. While the education system is Mexico is a patchwork of responsibilities and administration between the federal and the state government, the local context is not taken into account nor acknowledged.

This research throws light on the non-attendance tendency of Guelavían girls as well as boys at the local high school. This research could help inform education policy in regard to curriculum especially at the local, rural level. Education policy could be shifted and implemented differently based on the needs and desires of a community. In the case of Guelavía, two possibilities exist in regard to CBTA, the local, public high school. One, expand curriculum offerings beyond agriculture in an effort to re-enroll Guelavían teens; and two, integrate students, faculty, and administrators into the larger Guelavían community with workshops based on new agriculture methods and new product offerings. 
The lack of value that Guelavíans put on the agriculture curriculum shows a fissure in coordinating educational offerings with the needs and desires of the community showing a clear lack of a subsidiarity approach. Expansion of the curriculum by first involving the community and using citizen input as a basis for curriculum expansion. Two potential goals could be accomplished with a subsidiarity approach: one, ownership of new curriculum opportunities by the larger Guelavían community; and two, re-enrolling more children moving from middle school into high school due to renewed interest in new curriculum paths.

The second opportunity for changes in education policy is to integrate the agricultural curriculum more holistically into the larger Guelavían community. Few Guelavíans currently value the ag-based curriculum but the curriculum does offer benefits and opportunities that are unknown and unexplored in the community. Opportunities for organic farming offer a market outlet in one of the expanding organic mercados or specialty, natural-goods stores in the city of Oaxaca. CBTA workshops or inclusion of community members into the school curriculum on campus could offer or generate new crop possibilities, new methods, even new products for Guelavían families to generate new streams of income. It may be possible to renew Guelavía's agriculture designation if CBTA chose to educate the larger community through workshops, presentations, or projects. High school students are required to engage in community service thus offering an easy link from CBTA to the community through students serving as teachers, mentors, or assistants within a workshop setting. 
This research project also offers value in the minimally-understood area of migration and educational achievement. Kandel and Kao (2001), authors of one of the few studies of Mexican migration and children's education, note that while studies have claimed to show benefits of remittance dollars coming from U.S.-based Mexican migrants in relation to children's educational achievement and attendance, "few, if any [studies], have considered the tradeoff between increased material resources from migration on one hand, and negative consequences resulting from parental absence and migratory influence on the other" (p. 1206). While this research project does not look specifically nor focus directly on these linkages and the implications thereof, it does contribute understanding to the broad question of how male migration affects education of children. As a timely topic in the literature as well as the popular media, ${ }^{51}$ it is advantageous to Mexicanas, Mexicanos, the Mexican government administration, NGOs, and Mexican culture as a whole to better understand the impact of male migration on education. Education policy in

51 I state the topic of migration and education as "timely" since the broader, general topic of migration of one or both parents with children left behind or migration of the husband with the woman left behind appears in popular television programming nearly daily. In the two years that I spent in Mexico, the topic of migration of one or both parents with children left behind was commonly televised on various Mexican talk shows, telenovelas (soap operas), Catholic-based telenovelas, and news stories. Two main themes seemed to dominate talk shows: 1) left-behind mothers who could not support their children and blamed the absent husbands for their poverty situation as well as a wider myriad of additional problems; and 2) children left behind by one or both parents-claiming to be doing the best thing for the children - while the left-behind child or children expressed feelings of abandonment and resentment. While popular television program topics offer, at best, anecdotal information in a sensationalized setting, the consistency of diffusion of these two topics offers qualitative information that should simply not be ignored. While there is nothing scientific about the generalized claim of the prominence and significance of these two dominant themes, I began noting this repetitive programming topic shortly after arriving in Oaxaca and noted it consistently throughout my stay. It became routine to turn on the television and see various scenarios with the same migration-related theme repeated. 
Mexico can be informed by enhanced understanding of how student attendance, achievement, completion, and motivation may be linked with male migration.

Additionally, recognizing and addressing the two paths that many rural Mexican children see as their future-one, migration; the other, education—and appropriately constructing programs, campaigns, and solutions premised on enhanced understanding of male migration and women's reactions to it can offer benefit to the next generation. Programs that focus on the needs of rural Mexicans

must be constructed that deter what many see as their safety valve-emigration. This research project, in combination with the work of others, can enhance effectiveness of campaigns that help deter emigration and inform of the realistic challenges that it offers to women and families. Promoting education as a means to "success" as a viable and valuable alternative to migration can benefit rural Oaxacans, specifically, and rural Mexicans, in general.

\section{U.S. Border Policy}

Finally, this investigation bears on understanding the impact of U.S./Mexico border policy. Tight border control policies limit cross-border movement. Cross border movement is severely restricted due to U.S. security enforcement. If Mexican men are successful in illegally crossing the border from Mexico to the United States, movement back to Mexico with the intention of crossing back into the United States is highly risky, dangerous, and often prohibitively expensive. Conversely, border control policies restrict Mexico-based women and children from visiting husbands 
and fathers based in the United States. Strict border control policies burden women with the concern and worry of risk of death through illegal crossings. While the migrant is the one who physically endures the challenging and dangerous border crossing, women at home in the community endure much of the same just from a psychological rather than physical position and perspective. The burden of indebtedness to family and friends to fund a border crossing is also borne by both. U.S.-Mexico border policy is not the focus of this research project, yet it would be appropriate to consider this research wrapped within the larger context of U.S.Mexico immigration policies-all of which affect rural Oaxacan women and certainly the women of San Juan Guelavía.

\section{A Final Note on Categorizing Women}

In migration and gender-related research, there is much work to be done in terms of categorizing women through men's migration status. One contribution of this research project is the clarity of the wide array of lived experiences of women with absent husbands. Much of the literature speaks of stay-behind or left-behind wives with the implicit understanding that women with absent husbands receive remittances. There is little that speaks of the wide array of homes with absent husbands. In this project, in the category of "women with absent husbands," is a woman who communicates daily with her U.S.-based husband, a woman who receives more than $\$ 1,000$ US per month from her U.S.-based husband, and a woman who has not had contact with her U.S.-based "husband" for 26 years. The disparate 
experiences in the category of women with "absent" husbands-spouses living in the United States with the supposed intent of raising the family's economic sustainability—are rarely acknowledged in the literature. Future literature needs to be clearer in conveying that women with husbands living in the U.S. are not necessarily receiving remittances, are not necessarily awaiting a spouses' return, and are not necessarily thriving and gaining social status through a U.S.-based husband's clout, experiences, and/or remittances.

\section{Future Research}

As is often the case with exploratory research, this study generated at least as many questions as it tended to shed light upon. This research project has just scratched the surface of the impact of male migration on women with returned husbands and women with anchored husbands. Expansion and continuation of this research could expand on the impact that women with absent husbands have on women with husbands in the home. Are the impacts specific, direct, and one-to-one or are impacts more diffused and communal? Surveys, interviews, and possibly focus groups exclusively with women with anchored husbands could reveal more of the impacts and social osmosis that occurs within a community touched by male migration.

Conducting follow-up research with the 71 surveyed women five years, even ten years, after this initial research project may lend insight into the lives of all three categories of women. Knowing which absent husbands return and how their return 
affects the lives of women would lend insight to the study of migration and gender. Knowing which returned husbands stayed and how they were able or unable to integrate into local society and into the household or if they returned to the United States and how women were involved or not involved in those decisions would offer understanding into decision making and the gendered role of women.

More research is needed to understand the role women play in keeping anchored husbands in the home. The worry of becoming a wife of a husband who encounters another woman or of becoming a mujer abandonada was evident from the data in this research project, an important contribution to the literature. Women use strategies to attempt to keep husbands in the home in order to fight the possibility of becoming a mujer abandonada. This research project has suggested that land ownership and/or home construction on parents' or in-laws' land, the notion of sufficiency, and women economically contributing to the home are strategies that women use to keep anchored husbands anchored. These strategies appear, at times, successful, at times, not. Much more work is needed to further understand strategies that women use-consciously or unconsciously—to retain men in the home.

There is much more to be done to understand women's work in Mexico as much of the data are controversial with incongruent results (King, 2008). The data in this research project reveal that more women with absent husbands work for income-although some of those women receive remittances as well while others do not. But, the question remains: who are the women with anchored husbands and 
the small percentage of women with returned husbands that work? This research project suggests that motherhood is the highest priority of women and primarily, women see remunerated work as needing to fit within this priority, often through self-employed, in-home income generation. The question remains as to how, exactly, this disadvantages—or possibly advantages-women, children, and especially, daughters. It is also unclear as to how women's work has shifted by generation and if the younger generation is retaining the prioritization of motherhood over work as have previous generations.

A continued emphasis on understanding the connections between male migration and women's need and/or desire to generate income and the reasons behind it would tie into the literature of migration and gender. The generational differences among which women work should continue to be explored as well as what factors impact the very low percentage of women age 50 and older who work. Just one women of sixteen women surveyed ages 50 to 70 responded that she generated any income. Is women's role after age 50 to continue to care for adult children, grandchildren, as well as retired husbands or are the current generation of women age 50 and over minimally educated and thus, remunerated work is scarce or possibly non-existent? With a much larger percentage of women ages 35 to 50 currently working for income, in 10 or 20 years will that same group of women continue to work, untraditionally, past age 50 ?

The area with the greatest dearth in literature, the least understanding, and most potential is likely in the area of education. With educational attainment 
considerably higher for women ages 35 and under than their mother's or grandmother's generation, what is the career path for these girls? With the difference in male to female educational attainment shrinking, how is the strict, structured role of ama de casa (homemaker or housewife) and the male as economic provider culturally put at risk?

In Guelavía, all children in surveyed families with elementary age children were attending school—Guelavían public schools. Three trends take hold after elementary school: 1) Girls leave Guelavían public school for private schools outside of the community; 2) Girls do not attend Guelavían high school due to the agriculture-based curriculum; and 3) Boys drop out of school after $9^{\text {th }}$ grade with only 21 percent of all 16 to 18 year olds attending the agriculture-based high school, 527 percent attending private school, and 71 percent not attending at all. It appears that the ag-based curriculum of CBTA drives girls away but why do girls then flock to private schools whereas boys tend to drop out of school altogether? The assumption that boys may be generating income for the family in lieu of educational attainment is not substantiated by this research project. Could boys be retained in the education system and would girls remain in the community if CBTA changed or extended the curriculum beyond the current agriculture focus? Could workshops, seminars, and community education by CBTA change the opinions of Guelavíans to consider the value of the ag-based curriculum?

\footnotetext{
${ }^{52}$ Due to rounding the figures are slightly less than $100 \%$.
} 
What happens to girls that attend high school outside of Guelavía? Do they continue to live in Guelavía long term? Do they marry early and remain in Guelavía? Do they begin careers and move away? Are marriage and/or childbirth delayed? Are women's concerns of allowing their daughters to be exposure to the negative environment of the city realized or does the exposure bring positive consequences—-whatever those may be-back to the family? Additional important follow-up research should involve a comparison of the future lives of girls that do attend CBTA, girls that attend private schools in the city, and girls that do not attend high school. Which girls remain in Guelavía, which girls work for income, which emigrate to the United States, and which delay marriage and childbirth?

The data for this project show that mothers want their daughters to achieve "una carrera" (a career), usually representing high school completion, with only a few mentions of university studies. In fact, only one woman of 71 women surveyed had attended any schooling beyond high school. The data for this project suggest that women envision a high school degree followed by marriage as the most typical, traditional, safest, and desired path for their daughters. An exploratory study as to why and how girls choose a path of advanced education or marriage and remaining in Guelavía (since both higher education and marriage while remaining in Guelavía appear incompatible) would offer insight in regard to educational attainment but also connections between mothers', fathers', or others' influence on young girls and their futures. An additional question involves the impact of higher levels of education and young women's decision making role, domestic responsibilities, work 
status, and role in the larger community, including, possibly, local municipal government. There is much that is unclear about young Mexican girls and teens and education, careers, and the influences that impact decisions in these areas-all questions that warrant further attention.

\section{Closing}

Women's lives are impacted by male migration—some expectedly, like women with absent husbands; others less expectedly, women with returned as well as anchored husbands. A young wife in her mid-twenties with a husband who has never emigrated commented:

... precisamente hace como una semana, hace 8 días antes estuvimos platicando que cómo sería si nos fuéramos o él se fuera para allá. No lo consideramos posibilidad solo nos imaginamos y nos ponemos a pensar como seria.

(... precisely a week ago, eight days before, we were talking about how it would be if we went or if he went there [to the U.S.]. We aren't considering it as a possibility; we were just imagining and thinking about how it would be.)

This comes from one of the few women with a small, but consistent salary and a husband who has always had work. Even this wife and mother-stable, grounded to the community, and owner of a small, humble, but sufficient home-discusses migration with her spouse. Her interview revealed the extent to which male migration of friends, family, and acquaintances has impacted her life. She had, admittedly, chosen a path of contentment and humble sufficiency of an embedded life in Guelavía. Her mother had endured multiple departures and returns of her this 
young woman's father, and her uncle had died while crossing the border with notice not coming to the family in Guelavía more than a month later. Still, the young couple imagined what it might be like if migration were a part of their own nuclear family. Based on data from this Guelavía case study, this young woman's imaginings and conversations are not usual as data suggest that male migration is a part of the vast majority of nuclear families in San Juan Guelavía. 


\section{References}

Ahern, S., Bryan, D., \& Baca, R. (1985). Migration and La Mujer Fuerte. Migration Today, 13, 14-20.

Benería, L., \& Roldán, M. (1987). The Crossroads of Class and Gender: Industrial Homework, Subcontracting, and Household Dynamics in Mexico City. Chicago: University of Chicago Press.

Bever, S. (1999). Migration, Household Economy, and Gender: A Comparative Study of Households in a Rural Yucatec Maya Community. (Doctoral dissertation), Southern Methodist University.

Bryman, A. (2004). Social Research Methods (2nd ed.). Oxford, New York: Oxford University Press.

Cohen, J. H. (2001). Transnational Migration in Rural Oaxaca, Mexico: Dependency, Development, and the Household. American Anthropologist, 103(4), 954-967.

Cohen, J. H. (2004). The Culture of Migration in Southern Mexico. Austin, Texas: University of Texas Press.

Cohen, J. H., \& Browning, A. (2007). The Decline of a Craft: Basket Making in San Juan Guelavia, Oaxaca. Human Organization, 66(3), 229-239.

Cohen, J. H., Rodriguez, L., \& Fox, M. (2008). Gender and migration in the Central Valleys of Oaxaca. International Migration, 46(1), 79-100.

Consejo Nacional de Evaluación de la Politica de Dearollo Social. (2010). Medición de la México 2010, a Escala Municipal. Retrieved from 
http://www.coneval.gob.mx/cmsconeval/rw/pages/medicion/multidimenci onal/informacion_municipios.es.do

Consejo Nacional de Evaluación de la Politica de Desarollo Social. (2005). Carpeta Informativa 2005: Día Mundial de la Población.

Cruz, A. S. G. (2008). Migración Internacional y Calidad de Vida de las Familias de San Lucas Quiaviní, Oaxaca [International Migration and Quality of Life of the Families of San Lucas Quiaviní, Oaxaca]. (Doctorate dissertation), Instituto Tecnologico de Oaxaca, Oaxaca, Mexico.

Fernández Kelly, M. P. (1990). Delicate Transactions: Gender, Home, and Employment among Hispanic Women. In A. L. T. Faye Ginsburg (Ed.), Uncertain Terms: Negotiating Gender in American Culture. Boston: Beacon Press.

Gledhill, J. (1995). Neoliberalism, Transnationalization and Rural Poverty: A Case Study of Michoacán, Mexico. Boulder, Colorado: Westview Press, Inc.

González de la Rocha, M. (2001). From the Resources of Poverty to the Poverty of Resources? The Erosion of a Survival Model. Latin American Perspectives, $28(4), 72-100$.

Hamel, J., Dufour, S., \& Fortin, D. (1993). Study Methods. Newbury Park, California: Sage Publications, Inc.

Hellman, J. A. (2008). The World of Mexican Migrants: The Rock and the Hard Place. New York: New Press. 
Hirsch, J. S. (2003). A Courtship After Marriage: Sexuality and Love in Mexican Transnational Families. Berkeley: University of California Press.

Hondagneu-Sotelo, P. (1992). Overcoming Patriarchal Constraints: The Reconstruction of Gender Relations among Mexican Immigrant Women and Men. Gender and Society, 6(3), 393-415.

Hondagneu-Sotelo, P. (1994). Gendered Transitions: Mexican Experiences of Immigration. Berkeley, Calif.: University of California Press.

Hondagneu-Sotelo, P., \& Avila, E. (1997). "I'm Here, but I'm There." Gender \& Society, 11(5), 548-571.

Howell, J. (1999). Expanding Women's Roles in Southern Mexico: Educated, Employed Oaxaqueñas. Journal of Anthropological Research, 55(1), 99.

Instituto Nacional de Estadísticas Geografía e Informática. (2007). México Hoy. Retrieved from http://www.inegi.org.mx/prod_serv/contenidos/espanol/bvinegi/producto s/integracion/pais/mexhoy/2007/MexicoHoy_2007.pdf

Instituto Nacional de Estadísticas Geografía e Informática. (2008). Matrimonios y Divorcios. Retrieved from http://cuentame.inegi.org.mx/poblacion/myd.aspx?tema=P Instituto Nacional de Estadísticas Geografía e Informática. (2010). Censo de Población y Vivienda. Retrieved from http://www.inegi.org.mx/sistemas/mexicocifras/default.aspx?ent=20\&mun $=197 \& \operatorname{src}=487$ 
Instituto Nacional de Estadísticas Geografía e Informática. (2010). Migración. Retrieved from cuentame.inegi.org.mx/poblacion/migracion.aspx?tema=P International Organization for Migration. (2008). Migration Facts \& Figures. Retrieved from www.iom.or.id/infokit/eng/Migration(2May2008).pdf Kanaiaupuni, S. M. (2000). Reframing the Migration Question: An Analysis of Men, Women, and Gender in Mexico. Social Forces, 78(4), 1311-1347.

Kanaiaupuni, S. M. (July 2000). Sustaining Families and Communities: Nonmigrant Women and Mexico-U.S. Migration Processes. Center for Demography and Ecology: University of Wisconsin-Madison. Retrieved from http://majorsmatter.net/family/Kanaiaupuni.pdf

Kandel, W., \& Kao, G. (2001). The Impact of Temporary Labor Migration on Mexican Children's Educational Aspirations and Performance. International Migration Review, 35(4), 1205-1231.

King, M. C. (2008). Mexican Women's Work on Both Sides of the U.S./Mexican Border. Paper presented at the International Association for Feminist Economics, Torino, Italy.

Levitt, P. (2001). The Transnational Villagers. Berkeley: University of California Press.

Lopez Castañeda, D. (2008). Migration and Development, A Comprehensive View From a Gender Perspective. Paper presented at the International Conference on Gender, Migration and Development: Seizing Opportunities, Upholding Rights, Manila, Phillipines. 
Lopez, M., Livingston, G., \& Kochhar, R. (2009). Hispanics and the Economic Downturn: Housing Woes and Remittance Cuts. Pew Hispanic Center: Pew Research Center Project.

Lowell, B. L., Perderzini, C., \& Passel, J. (2008). Demography of Mexico-U.S. Migration. In A. E. Latapí \& S. F. Martin (Eds.). Mexico-U.S. Migration Management: A Binational Approach. Lanham, MD: Lexington Books. MacEwan, A. (2006). Liberalization, Migration, and Development: The Mexico-U.S. Relationship. Revista de Economia Mundial, 57-85.

Mahler, S. J. (1999). Engendering Transnational Migration: A Case Study of Salvadorans. The American Behavioral Scientist, 42, 690-719.

Marcelli, E. A., \& Cornelius, W. A. (2001). The Changing Profile of Mexican Migrants to the United States: New Evidence from California and Mexico. Latin American Research Review, 36(3), 105-131.

Mason, D. R., \& Beard, V. A. (2008). Community-based Planning and Poverty Alleviation in Oaxaca, Mexico. Journal of Planning Education and Research, 27, 245-260.

Massey, D. S., \& España, F. G. (1987). The Social Process of International Migration. Science, 237, 733-738.

McGuire, S., \& Martin, K. (2007). Fractured Migrant Families: Paradoxes of Hope and Devastation. Family Community Health, 30(3), 178-188. 
Pagán, J. A., \& Sanchez, S. M. (2000). Gender Differences in Labor Market Decisions: Evidence from Rural Mexico. Economic Development and Cultural Change, 48(3), 619-637.

Palloni, A., Massey, D. S., Ceballos, M., Espinosa, K., \& Spittel, M. (2001). Social Capital and International Migration: A Test Using Information on Family Networks. The American Journal of Sociology, 106(5), 1262-1298.

Parrado, E. A., \& Flippen, C. A. (2005). Migration and Gender among Mexican Women. American Sociological Review, 70(4), 606-632.

Parrado, E. A., Flippen, C. A., \& McQuiston, C. (2005). Migration and Relationship Power among Mexican Women. Demography, 42(2), 347-372.

Pauli, J. (2008). A House of One's Own: Gender, Migration, and Residence in Rural Mexico. American Enthonologist, 35(1), 171-187.

Pessar, P. R. (1999). Engendering Migration Studies. American Behavioral Scientist, 42(4), 577-600.

Pessar, P. R. (2005). Women, Gender, and International Migration Across and Beyond the Americas: Inequalities and Limited Empowerment. Expert Group Meeting on International Migration and Development in Latin America and the Caribbean.

Pessar, P. R., \& Mahler, S. J. (2003). Transnational Migration: Bringing Gender In. International Migration Review, 37(3), 812-846.

Ramírez, C., Domínguez, M. G., \& Morais, J. M. (2006). Gender, Remittances and Development: Research Gaps and Future Priorities. United Nations: 
International Research and Training Institute for the Advancement of Women.

Rosenau, J. N. (2003). Distant Proximities: Dynamics beyond Globalization. Princeton, New Jersey: Princeton University Press.

Rosenau, J. N. (n.d.). The Governance of Fragmegration: Neither a World Republic nor a Global Interstate System. Retrieved from http://www.lanna-websitepromotion.com/moonhoabinh/lunar_material/GovernanceOfFragmegration. pdf

Salgado de Snyder, N. (1993). Family Life Across the Border: Mexican Wives Left Behind. Hispanic Journal of Behavioral Sciences, 15(3), 391-401.

Secretaría de Desarrollo Social. (2010). Oportunidades, A Program of Results. Retrieved from http://www.oportunidades.gob.mx/Portal/work/sites/Web/resources/Arc hivoContent/623/Oportunidades,\%20a\%20program\%20of\%20results $\% 202$ 010.pdf

Secretaría de Desarrollo Social. (2010). Programa de Desarrollo Humano Oportunidades. Oportunidades, A Human Development Program. Retrieved from http://www.oportunidades.gob.mx/Portal/wb/Web/oportunidades_a_huma n_development_program

Shuman, M. H. (1998). Going Local. New York: The Free Press. 
Stark, O., \& Bloom, D. E. (1985). The New Economics of Labor Migration. The American Economic Review, 75(2), 173-178.

Stephen, L. (2005). Zapotec Women: Gender, Class, and Ethnicity in Globalized Oaxaca (2nd ed.). Durham, N.C.: Duke University Press.

Stephen, L. (2007). Transborder Lives: Indigenous Oaxacans in Mexico, California, and Oregon. Durham and London: Duke University Press.

Subsecretaría de educación Básica de Mexico. (2011). Plan de Estudios 2011.

Retrieved from http://basica.sep.gob.mx/dgdc/sitio/pdf/PlanEdu2011.pdf

United Nations. (n.d.). International Migration and Development Factsheet. Retrieved from http://www.un.org/esa/population/migration/hld/Text/Migration_factshee t.pdf

Vázquez García, V. (2011). Usos y Costumbres y Ciudadania Femenina: Hablan las Presidentas Municipales de Oaxaca, 1996-2010. Distrito Federal, Mexico: INMUJERES-CONACYT.

Yin, R. K. (1994). Study Research: Design and Methods. Thousand Oaks, California: Sage Publications, Inc.

Zafra, G., \& López-Rocha, M. (January-April, 2009). Impactos De La Migración En La Juventud: San Juan Guelavía [Impacts of Migration In Youth: San Juan Guelavía]. Agricultura, Sociedad y Desarrollo [Agriculture, Society, and Development], 6. 


\section{Appendix: Survey Packet for Participants}

Permission Letter from the Presidente Municipal, letter from the PSU Human Subjects Research Review Committee, and the Survey 


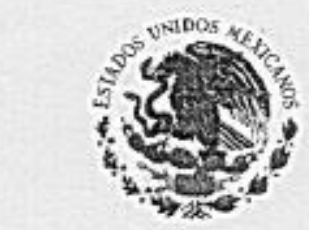

H. AYUNTAMIENTO CONSTITUCIONAL

San Juan Guelavia. Thacolula Qax: $2005+2010$
DEPENDENCIA: PRESIDENCIA MUNICIPAL.

SAN JUAN GUELAVIA, TLACOLULA. OAX.

OFICIO: $\quad 018 / 2010$

EXPEDIENTE:

A QUIEN CORRESPONDA:

EL QUE SUSCRIBE C. PANFILO PLATAS LOPEZ PRESIDENTE MUNICIPAL INTERINO DEL PUEBLO Y MUNICIPIO DE SAN JUAN GUELAVIA TLACOLULA OAXACA; EN USO DE LAS FACULTADES QUE LA LEY MUNICIPAL EN VIGOR ME OTORGA AUTORIZO A MTRA. JULIA BOYLES ALUMNA DE DOCTORADO EN LA PORTLAND STATE UNIVERSITY DE LOS ESTADOS UNIDOS DE AMERICA: PARA QUE SIN NINGÚN INCONVENIENTE REALICE INVESTIGACIONES A ESTA COMUNIDAD

A PETICIÓN DE LA PARTE INTERESADA Y PARA LOS FINES LEGALES CORRESPONDIENTES, SE EXTIENDE LA PRESENTE CONSTANCIA EN SAN JUAN GUELAVIA, TLACOLULA, OAXACA, A 21 DE ABRIL DE 2010.

ATENTAMENTE

"SUFRAGIO EFECTIVO NO-REELECCION"

"EL RESPETO AL DERECHO AJENO ES LA PAZ" PRESIDENTE MUNICIPAL INTERINO

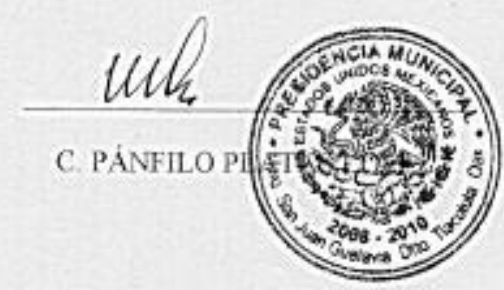


Buenos días, Señora,

Usted esta invitada a participar en un estudio de investigaciones conducido de Julia Boyles, alumna de doctorado de Portland State University (Universidad de Portland State--PSU) del estado de Oregon en EEUU. La investigadora desea aprender más de cómo las señoras de San Juan Guelavía son afectadas por la emigración. La investigadora es parte de un programa de doctorado bajo la supervisión de la Doctora Mary King y Doctor Jack Corbett de PSU (Doctor Corbett ha vivido en Oaxaca por 30 años). Usted ha sido seleccionada para participar en este estudio porque usted vive en Guelavía, es mujer, tiene 18 años o más, y su experiencia y su opinión es valiosa.

Su participación es voluntaria y no tiene que participar en esta encuesta si no quiere. Si usted decide contribuir en la encuesta, tomará alrededor de una hora. Su participación ayudará aumentar la información disponible sobre las vidas de las mujeres que se quedan en sus pueblos mientras los hombres se van a EEUU.

La información que usted no da será completamente confidencial. Ninguna persona aparte de la investigadora y sus asistentes van a ver la información que nos da. Además, su nombre nunca jamás aparecerá. Es importante que sepa que he obtenido permiso del Presidente Municipal para llevar a cabo la encuesta; ninguna parte de esta encuesta será compartida con él Presidente o con ningún otro miembro de su gobierno.

Es importante que usted sepa que mis asistentes han sido entrenados y mantendrán la información y datos que reúnen durante el estudio son totalmente confidenciales.

Si tiene alguna duda de cualquier parte de este estudio o de los derechos de los participantes, se puede poner en contacto con:

Instituto de Welte de Estudios Oaxaqueños

Dr. Jack Corbett

Emilio Carranza 203, Colonia Reforma

68050 Oaxaca, Mexico

Teléfono: 951-513-8323

o

Comité de Sujetos Humanos de Investigaciones

Oficina de Investigaciones y Proyectos

600 Unitus Bldg

Portland State University

Portland, Oregon, U.S.

001-503- 725-4288

Muchas gracias, 


\section{Guía de Encuesta Para Jefas/Amas de la Casa}

\section{Información general:}

\begin{tabular}{|ll|l|}
\hline 1. & $\begin{array}{l}\text { Nombre de la } \\
\text { entrevistadora: }\end{array}$ & \\
\hline 2. & Pueblo: & \\
\hline 3. & Fecha: & \\
\hline 4. & $\begin{array}{l}\text { Hora que } \\
\text { comienza: }\end{array}$ & \\
\hline 5. & $\begin{array}{l}\text { Hora que } \\
\text { termina: }\end{array}$ & \\
\hline 6. & Dirección: & \\
\hline
\end{tabular}

\section{Información de la Participante:}

\begin{tabular}{|c|c|}
\hline $\begin{array}{l}\text { 7. } \\
\text { pombre de la } \\
\text { (jefa de familia): }\end{array}$ & \\
\hline 8. Fecha de nacimiento: & \\
\hline 9. Lengua materna: & $\square$ Zapoteco $\quad \square$ Español $\quad \square$ Otra: \\
\hline 10. Segundo idioma: & $\square$ Zapoteco $\square$ Español $\square$ Ninguna \\
\hline 11. Estado civil: & 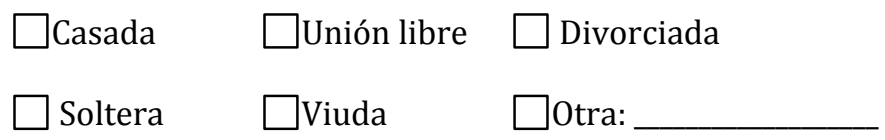 \\
\hline $\begin{array}{l}\text { 12. Si es que es casada, } \\
\text { cuantos años tiene de } \\
\text { matrimonio?: }\end{array}$ & \\
\hline $\begin{array}{l}\text { 13. Cuantos años tenía } \\
\text { cuando se casó?: }\end{array}$ & \\
\hline 14. Nivel de estudio: & $\begin{array}{l}\square \text { Primaria } \square \text { Secundaria } \square \text { Nivel medio superior } \\
\square \text { Nivel superior } \quad \text { Diga que grado: }\end{array}$ \\
\hline $\begin{array}{l}\text { 15. ¿Usted se considera } \\
\text { ama de casa? }\end{array}$ & $\square$ Sí $\quad \square$ No \\
\hline 16. ¿Trabaja por dinero? & $\square$ No \\
\hline $\begin{array}{l}\text { 17. ¿Qué tipo de trabajo } \\
\text { hace para ganar } \\
\text { dinero? }\end{array}$ & $\begin{array}{l}\square \text { Trabajo domestico } \square \text { Comerciante } \square \text { Campesina } \\
\square \text { otra: }\end{array}$ \\
\hline
\end{tabular}




\begin{tabular}{|l|l|}
\hline 18. ¿Dónde trabaja? & $\square$ En el mismo pueblo $\square$ En otro pueblo $\square$ En la ciudad \\
& En qué área: \\
\hline $\begin{array}{l}\text { 19. ¿Durante una semana, } \\
\text { cuantas horas trabaja } \\
\text { (fuera de la casa)? }\end{array}$ & $\square$ 1-10 $\square$ 11-20 $\square$ 21-30 $\square$ 31-40 \\
\hline ful-50 & $\square$ Más de 50
\end{tabular}

\section{Información de Esposo (de le descripción de la mujer)}

\begin{tabular}{|c|c|}
\hline \multicolumn{2}{|l|}{ 20. Nombre de esposo: } \\
\hline 21. Fecha de nacimiento: & \\
\hline 22. Lengua materna: & $\square$ Zapoteco $\square$ Español $\square$ Otra: \\
\hline 23. Segundo Idioma: & $\square$ Zapoteco $\square$ Español $\square$ Ninguna $\quad \square$ otra: \\
\hline \multicolumn{2}{|l|}{$\begin{array}{l}\text { 24. Cuantos años tenía } \\
\text { cuando se casaron? }\end{array}$} \\
\hline 25. Nivel de estudio: & $\begin{array}{l}\square \text { Primaria } \square \text { Secundaria } \square \text { Nivel medio superior } \\
\square \text { Nivel superior } \quad \text { Diga que grado: }\end{array}$ \\
\hline 26. ¿Trabaja por dinero? & $\square$ Sí $\quad \square$ No \\
\hline $\begin{array}{l}\text { 27. ¿Qué tipo de trabajo } \\
\text { hace su esposo para } \\
\text { ganar dinero? }\end{array}$ & $\begin{array}{l}\square \text { Albañilería } \square \text { Campesino } \square \text { Mercante } \\
\square \text { otra: }\end{array}$ \\
\hline $\begin{array}{l}\text { 28. Donde trabaja su } \\
\text { esposo-en que } \\
\text { ciudad o área? }\end{array}$ & $\begin{array}{l}\square \text { En el mismo pueblo } \square \text { En otro pueblo } \square \text { En la Ciudad } \\
\text { En qué área: }\end{array}$ \\
\hline $\begin{array}{l}\text { 29. Cuantas horas } \\
\text { trabaja durante la } \\
\text { semana? }\end{array}$ & $\begin{array}{ll}\square \text { 1-10 } \\
\square \text { 41-50 } \square \text { Más de } 50\end{array}$ \\
\hline
\end{tabular}


Miembros de la Casa:

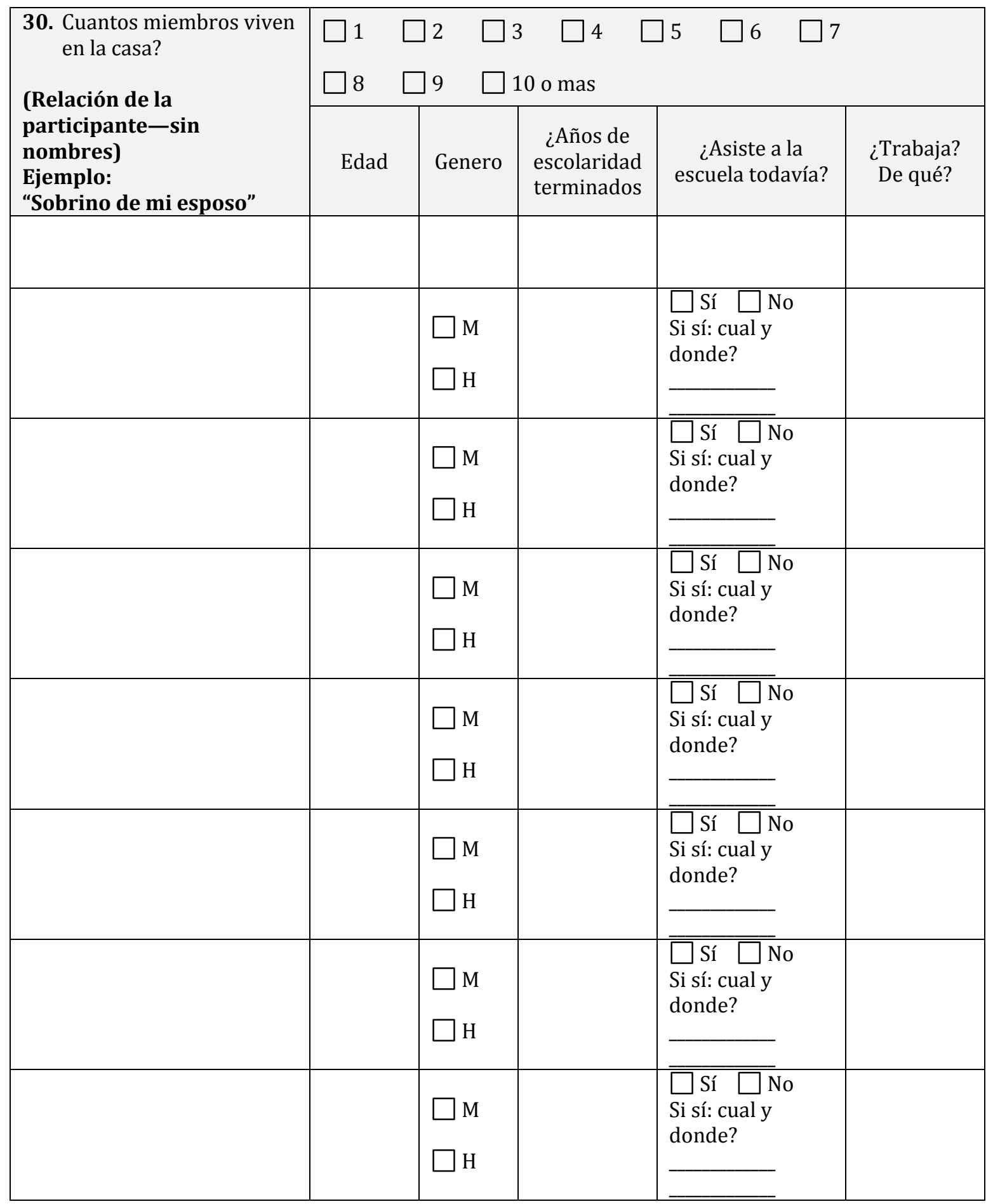




\section{El esposo y emigración:}

\begin{tabular}{|l|l|}
\hline $\begin{array}{l}\text { 31. Podría responder a } \\
\text { uno de esos: }\end{array}$ & $\square$ Mi esposo esta en EEUU por trabajo/dinero (Pase a \#32) \\
& $\square$ Mi esposo estuvo en EEUU por trabajo/dinero pero ha regresado \\
& (Pase a \#53) \\
& $\begin{array}{l}\square \text { Mi esposo nunca ha estado en EEUU por trabajo/dinero } \\
\text { (Pase a \#79) }\end{array}$ \\
\hline
\end{tabular}

\section{El esposo ESTA en EEUU:}

\section{Esposo información}

32. A qué edad emigró:

33. Con quien vivía antes de la emigración:

34. Estaban casados cuando emigró?

\section{$\square$ Sí $\square$ No}

35. Que información tiene de su vida--por ejemplo: donde vive, tipo de trabajo, cuando va a regresar)

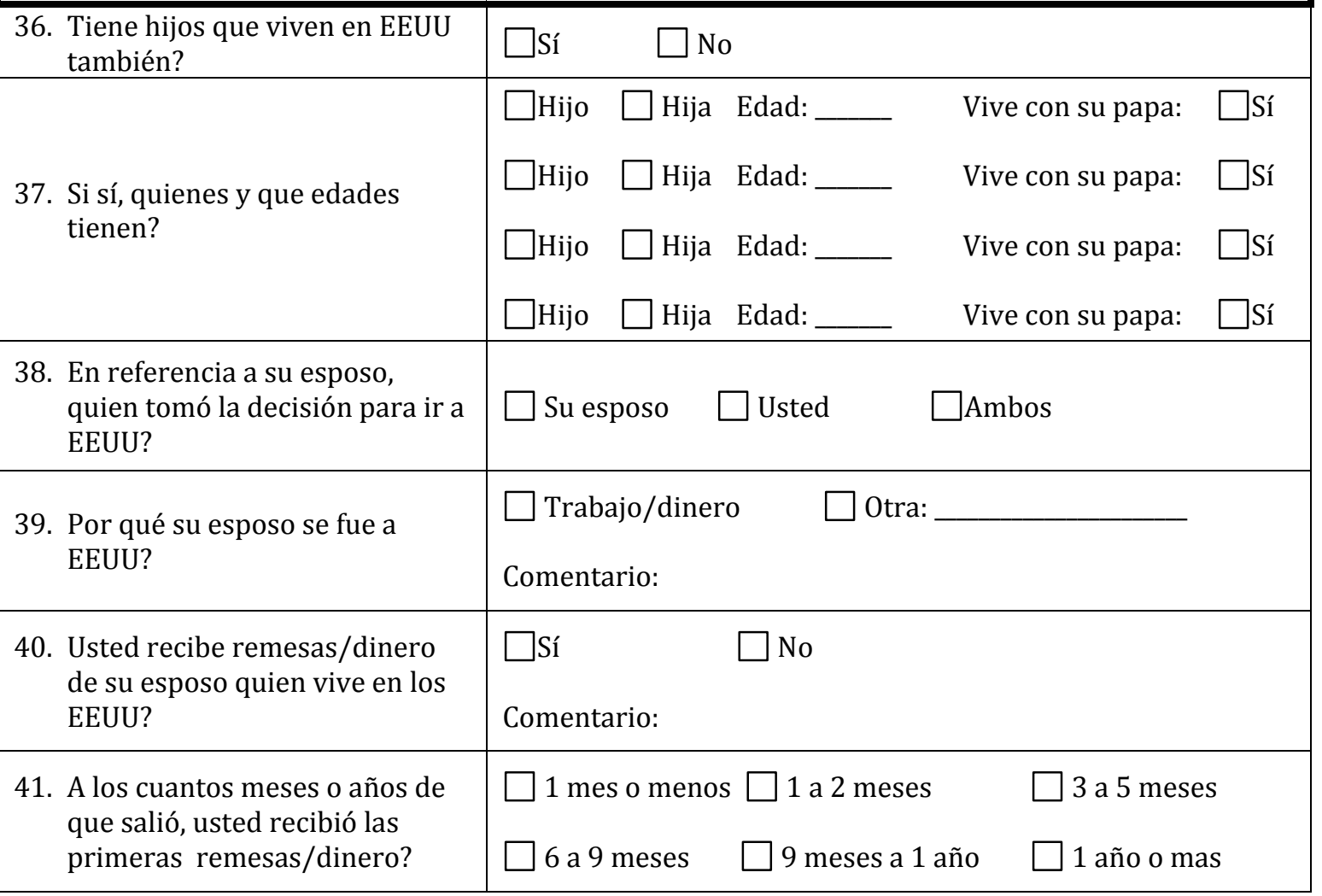




\begin{tabular}{|c|c|}
\hline $\begin{array}{l}\text { 42. Si su esposo ha vivido en EEUU } \\
\text { más de un año, sigue enviando } \\
\text { dinero? }\end{array}$ & $\begin{array}{l}\square \text { Sí } \square \text { No } \\
\text { Comentario: }\end{array}$ \\
\hline $\begin{array}{l}\text { 43. Podría decirme que el dinero } \\
\text { que recibe actualmente: }\end{array}$ & $\square$ Sigue igual $\quad \square$ Ha aumentado $\quad \square$ Ha disminuido \\
\hline $\begin{array}{l}\text { 44. En 2009, en comparación con } \\
2008 \text {, (si él ha estado fuera los } \\
\text { dos años) las remesas que } \\
\text { mandó fueron: }\end{array}$ & $\square$ Igual \\
\hline $\begin{array}{l}\text { 45. Si usted ha recibido remesas en } \\
\text { los últimos seis meses, cuál fue } \\
\text { el promedio que recibió cada } \\
\text { mes? }\end{array}$ & $\begin{array}{ll}\square \text { Menos de } \$ 100 \text { US } & \square \text { \$100US a } \$ 250 \text { US } \\
\square \text { \$250US a } \$ 500 \text { US } & \square \$ 500 \text { US a } \$ 750 \text { US } \\
\square \text { \$750US a } \$ 1,000 \text { US } & \square \$ 1,000 \text { o más }\end{array}$ \\
\hline $\begin{array}{l}\text { 46. En que usa las remesas que } \\
\text { recibe? } \\
\text { Marca todos los que aplican } \\
\text { (Lee detenidamente todas las } \\
\text { respuestas de la lista antes } \\
\text { de responder) } \\
\text { 47. Donde usó las remesas? } \\
\text { Marque } 1,2 \text { y } 3 \text { en el espacio } \\
\text { después }\end{array}$ & $\begin{array}{l}\square \text { Para comprar comida } \_-\square \text { Remodelar su casa } \_ \\
\square \text { Para construir su casa } \_-\square \text { Comprar aparatos }- \\
\square \text { La educación de los hijos } \_\square \text { Comprar animales }- \\
\square \text { Ampliar o mejorar un negocio } \_ \\
\square \text { Comprar un carro } \_ \\
\square \text { Otro: }\end{array}$ \\
\hline $\begin{array}{l}\text { 48. Quién toma la decisión sobre } \\
\text { cómo usar las remesas? }\end{array}$ & $\begin{array}{l}\square \text { Su esposo } \square \text { Usted } \square \text { Ambos } \\
\text { Otra persona: }\end{array}$ \\
\hline $\begin{array}{l}\text { 49. Si usted no recibiera las } \\
\text { remesas, cuál sería la razón, en } \\
\text { su opinión? }\end{array}$ & $\begin{array}{l}\square \text { No hay dinero suficiente a mandar } \square \text { No tiene trabajo } \\
\square \text { Otra mujer } \quad \square \text { Prefiere gastarlo en sí mismo } \\
\text { Otro: }\end{array}$ \\
\hline $\begin{array}{l}\text { 50. Piensa usted que su esposo } \\
\text { regresará con dinero para la } \\
\text { familia y usted? }\end{array}$ & $\begin{array}{l}\square \text { Sí } \square \text { No } \\
\text { Por qué piensa así? }\end{array}$ \\
\hline $\begin{array}{l}\text { 51. Si sí, como estará utilizado ese } \\
\text { dinero? }\end{array}$ & \\
\hline $\begin{array}{l}\text { 52. Quien tomará la decisión de } \\
\text { cómo utilizar ese dinero? }\end{array}$ & $\begin{array}{l}\square \text { Usted } \quad \square \text { Su esposo } \\
\square \text { Otra persona } \\
\end{array}$ \\
\hline
\end{tabular}




\section{El esposo estuvo en EEUU y ha regresado:}

\begin{tabular}{|c|c|}
\hline Esposo información & \\
\hline 53. A qué edad emigró: & \\
\hline $\begin{array}{l}\text { 54. Con quien vivía antes de la } \\
\text { emigración: }\end{array}$ & \\
\hline $\begin{array}{l}\text { 55. Estaban casados cuando } \\
\text { emigró? }\end{array}$ & $\square$ Sí \\
\hline $\begin{array}{l}\text { 56. Que información tenia de su } \\
\text { vida--por ejemplo: donde } \\
\text { vive, tipo de trabajo, cuando } \\
\text { va a regresar) }\end{array}$ & \\
\hline $\begin{array}{l}\text { 57. Tiene hijos que viven en } \\
\text { EEUU también? }\end{array}$ & $\square$ Sí $\square$ No \\
\hline $\begin{array}{l}\text { 58. Si sí, quienes y que edades } \\
\text { tienen? }\end{array}$ & $\begin{array}{lll}\square \text { Hijo } & \square \text { Hija } \text { Edad: } \_ \text {Con quien vive: } \\
\square \text { Hijo } & \square \text { Hija } \text { Edad: } \_ \text {Con quien vive: } \\
\square \text { Hijo } & \square \text { Hija } \text { Edad:__ Con quien vive: } \\
\square \text { Hijo } & \square \text { Hija } \text { Edad: } \_ \text {Con quien vive: }\end{array}$ \\
\hline $\begin{array}{l}\text { 59. En referencia a su esposo, } \\
\text { quien tomó la decisión para } \\
\text { ir a EEUU? }\end{array}$ & $\square$ Su esposo $\square$ Usted $\quad \square$ Ambos \\
\hline $\begin{array}{l}\text { 60. Por qué su esposo se fue a } \\
\text { EEUU? }\end{array}$ & $\begin{array}{l}\square \text { Trabajo/dinero } \square \text { otra: } \\
\text { Comentario: }\end{array}$ \\
\hline $\begin{array}{l}\text { 61. Usted recibió } \\
\text { remesas/dinero de su } \\
\text { esposo cuando vivió en los } \\
\text { EEUU? }\end{array}$ & $\begin{array}{l}\square \text { Sí } \square \text { No } \\
\text { Comentario: }\end{array}$ \\
\hline $\begin{array}{l}\text { 62. A los cuantos meses o años } \\
\text { de que salió, usted recibió } \\
\text { las primeras } \\
\text { remesas/dinero? }\end{array}$ & $\begin{array}{ll}\square 1 \text { mes o menos } & \square 1 \text { a } 2 \text { meses } \\
\square \text { 6 a 9 meses } & \square \text { 9 meses a } 1 \text { año } \quad \square 1 \text { año o mas }\end{array}$ \\
\hline $\begin{array}{l}\text { 63. Si su esposo vivía en EEUU } \\
\text { más de un año, sigue } \\
\text { enviando dinero todo del } \\
\text { tiempo? }\end{array}$ & $\begin{array}{l}\square \text { Sí } \square \text { No } \\
\text { Comentario: }\end{array}$ \\
\hline $\begin{array}{l}\text { 64. Durante su tiempo en EEUU, } \\
\text { podría decirme que el } \\
\text { dinero que recibió } \\
\text { actualmente: }\end{array}$ & $\square$ Siguió igual $\square$ Aumentado \\
\hline
\end{tabular}




\begin{tabular}{|c|c|}
\hline $\begin{array}{l}\text { 65. En 2009, en comparación } \\
\text { con 2008, (si él ha estado } \\
\text { fuera los dos años) las } \\
\text { remesas que mandó fueron: }\end{array}$ & $\square$ Menos \\
\hline $\begin{array}{l}\text { 66. Qué año fue el último de } \\
\text { cual su esposo estaba en } \\
\text { EEUU? }\end{array}$ & \\
\hline $\begin{array}{l}\text { 67. En ese año, usted recibió } \\
\text { remesas? }\end{array}$ & $\begin{array}{l}\square \text { Sí } \square \text { No } \\
\text { Comentario: }\end{array}$ \\
\hline $\begin{array}{l}\text { 68. Si sí, que fue el promedio } \\
\text { que recibió cada mes? }\end{array}$ & $\begin{array}{ll}\square \text { Menos de } \$ 100 \text { US } & \square \text { \$100US a } \$ 250 \text { US } \\
\square \text { \$250US a \$500US } & \square \text { \$500US a \$750US } \\
\square \text { \$750US a \$1,000US } & \square \$ 1,000 \text { o más }\end{array}$ \\
\hline $\begin{array}{l}\text { 69. En que usó las remesas que } \\
\text { recibió? } \\
\text { Marca todos los que } \\
\text { aplican (Lee } \\
\text { detenidamente todas las } \\
\text { respuestas de la lista } \\
\text { antes de responder) } \\
\text { 70. Donde usó las remesas? } \\
\text { Marque } 1,2 \text { y } 3 \text { en el } \\
\text { espacio después }\end{array}$ & $\begin{array}{l}\square \text { Para comprar comida } \_-\square \text { Remodelar su casa } \_ \\
\square \text { Para construir su casa } \_-\square \text { Comprar aparatos }- \\
\square \text { La educación de los hijos } \_\square \text { Comprar animales }- \\
\square \text { Ampliar o mejorar un negocio } \_ \\
\square \text { Comprar un carro _ } \square \text { Poner un negocio } \_ \\
\square \text { Otro: }\end{array}$ \\
\hline $\begin{array}{l}\text { 71. Quién tomó la decisión } \\
\text { sobre cómo usar las } \\
\text { remesas? }\end{array}$ & $\begin{array}{l}\square \text { Su esposo } \square \text { Usted } \square \text { Ambos } \\
\text { Otra persona: }\end{array}$ \\
\hline $\begin{array}{l}\text { 72. Si usted no recibiera las } \\
\text { remesas, cuál sería la razón, } \\
\text { en su opinión? }\end{array}$ & $\begin{array}{l}\square \text { No hay dinero suficiente a mandar } \square \text { No tiene trabajo } \\
\square \text { Otra mujer } \quad \square \text { Prefiere gastarlo en sí mismo } \\
\text { Otro: }\end{array}$ \\
\hline $\begin{array}{l}\text { 73. Cuando su esposo regreso el } \\
\text { trajo dinero para la familia y } \\
\text { usted? }\end{array}$ & $\square$ No \\
\hline $\begin{array}{l}\text { 74. Si sí, como utilizo ese } \\
\text { dinero? }\end{array}$ & \\
\hline $\begin{array}{l}\text { 75. Quien tomó la decisión de } \\
\text { cómo utilizar ese dinero? }\end{array}$ & $\begin{array}{l}\square \text { Usted } \square \text { Su esposo } \square \text { Ambos } \\
\square \text { Otra persona }\end{array}$ \\
\hline $\begin{array}{l}\text { 76. Que fue la razón más fuerte } \\
\text { que su esposo volvió? }\end{array}$ & \\
\hline
\end{tabular}




\begin{tabular}{|l|l|}
\hline $\begin{array}{l}\text { 77. Piensa usted que el irá a } \\
\text { EEUU otra vez? }\end{array}$ & $\square$ Sí $\square$ No \\
Si sí, por que piensa así?:
\end{tabular}

Su esposo NUNCA ha emigrado:

\begin{tabular}{|c|c|}
\hline $\begin{array}{l}\text { 79. Si su esposo nunca ha } \\
\text { emigrado a EEUU, cual es } \\
\text { la razón? } \\
\text { (Lee todas la opciones } \\
\text { antes de aceptar una } \\
\text { respuesta) }\end{array}$ & $\begin{array}{l}\square \text { No quiere dejar la familia } \square \text { Falta de conexiones de ayuda } \\
\square \text { Por los gastos tan alto en EEUU } \\
\square \text { Por el peligro de cruzar la frontera } \\
\square \text { No tiene un trabajo asegurado } \\
\square \text { Porque los niños necesitan su padre en casa } \\
\square \text { No hay necesidad de dinero } \square \text { Temor } \\
\square \text { Otra: }\end{array}$ \\
\hline $\begin{array}{l}\text { 80. Piensa que su familia } \\
\text { estaría mejor } \\
\text { económicamente si su } \\
\text { esposo viviera en EEUU? }\end{array}$ & $\begin{array}{l}\square \text { Sí } \quad \square \text { No } \\
\text { Porque piensa así: }\end{array}$ \\
\hline $\begin{array}{l}\text { 81. Su esposo tiene planes de } \\
\text { ir a EEUU? }\end{array}$ & $\begin{array}{l}\square \text { Sí } \quad \square \text { No } \\
\text { Porque y cuando: }\end{array}$ \\
\hline $\begin{array}{l}\text { 82. Si sí, cual es el motivo } \\
\text { primario o más fuerte? }\end{array}$ & $\begin{array}{l}\square \text { Dinero/trabajo } \\
\text { Otra: } \\
\text { Comentario: }\end{array}$ \\
\hline
\end{tabular}


Hábleme un poco sobre sus hijos (si no tiene hijos en casa, pasa a \#99):

\begin{tabular}{|c|c|c|c|}
\hline $\begin{array}{l}\text { 83. Que tan importante } \\
\text { para usted es la } \\
\text { educación de su } \\
\text { hija(s)? }\end{array}$ & $\begin{array}{l}\square \text { Muy importante } \\
\square \text { Poco importante } \\
\text { Comentario: }\end{array}$ & $\begin{array}{l}\square \text { Importante } \\
\square \text { No es importante }\end{array}$ & Mas o menos importante \\
\hline $\begin{array}{l}\text { 84. Que tan importante } \\
\text { para usted es la } \\
\text { educación de su } \\
\text { hijo(s)? }\end{array}$ & $\begin{array}{l}\square \text { Muy importante } \\
\square \text { Poco importante } \\
\text { Comentario: }\end{array}$ & $\begin{array}{l}\square \text { Importante } \\
\square \text { No es importante }\end{array}$ & Mas o menos importante \\
\hline $\begin{array}{l}\text { 85. Piensa usted que es } \\
\text { probable si su hija(s) } \\
\text { pudiera emigraría a } \\
\text { EEUU? }\end{array}$ & $\begin{array}{l}\square \text { Muy probable } \\
\square \text { Poco probable } \\
\text { Comentario: }\end{array}$ & $\begin{array}{l}\square \text { Probable } \\
\square \text { No es probable }\end{array}$ & Mas o menos probable \\
\hline $\begin{array}{l}\text { 86. Piensa usted que es } \\
\text { probable si su hijo(s) } \\
\text { pudiera, emigraría a } \\
\text { EEUU? }\end{array}$ & $\begin{array}{l}\square \text { Muy probable } \\
\square \text { Poco probable } \\
\text { Comentario: }\end{array}$ & $\begin{array}{l}\square \text { Probable } \\
\square \text { No es probable }\end{array}$ & Mas o menos probable \\
\hline $\begin{array}{l}\text { 87. Si recibe remesas, que } \\
\text { tan importante son } \\
\text { para la educación de } \\
\text { su hija(s)? }\end{array}$ & $\begin{array}{l}\square \text { Muy importante } \\
\square \text { Poco importante } \\
\text { Comentario: }\end{array}$ & $\begin{array}{l}\square \text { Importante } \\
\square \text { No es importante }\end{array}$ & Mas o menos importante \\
\hline $\begin{array}{l}\text { 88. Si recibe remesas, que } \\
\text { tan importante son } \\
\text { para la educación de } \\
\text { su hijo(s)? }\end{array}$ & $\begin{array}{l}\square \text { Muy importante } \\
\square \text { Poco importante } \\
\text { Comentario: }\end{array}$ & $\begin{array}{l}\square \text { Importante } \\
\square \text { No es importante }\end{array}$ & Mas o menos importante \\
\hline $\begin{array}{l}\text { 89. Que tan importante es } \\
\text { para usted que su } \\
\text { hija(s) se case } \\
\text { eventualmente? }\end{array}$ & $\begin{array}{l}\square \text { Muy importante } \\
\square \text { Poco importante } \\
\text { Comentario: }\end{array}$ & $\begin{array}{l}\square \text { Importante } \\
\square \text { No es importante }\end{array}$ & Mas o menos importante \\
\hline $\begin{array}{l}\text { 90. Que tan importante es } \\
\text { para usted que su } \\
\text { hijo(s) se case } \\
\text { eventualmente? }\end{array}$ & $\begin{array}{l}\square \text { Muy importante } \\
\square \text { Poco importante } \\
\text { Comentario: }\end{array}$ & $\begin{array}{l}\square \text { Importante } \\
\square \text { No es importante }\end{array}$ & Mas o menos importante \\
\hline $\begin{array}{l}\text { 91. Piensa usted de que es } \\
\text { muy probable de que } \\
\text { su hija se case con } \\
\text { alguien que se va a } \\
\text { emigrar, mientras ella } \\
\text { se quede en su } \\
\text { comunidad? }\end{array}$ & $\begin{array}{l}\square \text { Muy probable } \\
\square \text { Poco probable } \\
\text { Comentario: }\end{array}$ & $\begin{array}{l}\square \text { Probable } \\
\square \text { No es probable }\end{array}$ & Mas o menos probable \\
\hline
\end{tabular}




\begin{tabular}{|c|c|}
\hline $\begin{array}{l}\text { 92. Que tan importante es } \\
\text { para usted de que su } \\
\text { hija(s) sea } \\
\text { independiente } \\
\text { financieramente sin } \\
\text { depender de un } \\
\text { hombre? }\end{array}$ & $\begin{array}{l}\square \text { Muy importante } \square \text { Importante } \square \text { Mas o menos importante } \\
\square \text { Poco importante } \square \text { No es importante } \\
\text { Comentario: }\end{array}$ \\
\hline $\begin{array}{l}\text { 93. Es probable es que su } \\
\text { hija pueda ser } \\
\text { independiente } \\
\text { financieramente sin } \\
\text { depender de un } \\
\text { hombre? }\end{array}$ & $\begin{array}{ll}\square \text { Muy probable } & \square \text { Probable } \quad \square \text { Mas o menos probable } \\
\square \text { Poco probable } \quad \square \text { No es probable ni posible } \\
\text { Comentario: }\end{array}$ \\
\hline $\begin{array}{l}\text { 94. Podría decirme, en su } \\
\text { opinión, si es } \\
\text { probable de que su } \\
\text { hija(s) pueda ser } \\
\text { independiente } \\
\text { financieramente sin la } \\
\text { necesidad de ir a } \\
\text { EEUU o sin depender } \\
\text { en un esposo que se va } \\
\text { a EEUU? } \\
\end{array}$ & $\begin{array}{ll}\square \text { Muy probable } \quad \square \text { Probable } \quad \square \text { Mas o menos probable } \\
\square \text { Poco probable } \quad \square \text { No es probable } \\
\text { Comentario: }\end{array}$ \\
\hline $\begin{array}{l}\text { 95. Para usted cual es el } \\
\text { grado de escolaridad } \\
\text { más importante que } \\
\text { su hija debe de tener? }\end{array}$ & Grados de escolaridad: \\
\hline $\begin{array}{l}\text { 96. Para usted cual es el } \\
\text { grado de escolaridad } \\
\text { más importante que } \\
\text { su hijo debe de tener? }\end{array}$ & Grados de escolaridad: \\
\hline \multirow[t]{2}{*}{$\begin{array}{l}\text { 97. Si fuera la decisión de } \\
\text { usted, que profesión } \\
\text { escogería para su hija? }\end{array}$} & \\
\hline & Comentario: \\
\hline \multirow{2}{*}{$\begin{array}{l}\text { 98. Si fuera la decisión de } \\
\text { usted, que profesión } \\
\text { escogería para su hijo? }\end{array}$} & \\
\hline & omentario: \\
\hline
\end{tabular}




\section{Encuesta adicional:}

\begin{tabular}{|l|l|}
\hline $\begin{array}{l}\text { 99. Estaría usted dispuesta a } \\
\text { participar en otra entrevista de } \\
\text { uno o dos horas en algunas } \\
\text { semanas? }\end{array}$ & $\square$ sí $\square$ No \\
\hline $\begin{array}{l}\text { 100. Si sí, cual de los siguientes } \\
\text { estaría dispuesta participar? }\end{array}$ & $\square$ Entrevista individual _ \\
$\begin{array}{l}\text { 101. Cuál de esas preferiría usted? } \\
\text { (Marca 1, 2,y/o } 3 \text { en los } \\
\text { espacios) }\end{array}$ & $\begin{array}{l}\square \text { Entrevista con } 1 \text { o } 2 \text { mujeres de las cuales usted escoja o } \\
\text { aprueba — }\end{array}$ \\
\hline Entrevista en grupo con cuatro a ocho mujeres _
\end{tabular}

Gracias por su tiempo y por sus respuestas honestas. Toda la información que proporcionó será guardada en completa confidencialidad. Su información es muy valiosa, importante, y muy apreciado.

\section{NOTAS:}

